University of Massachusetts Amherst

ScholarWorks@UMass Amherst

Environmental \& Water Resources Engineering

Masters Projects

Civil and Environmental Engineering

$5-2011$

Utilizing a Decision Support System to Optimize Reservoir Operations to Restore the Natural Flow Distribution in the Connecticut River Watershed

Brian Pitta

Follow this and additional works at: https://scholarworks.umass.edu/cee_ewre

Part of the Environmental Engineering Commons

Pitta, Brian, "Utilizing a Decision Support System to Optimize Reservoir Operations to Restore the Natural Flow Distribution in the Connecticut River Watershed" (2011). Environmental \& Water Resources Engineering Masters Projects. 50.

https://doi.org/10.7275/RJHD-KD68

This Article is brought to you for free and open access by the Civil and Environmental Engineering at ScholarWorks@UMass Amherst. It has been accepted for inclusion in Environmental \& Water Resources Engineering Masters Projects by an authorized administrator of ScholarWorks@UMass Amherst. For more information, please contact scholarworks@library.umass.edu. 


\title{
UTLIZING A DECISION SUPPORT SYSTEM TO OPTIMIZE RESERVOIR OPERATIONS TO RESTORE THE NATURAL FLOW DISTRIBUTION IN THE CONNECTICUT RIVER WATERSHED
}

\author{
A Master’s Project Report Presented By: \\ Brian Pitta
}

Submitted to the Department of Civil and Environmental Engineering of the University of Massachusetts Amherst in partial fulfillment of the requirements for the degree of

Master of Science in Environmental Engineering

January 2010

Department of Civil and Environmental Engineering 
UTILIZING A DECISION SUPPORT SYSTEM TO OPTIMIZE RESERVOIR OPERATIONS TO RESTORE THE NATURAL FLOW DISTRIBUTION IN THE CONNECTICUT RIVER WATERSHED

A Masters Project Presented

by .

Approved as to style and content by:

BRIAN PITTA

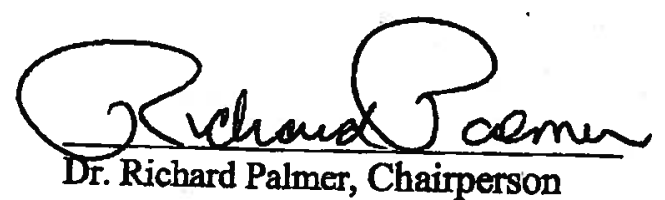

Dr. Richard Palmer, Chairperson
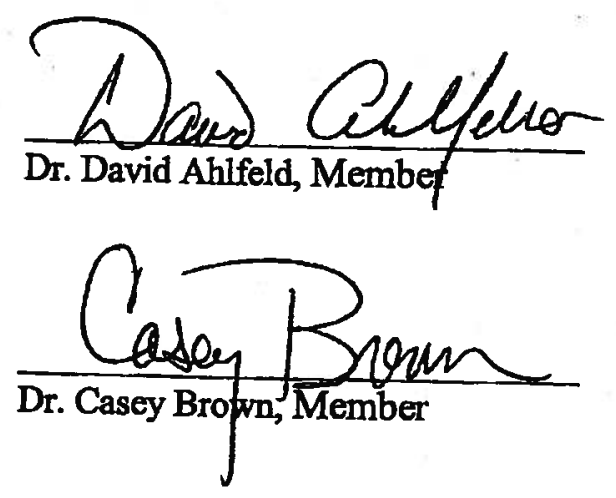

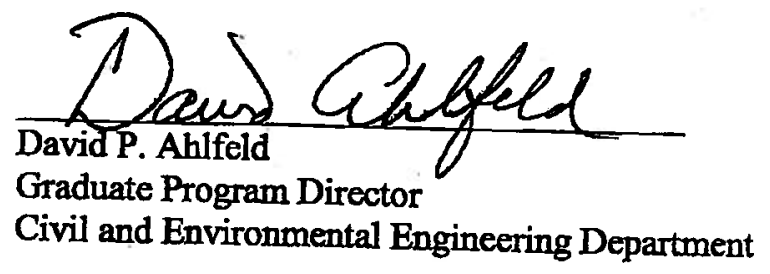




\section{Acknowledgements}

The research for this thesis was part of a larger research effort being funded by The Nature Conservancy. I would like to thank The Nature Conservancy for the opportunity to be a part of the Connecticut River Project.

I consider myself very fortunate to have spent my graduate research time with the University of Massachusetts Amherst Water Resources group. I especially would like to thank my advisor, Dr. Richard Palmer, for all of his guidance and expertise throughout the entire research project and thesis process. I would also like to thank the other committee members, Dr. David Ahlfeld and Dr. Casey Brown, for their support and help.

It has been a pleasure to work with my fellow graduate students, Kelcy Adamec and Scott Steinschneider, on this project. A special thanks to Dr. Austin Polebitski for all that he taught me and his willingness to help in any aspect.

Lastly, I would like to thank my friends and family for all their encouragement and support throughout my five and a half years at the University of Massachusetts Amherst. 


\begin{abstract}
Reservoir development on the Connecticut River Basin has altered the natural hydrograph and detrimentally affected the region's aquatic ecosystems that thrive on natural variability. This thesis examines ways in which flows in the river and its tributaries can be returned to a more natural regime without negatively impacting other users. The analysis offers alternative operations to meet the various objectives as well as evaluates the impacts of climate change on the basin. This paper focuses on the upper third of the basin as a proof of concept to demonstrate the decision support system and to generate initial results for the larger effort.

The upper third of the basin contains 11 sub-watersheds, six major reservoirs, and three ecological points of interest. The analysis employs simulation, optimization, and hydrology models that work in symphony. The process starts with a simulation model of the system that reflects the current reservoir operations; this assures the modeling efforts accurately portray the current conditions. The linear program optimization model is used to determine optimal operating policies and the trade-offs between reservoir objectives for three operational schemes: operating for ecological targets, hydropower, and flood control. The output from the optimization model suggests how to alter the operating polices to achieve the given objective. Downscaled climate change meteorological data (temperature and precipitation) from five General Circulation Models and two emissions scenarios are used as input into the hydrology model to produce climate impacted streamflow to examine reservoir operations under climate change. The analysis does not suggest a single operating policy, but rather a range of options to be discussed among stakeholders to best address all objectives.
\end{abstract}




\section{Table of Contents}

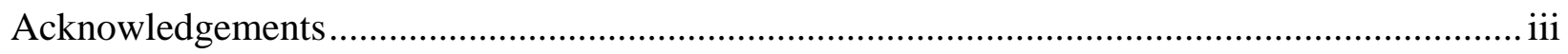

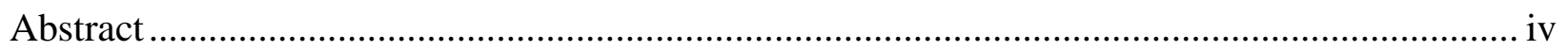

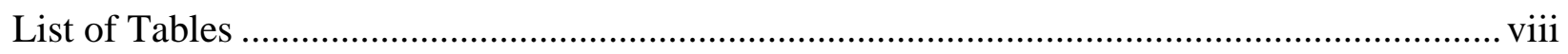

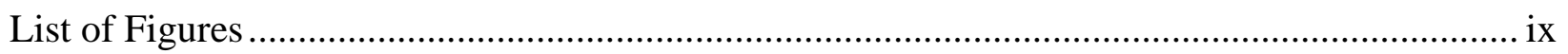

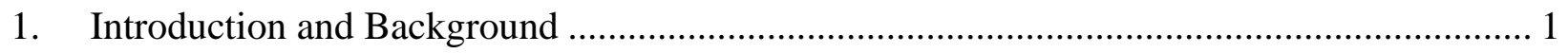

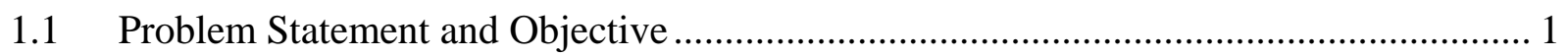

1.2 Overview of the Connecticut River Project ………………………................................ 2

1.3 General Process of Developing the Decision Support System ………………................. 3

1.4 Thesis Study Area: Upper Third of the Connecticut River Basin...................................... 4

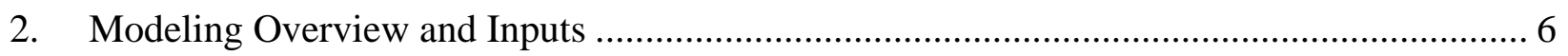

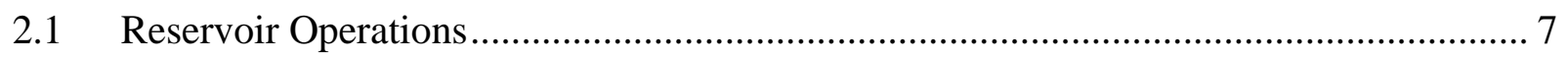

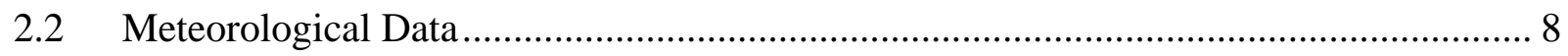

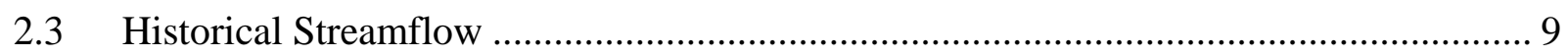

$2.4 \quad$ Ecological Flow Targets.......................................................................................... 11

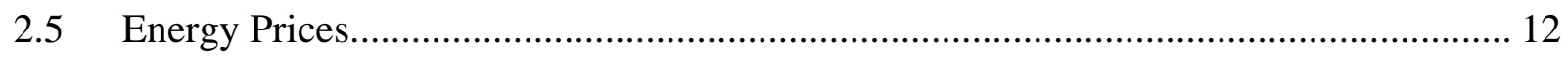

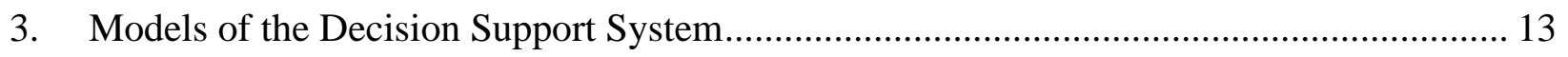

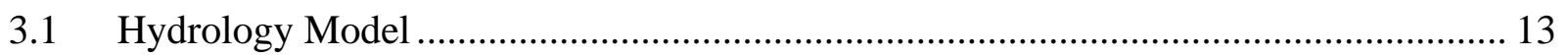

3.2 Simulation Model .............................................................................................. 17

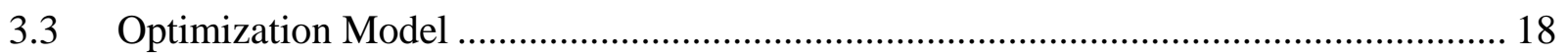

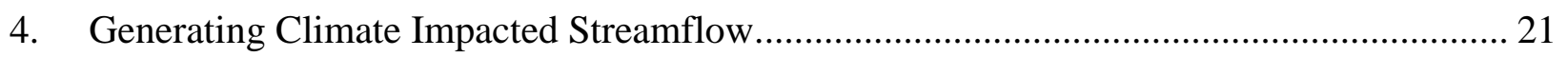

4.1 General Circulation Models ..................................................................................... 21

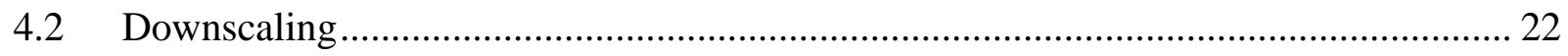

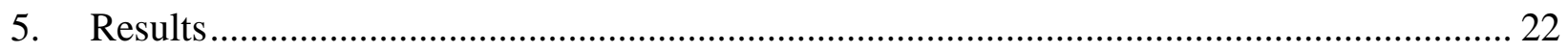




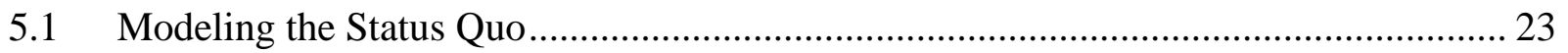

5.1.1 Simulation Model Monthly Flow Duration Curves ............................................... 25

5.1.2 Optimization Model Monthly Flow Distributions ................................................... 28

5.1.3 Income from Current Operations ......................................................................... 30

5.2 Results: Operating to Improve Ecological Flows …………………………................. 31

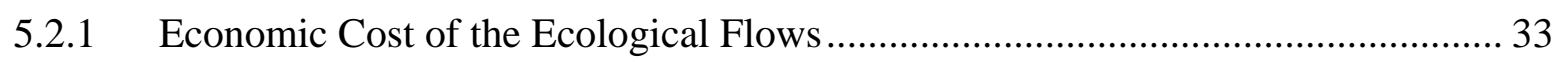

5.2.2 Effects on the Q10, Q50, and Q90 at Different Allowance Levels ........................ 35

5.2.3 Monthly Flow Duration Curves at Selected Alteration Levels................................ 38

5.2.4 Effects on System Storage at Select Alteration levels ............................................. 40

5.2.5 Ecological Flow at Eco-Node 1 Operation Recommendations ............................... 41

5.3 Results - Operating for Hydropower .......................................................................... 42

5.3.1 Trade-off Between Current Target Storage and System Income............................... 43

5.3.2 Reservoir Storage at Different Income Levels......................................................... 44

5.3.3 Operational Recommendations for Storage Facilities to Increase System Income 45

5.4 Results - Operating for Flood Control ......................................................................... 46

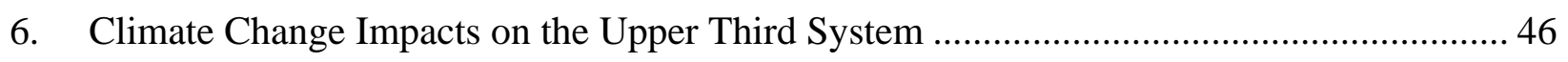

6.1 Climate Impacted Conditions - A2 Emissions Scenario ............................................. 47

6.2 Climate Impacted Conditions - B1 Emissions Scenario................................................... 50

6.3 Monthly Flow Duration Curves ……………………………................................... 54

6.4 Average Annual System Income................................................................................ 57

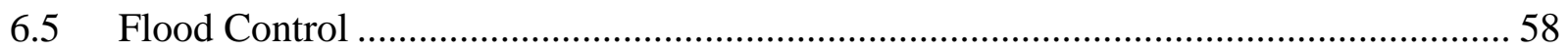

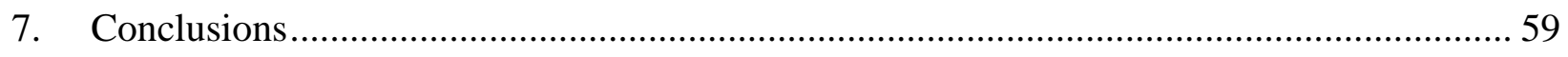

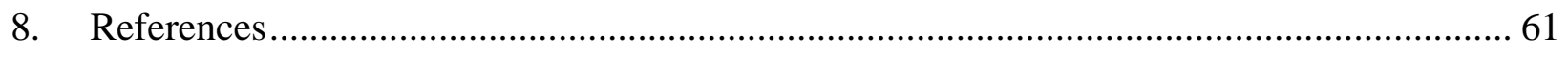

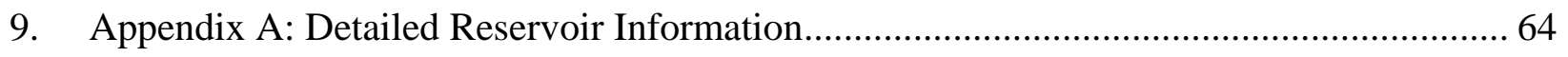

9.1 Second Connecticut Lake................................................................................................ 64 


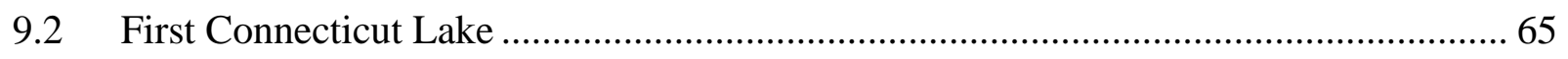

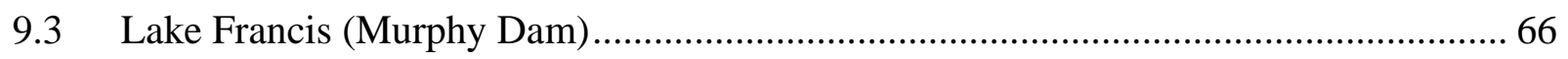

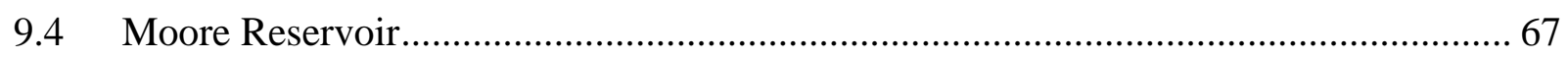

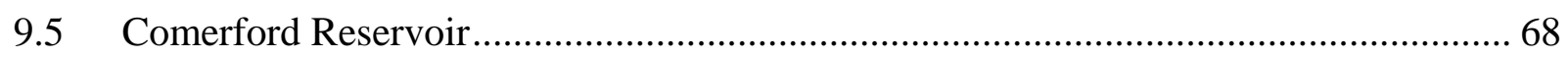

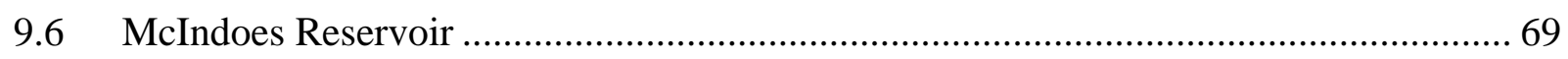

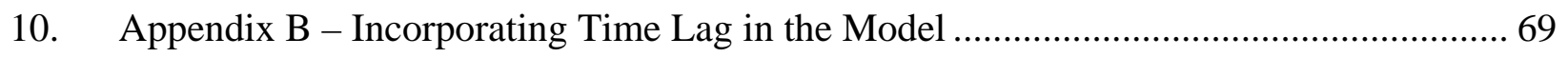

11. Appendix C - Optimization Model Documentation ............................................................. 70

11.1 Architecture of the Optimization Model ..................................................................... 70

$11.2 \quad$ Model Node Types .............................................................................................. 72

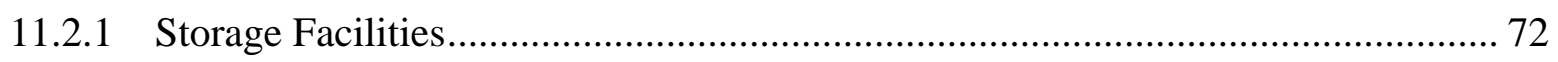

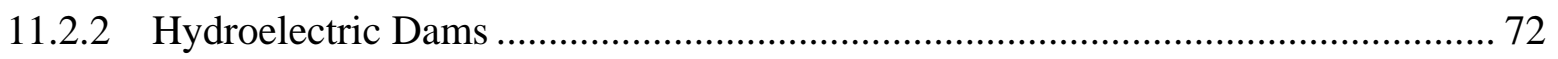

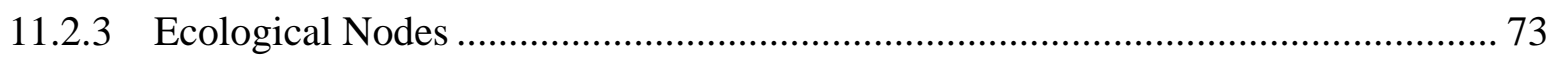

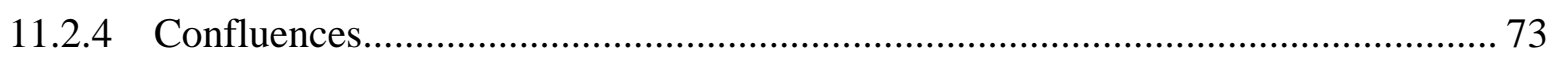

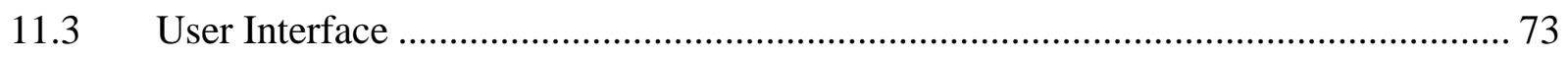

12. Appendix D - GCM Temperature and Precipitation Data.................................................... 74

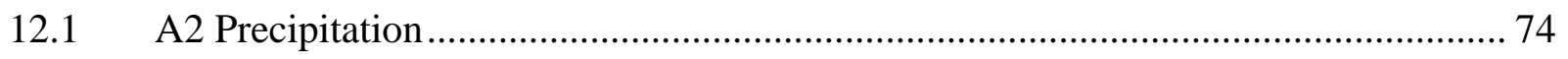

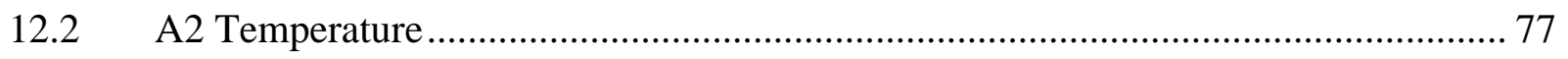

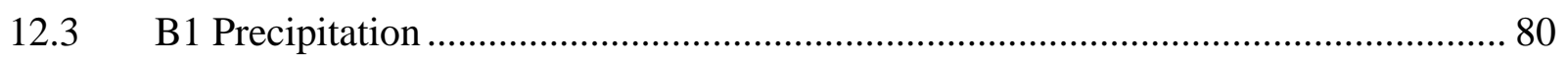

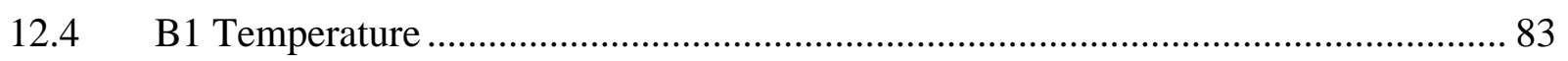

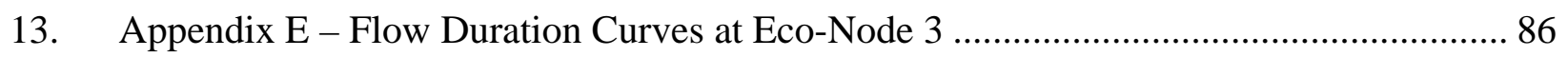




\section{List of Tables}

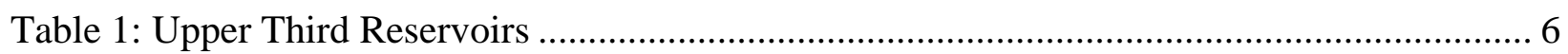

Table 2: Meteorological Stations ............................................................................................ 9

Table 3: DHSVM constant parameters used in calibration. ............................................................ 14

Table 4: Objective function coefficient weights for current operations....................................... 28

Table 5: Objective function weighting coefficients for operating to improve ecological flows .. 31

Table 6: Flow Statistics at the Indian gage during current operations............................................ 46

Table 7: The A2 and B1 GCM Ensemble comparison of temperature and precipitation changes54

Table 8: Average annual income generated under the A2 and B1 emissions scenarios. (Note:

little income difference between A2 and B1 climate chance scenarios) ……………………....... 58

Table 9: Number of times the Indian Gage flood control target is exceeded without considering flood control in the objective function for the current operations and the A2 GCM ensemble. .. 59

Table 10A: Second Connecticut Lake information ........................................................................ 64

Table 11A: Second Connecticut Lake minimum releases ........................................................ 64

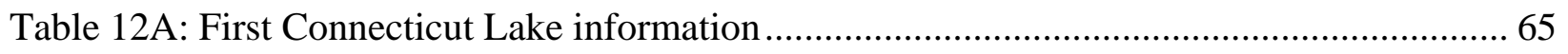

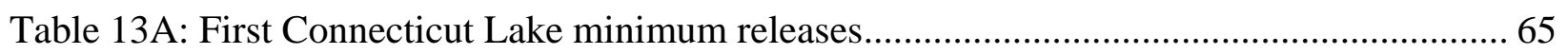

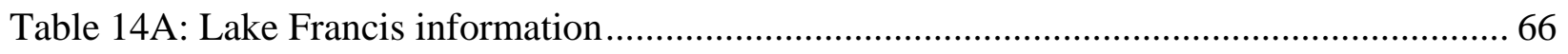

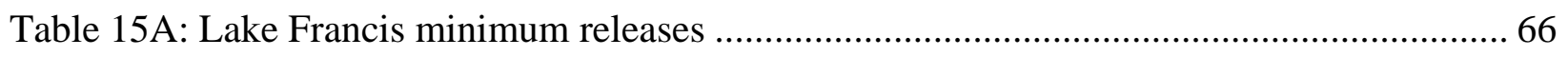

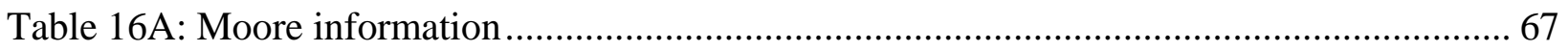

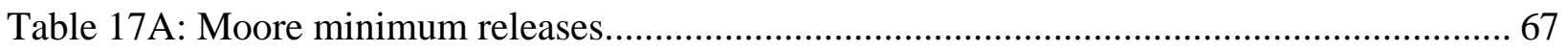

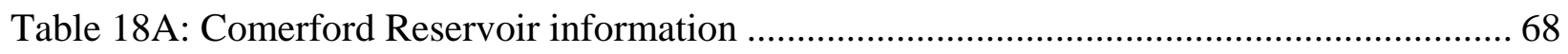

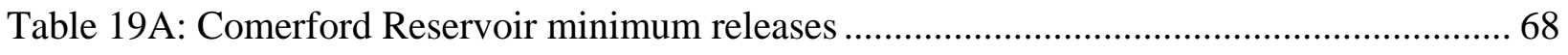

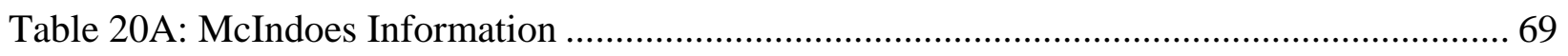

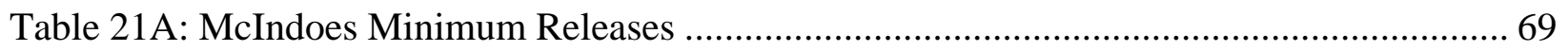




\section{List of Figures}

Figure 1: The Connecticut River Watershed (Sub-basins indicated by separate colors)............... 2

Figure 2: The Connecticut River Reservoir Operations Decision Support System...................... 4

Figure 3: The Upper Third of the Connecticut River. Storage facilities are indicated by blue squares, from top to bottom: Second Connecticut Lake, First Connecticut Lake, and Lake Francis. Generating facilities are indicated by red stars, from top to bottom: Moore, Comerford, and McIndoes. Yellow circles indicate ecological points of interest........................................ 5

Figure 4: Meteorological stations used in hydrology model ................................................. 9

Figure 5: Precipitation (on days where precipitation>0) at First Connecticut Lake from 1930-

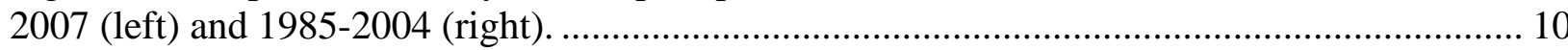

Figure 6: Flow duration curve at the Indian gage (below the confluence of the storage facilities and the Indian sub basin). The black line is the full period of record from 1957-2010 and the red line is the simulation period used in this study from 1985-2005......................................... 11

Figure 7: Piecewise linear exponential ecological flow penalty structure................................ 12

Figure 8: Hydrology model calibration points (indicated by gold circles). The two calibration points, Upper Ammonoosuc (upper right point) and the Passumpsic (lower left point) are each at

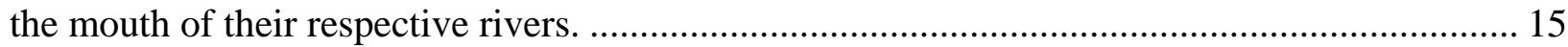

Figure 9: Three year daily time series in the validation period for the Passumpsic River (top) and the Upper Ammonoosuc River (bottom) ............................................................................ 15

Figure 10: Passumpsic River (top) and Upper Ammonoosuc River (bottom) average monthly flows from the validation period of 1986-2004 .................................................................... 16

Figure 11: Passumpsic River (top) and Upper Ammonoosuc River(bottom) average yearly flows

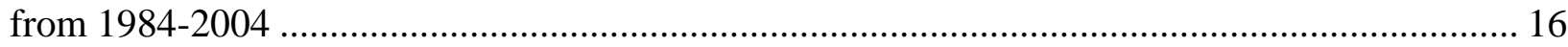

Figure 12: Flow duration curves for the Passumpsic (left) and Ammonoosuc (right) calibration points. The black line represents the historic flows and the red line represents the hydrology

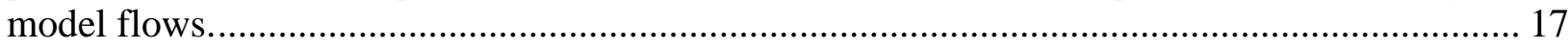

Figure 13: Drainage areas of Eco-Node 1 (red) and Eco-Node 3 (yellow). .............................. 24

Figure 14: Average monthly energy prices used in simulation and optimization model (ISO New

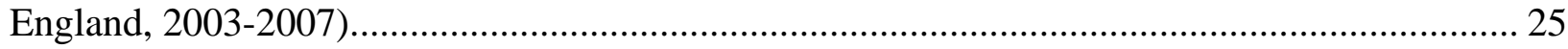


Figure 15: Target storage for the combined storage system in the Upper Connecticut Basin (Second CT Lake, First CT Lake, and Lake Francis).

Figure 16: Simulation model monthly flow duration curves with current operations at Eco-Node 1 below the 3 storage facilities. The red line represents the simulation model and the black solid line is the natural flow in the river if the reservoirs passed all inflow. (Note the y-axis is a logarithmic scale).

Figure 17: Optimization model monthly flow duration curves at Eco-Node 1 with ecological targets not considered. The objective function forces the reservoirs to follow their target storages while maximizing income. The red line represents the optimization model and the black solid line is the natural flow in the river if the reservoirs passed all inflow.

Figure 18: Optimization model combined system storage that corresponds to the monthly flow duration curves in Figure 17. The objective function forces the reservoirs close to the target storage while allowing deviations to maximize income.

Figure 19: The optimization model results at Eco-Node 1 with ecological targets being heavily weighed to be with $+/-10 \%$ of the inflow.

Figure 20: Optimization model results for the Upper Connecticut system storages associated with meeting within $10 \%$ of the inflow at Eco-Node 1.

Figure 21: Trade-off curve for the flows at Eco-Node 1 comparing average annual income to the maximum percent alteration. The figure on the left (18a) compares the full range of maximum allowable alterations. The figure on the right (18b) is the same data, but only showing $10 \%-$ $100 \%$ maximum allowable alteration.

Figure 22: Monthly changes in the Q10, Q50, and Q90 compared to the natural flow distribution as the maximum allowable \% alteration increases.

Figure 23: Monthly flow duration curves for points along the trade-off curve. The black line represents the natural flow duration curve. Different alteration levels of $10 \%, 40 \%$, and $100 \%$ are represented by red, blue, and purple lines. The gray line is the current operations.

Figure 24: System storage levels at select points along the trade-off curve. The maximum allowable percent alteration to inflow (+/-) along with the cumulative system income is shown above each graph

Figure 25: Trade-off between average annual system income and the average daily deviation from system storage target.....

Figure 26: Storage Levels of the combined reservoir storage system (SCL, FCL, and LFR) for four points along the trade-off curve in Figure 25. The red line is the model storage and the black line is the target storage. 
Figure 27: Temperature (top), precipitation (middle), and streamflow (bottom) at the outlet of the outlet of the Upper Third of the Connecticut River. Historic meteorological data (black) and the 5-GCM Ensemble A2 scenarios centered around 2000 (purple), 2040 (red), and 2080 (blue)... 49

Figure 28: Change in temperature (top), precipitation (middle), and streamflow(bottom) projected by the 5-GCM Ensemble A2 Scenarios centered around 2000 (purple), 2040 (red), and 2080 (purple). The 2000 change should match the GCM and shows bias. 50

Figure 29: Temperature (top), precipitation (middle), and streamflow (bottom) at the outlet of the outlet of the Upper Third of the Connecticut River. Historic meteorological data (black) and the 5-GCM Ensemble B1 scenarios centered around 2000 (purple), 2040 (red), and 2080 (blue)... 52

Figure 30: Change in temperature (top), precipitation (middle), and streamflow(bottom) projected by the 5-GCM Ensemble B1 Scenarios centered around 2000 (purple), 2040 (red), and 2080 (purple). The 2000 change should match the GCM and shows bias. 53

Figure 31: Optimization model monthly flow duration curves at Eco-Node 1. The black (current, natural flow) and red (current operations) are the same as in Figure 17. The blue, purple, and gray lines represent the A2 GCM ensemble under current operations for hydrologic conditions centered around 2000, 2040, and 2080.

Figure 32:Optimization model monthly flow duration curves at Eco-Node 1. The black (current, natural flow) and red (current operations) are the same as in Figure 17. The blue, purple, and gray lines represent the B1 GCM ensemble under current operations for hydrologic conditions

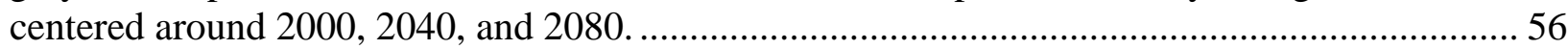

Figure 33: Average annual system income for the current conditions and the A2 Ensemble GCM for the time periods centered around 2000, 2040, and 2080 ............................................... 58

Figure 34A: Second Connecticut Lake Target Storage ...................................................... 64

Figure 35A: First Connecticut Lake Target Storage........................................................ 65

Figure 36A: Lake Francis Target Storage....................................................................... 66

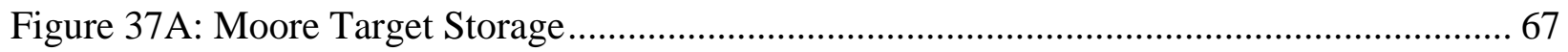

Figure 38C: The Upper Third system with the day divides.................................................. 70

Figure 39D: Total monthly precipitation for each GCM for the time period centered around 2000 using the A2 emissions scenario. (1= cccma_cgcm3, 2= ccsm3, 3= giss, $4=$ mri, $5=$ pcm)....... 74

Figure 40D: Total monthly precipitation for each GCM for the time period centered around 2040 using the A2 emissions scenario. (1= cccma_cgcm3, 2= ccsm3, 3= giss, $4=$ mri, $5=$ pcm)....... 75

Figure 41D: Total monthly precipitation for each GCM for the time period centered around 2080 using the A2 emissions scenario. (1= cccma_cgcm3, 2= ccsm3, 3= giss, $4=$ mri, $5=$ pcm)....... 76 
Figure 42D: Average monthly temperature for each GCM for the time period centered around 2000 using the A2 emissions scenario. (1= cccma_cgcm3, 2= ccsm3, 3= giss, $4=$ mri, $5=$ pcm). 77

Figure 43D: Average monthly temperature for each GCM for the time period centered around 2040 using the A2 emissions scenario. ( $1=$ cccma_cgcm3, 2= ccsm3, $3=$ giss, $4=$ mri, $5=$ pcm). 78

Figure 44D: Average monthly temperature for each GCM for the time period centered around 2080 using the A2 emissions scenario. ( $1=$ cccma_cgcm3, 2= ccsm3, $3=$ giss, $4=$ mri, $5=$ pcm). 79

Figure 45D: Total monthly precipitation for each GCM for the time period centered around 2000 using the B1 emissions scenario. (1= cccma_cgcm3, $2=$ ccsm3, $3=$ giss, $4=$ mri, $5=\mathrm{pcm})$......... 80

Figure 46D: Total monthly precipitation for each GCM for the time period centered around 2040 using the B1 emissions scenario. (1= cccma_cgcm3, $2=$ ccsm3, $3=$ giss, $4=$ mri, $5=\mathrm{pcm})$. ........ 81

Figure 47D: Total monthly precipitation for each GCM for the time period centered around 2080 using the B1 emissions scenario. (1= cccma_cgcm3, 2= ccsm3, 3= giss, $4=$ mri, $5=\mathrm{pcm}$ ).

Figure 48D: Average monthly temperature for each GCM for the time period centered around 2000 using the B1 emissions scenario. (1= cccma_cgcm3, 2= ccsm3, 3= giss, $4=$ mri, $5=$ pcm). 83

Figure 49D: Average monthly temperature for each GCM for the time period centered around 2040 using the B1 emissions scenario. (1= cccma_cgcm3, 2= ccsm3, 3= giss, $4=$ mri, 5=pcm). 84

Figure 50D: Average monthly temperature for each GCM for the time period centered around 2080 using the B1 emissions scenario. (1= cccma_cgcm3, 2= ccsm3, 3= giss, 4= mri, 5=pcm). 85

Figure 51E: Simulation model monthly flow duration curves with current operations at EcoNode 3 below the 3 generating facilities. The red line represents the simulation model and the black solid line is the natural flow in the river if the reservoirs passed all inflow.

Figure 52E: Optimization model monthly flow duration curves at Eco-Node 3 with ecological targets not considered. The objective function forces the reservoirs to follow their target storages while maximizing income. The red line represents the optimization model and the black solid line is the natural flow in the river if the reservoirs passed all inflow. 


\section{Introduction and Background}

\subsection{Problem Statement and Objective}

Humans rely on reservoirs for a variety of essential needs: drinking water supply, electricity from hydropower generation, protection from floods, and enjoyment from recreational purposes. To meet these needs, reservoirs store and release water, which alters the hydrograph and removes the natural variability of the river. Many ecosystems rely on natural variability (i.e. high spring flows, low summer flows) and have been detrimentally affected by the altered hydrographs (Richter et al., 2003). There are an infinite number of potential release schedules and storage targets for a reservoir; the challenge is finding those operating policies that allow human needs to be met while minimizing the negative impacts on the aquatic life.

This challenge of managing reservoirs to best meet all objectives, human and ecological, is compounded by the uncertainty associated with climate change. Reservoir operations have typically been established using historic hydrologic and meteorological data, that assumes a stationary climate. It is widely accepted among the scientific community that the assumption of stationarity is no longer applicable; planning and operations must accommodate the dynamic climate (Milly et al., 2008; Payne et al., 2004; Vorosmarty et al., 2000; Brown et al., 2008). Continuing to operate under past paradigms will result in missed opportunities, or even failures, in a reservoir system.

This thesis explores current reservoir operations to determine the effect regulation has on the hydrograph in the Upper Third of the Connecticut River Watershed. Regulation is examined on a monthly basis by comparing the natural flow duration curve to the regulated flow duration curve. Once the status quo is established, alternative operations are examined for different system objectives: restoring natural flows at ecological points of interest, increasing revenue from hydropower, and providing flood control. The reservoir operations are also tested against possible climate change scenarios to determine how the metrics might shift in a changing climate. 


\subsection{Overview of the Connecticut River Project}

This thesis is part of a larger research project funded by The Nature Conservancy in conjunction with other researchers at the University of Massachusetts Amherst, the United States Army Corps of Engineers (USACE), and the United States Geological Survey (USGS). The goal of this larger project is to improve flows for ecological targets in the Connecticut River Watershed. The Connecticut River originates at the Canadian border and flows southward to Long Island Sound. The watershed (Figure 1) consists of 46 sub basins; covers 11,250 square miles; and spans four states: Vermont, New Hampshire, Massachusetts, and Connecticut.

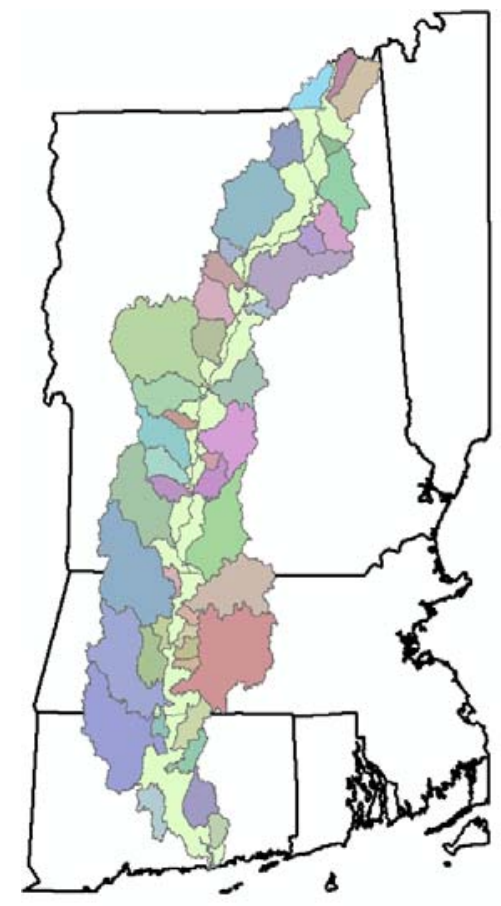

Figure 1: The Connecticut River Watershed (Sub-basins indicated by separate colors)

The Nature Conservancy has identified portions of the Connecticut River and its major tributaries (defined as points and reaches) where species are significantly affected by regulated flows. The decision support system described in this thesis is used to determine how reservoir operations can be improved to more closely resemble the river's natural flow regime. The Connecticut River Project is also examining the use of short and long term forecasts in reservoir planning and management, but is outside the scope of this thesis. 


\subsection{General Process of Developing the Decision Support System}

Decision support systems provide a framework to help support decision making. This support typically includes analytical or numeric evaluations of the impacts of decisions that were not previously an option, thus providing insights useful to making better decisions. In the past several decades, decision support systems have also been used to engage stakeholders in cooperative decision making. They help create situations in which interested parties can explore alternatives in an effort to arrive at mutually acceptable solutions that are new and innovative. Computer-based decision support systems allow water managers to explore a range of options before a decision has to be made (Westphal et al., 2003). The Connecticut River Decision Support System consists of simulation models, optimization models, and hydrology models (Figure 2).

The simulation model uses a hierarchy of mathematical logic functions to determine releases for reservoirs on a daily time step. The simulation model is the virtual system that can be used to investigate system response to changing conditions. The optimization model uses linear programming to calculate the best set of releases to meet a given objective. The optimal set of releases from the linear program can vary depending on the priority assigned to competing objectives. The optimization model is used to find improvements in the system as well as the trade-offs between objectives. The streamflow that drives the simulation and optimization model is calculated by the hydrology model, which uses meteorological data (temperature and precipitation) and the basin's physical characteristics to calculate runoff. General circulation models, downscaled to represent regional conditions, provide the meteorological data needed to generate projected streamflow in a changing climate. 


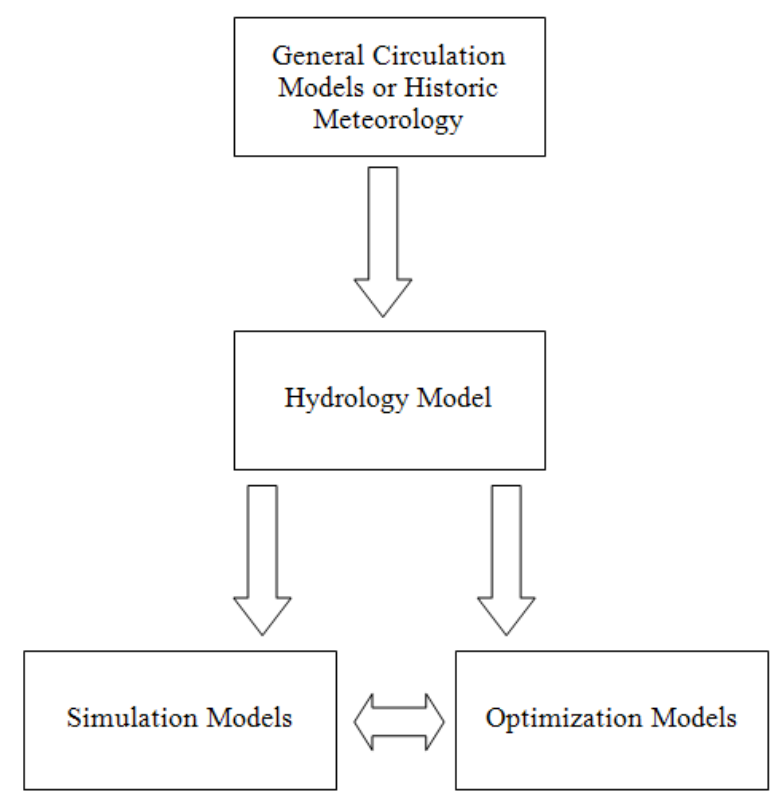

Figure 2: The Connecticut River Reservoir Operations Decision Support System

Two deliverables will be produced by this process: 1) proposed operating alternatives to improve reservoir operations, and 2) the decision support system tool to be used in reservoir planning and management. The decision support system will be used in conjunction with long and short term forecasts. In the short term (days), weather forecasts can provide input to the hydrology model. The coupled simulation and optimization model will provide a guideline to plan operations based on the forecasted streamflow. Long term climate forecasts (months) based on climate teleconnections can be used in a similar manner to forecast the hydrology a season in advance.

\subsection{Thesis Study Area: Upper Third of the Connecticut River Basin}

The application area of this thesis is the Upper Third of the Connecticut River Basin (Figure 3). These methods will be applied to the entire watershed as the Connecticut River Project progresses. For the purposes of this thesis, the Upper Third is defined as the headwaters through the confluence with the Wells River. The reservoir system consists of six reservoirs, three ecological points of interest (noted as eco-nodes), and eleven sub-basins. The six reservoirs are owned and operated by TransCanada as one hydropower system; three are storage facilities and three have generating units (Table 1). 


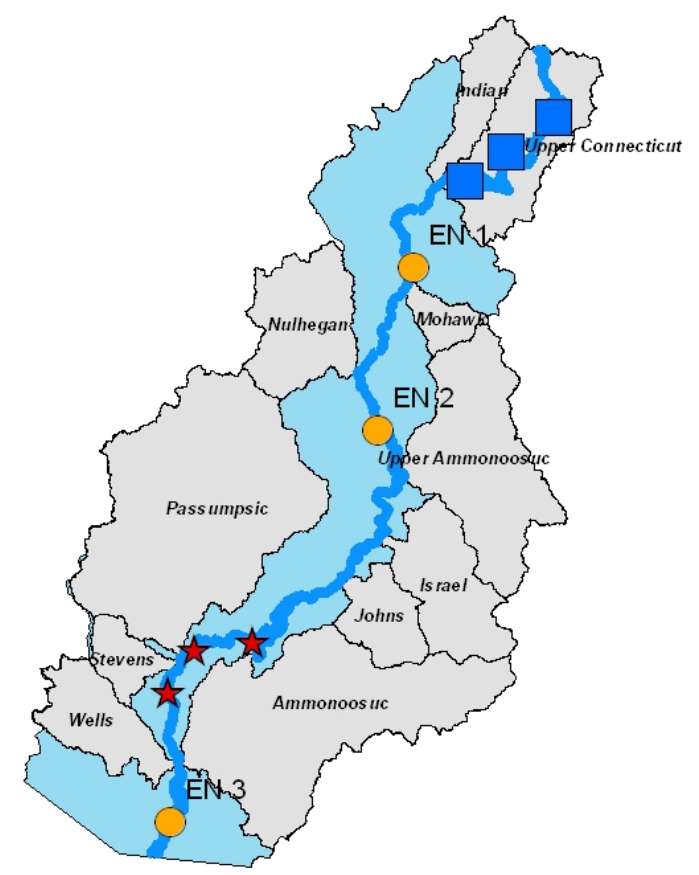

Figure 3: The Upper Third of the Connecticut River. Storage facilities are indicated by blue squares, from top to bottom: Second Connecticut Lake, First Connecticut Lake, and Lake Francis. Generating facilities are indicated by red stars, from top to bottom: Moore, Comerford, and McIndoes. Yellow circles indicate ecological points of interest. 
Table 1: Upper Third Reservoirs

\begin{tabular}{|ccccc|}
\hline Reservoir & Abbrev. & Purpose & Storage (acre-ft) & Generating Capacity (MW) \\
\hline Second CT Lake & SCL & Storage & 12,500 & - \\
\hline First CT Lake & FCL & Storage & 114,000 & - \\
\hline Lake Francis & LFR & Storage & 131,375 & - \\
\hline Moore & MOR & Generating & 223,722 & $192 \mathrm{MW}$ \\
\hline Comerford & COM & Generating & 32,270 & $145 \mathrm{MW}$ \\
\hline McIndoes & MCD & Generating & 5,988 & $10.6 \mathrm{MW}$ \\
\hline
\end{tabular}

\section{Modeling Overview and Inputs}

Four types of information were needed to initiate this research: 1) reservoir operations, 2) meteorological data, 3) hydrological data, and 4) ecological flow targets. With this information, three models were constructed to create the necessary framework. The modeling process began with constructing a hydrology model of the Upper Third of the Connecticut Basin. The model used historic meteorological data to produce natural streamflow at all points in the study area and was calibrated to unregulated USGS gage stations. The calibrated hydrology model provided the inputs to the reservoir operation models (simulation and optimization) for current conditions and climate-impacted conditions. By using the same hydrology model for both, any changes in future streamflow could be attributed solely to a change in climate and not any error from the hydrology model.

The reservoir modeling began with a simulation model that could mimic current operating rules and policies. The outputs from the simulation model were compared to flows at USGS gage sites below reservoirs to evaluate the quality of the model results. This step assured proper verification and validation of the simulation models and allowed appropriate interpretation of the current system. The simulation model was translated into a linear program 
optimization model. This optimization model is prescriptive, allowing the user to define objectives functions for the system of reservoirs and physical constraints, but removing the generic release rules that control operations in the simulation model. Once the linear program was made to reflect current system operation, new objectives and targets were introduced to determine alternate operating policies and trade-offs. The results of this process were tested with climate-impacted streamflow to examine the robustness to climate change. Each step of the modeling process is discussed in detail in Section 3.

\subsection{Reservoir Operations}

Physical and operational data were collected for each of the reservoirs through literature searches, from reports, and from in-person and telephone interviews with system operators and managers in the basin. In particular, TransCanada and the New Hampshire Department of Environmental Services (NHDES) dam safety office provided the majority of information collected.

The target storage approach was used to model the Upper Third reservoirs. The target storages, which were provided by the operators, vary over the year and were derived from past studies and operational experience. Target storages define the release that must be made during a day. If the current model storage plus inflow is below the target, the reservoir needs to store water, thus having a target release of zero. The release calculated to meet the target storage is then compared to the other constraints on the system such as minimum/maximum release and any existing ecological considerations. Detailed descriptions of each reservoir are in Appendix A.

The storage facilities in the Upper Connecticut Basin have a minimum flow requirement (minimum release): a smaller minimum flow from June 1 to September 30 and a larger requirement from October 1 to May 31. These minimum flows are all dependent on the inflow; if the inflow is less than the minimum flow requirement, then the inflow is set as the minimum release. NHDES records were used for rating curves of maximum releases at various reservoir elevations. Along with individual rules, the three reservoirs are operated to mitigate floods

downstream. The only flood control target for the Upper Third system is to maintain flows below 10,000 cfs at the USGS gage at the confluence of the Indian River. 
The generating facilities downstream are dominated by the operations of Moore Reservoir. Moore is the most upstream and largest (both in storage and generation capacity) reservoir. Moore Reservoir's capacity is approximately 6 times that of Comerford and McIndoes combined. Releases from Moore are made to attain a target storage, as detailed above. Moore has a constant minimum flow requirement (as opposed to seasonal) and, like the other reservoirs, if the inflow is less than the minimum flow, the inflow becomes the minimum release. Comerford and McIndoes do not have target storages and thus no resulting target releases. They each have minimum releases that are dependent on season: June- September, October - March, and AprilMay. Comerford must use storage if the minimum release cannot be met by inflows, while McIndoes does not have to draw from storage to meet a minimum flow. The generating facilities have the additional constraint of maximum flow through the turbine. The releases for each facility were divided into releases made through gates, generating units, or the spillway.

Reservoir rules are interpreted differently in the optimization model than in the simulation model to allow a linear programming formulation. In the optimization model, maximum releases are simplified and set independently of storage levels. This simplification is appropriate since these maximum releases only occur when the reservoir is full. Also, in the simulation model the flood control target is implemented at each reservoir requiring less water to be released during extreme high flows. In the optimization model, flood control is handled as one target in the objective function.

\subsection{Meteorological Data}

Connecticut River Basin meteorological data were downloaded from the National Climatic Data Center's (NCDC) website. Only stations that had recorded data running contiguously from 1930 to 2004 at least $70 \%$ of the time were selected for this study. Since no station had a complete record from 1930 to 2004, the gaps required missing data to be estimated. That process is referred to here as "patching." The precipitation data were patched through correlation coefficient weighting and the temperature by linear regression. The dataset created through this method produced 9 usable stations in and near the Upper Third of the Connecticut Basin (Figure 4 and Table 2). The historic meteorological data from these stations provided the input necessary to calibrate the hydrology model to streamflow at unregulated USGS stations. 


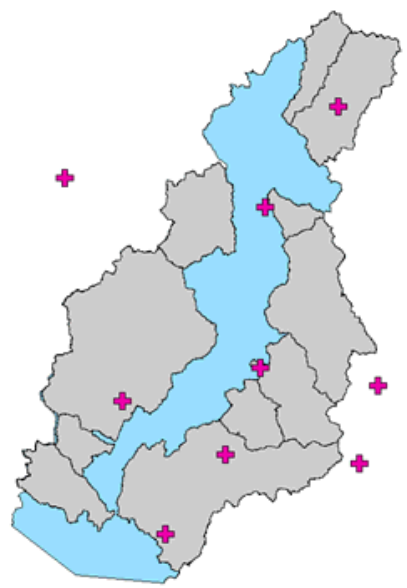

Figure 4: Meteorological stations used in hydrology model

Table 2: Meteorological Stations

\begin{tabular}{|lcc|}
\hline Station Name & State & ID Number \\
\hline First CT Lake & NH & 272999 \\
\hline Newport & VT & 435542 \\
\hline Colebrook 3SW & NH & 271647 \\
\hline Lancaster & NH & 274556 \\
\hline Berlin & NH & 270690 \\
\hline St. Johnsbury & VT & 437054 \\
\hline Bethlehem & NH & 270703 \\
\hline Pinkham Notch & NH & 276818 \\
\hline Benton & NH & 270675 \\
\hline
\end{tabular}

\subsection{Historical Streamflow}

As previously discussed, the streamflow data for the current conditions models were calculated by the hydrology model based on the historic meteorological data. The alternative to this method was using unregulated USGS gages to build a historic reservoir inflow dataset. Reservoirs that did not have unregulated gaging stations require some type of mapping (i.e. by drainage area) from an unregulated site. Simulation/optimization results of the current system based on hydrology model data are presented here to remove any bias when examining changes due to climate change. If spatially mapped USGS gage data were used to build the historic inflow database, the impacts of climate change would be more difficult to quantify. Creating the 
base case using hydrology model generated streamflow may lack some accuracy in replicating historic results, but any changes in the future can be attributed to climate change.

USGS gage data were used at regulated sites for verifying the 20-year simulation model period from 1985-2005. Figure 5 and Figure 6 compared the simulation period to longer periods of record. Figure 5 compares the precipitation at First Connecticut Lake from 1930-2007 to the simulation period. The distribution of the data is similar, but there are some extreme high events that are not included in the study time period. Figure 6 compares the flow duration curve at the Indian gage (below the storage facilities) from 1957 to 2007 to the simulation period. The simulation period includes all the high flow events, but does not incorporate some drought instances, such as the drought of the 1960s.
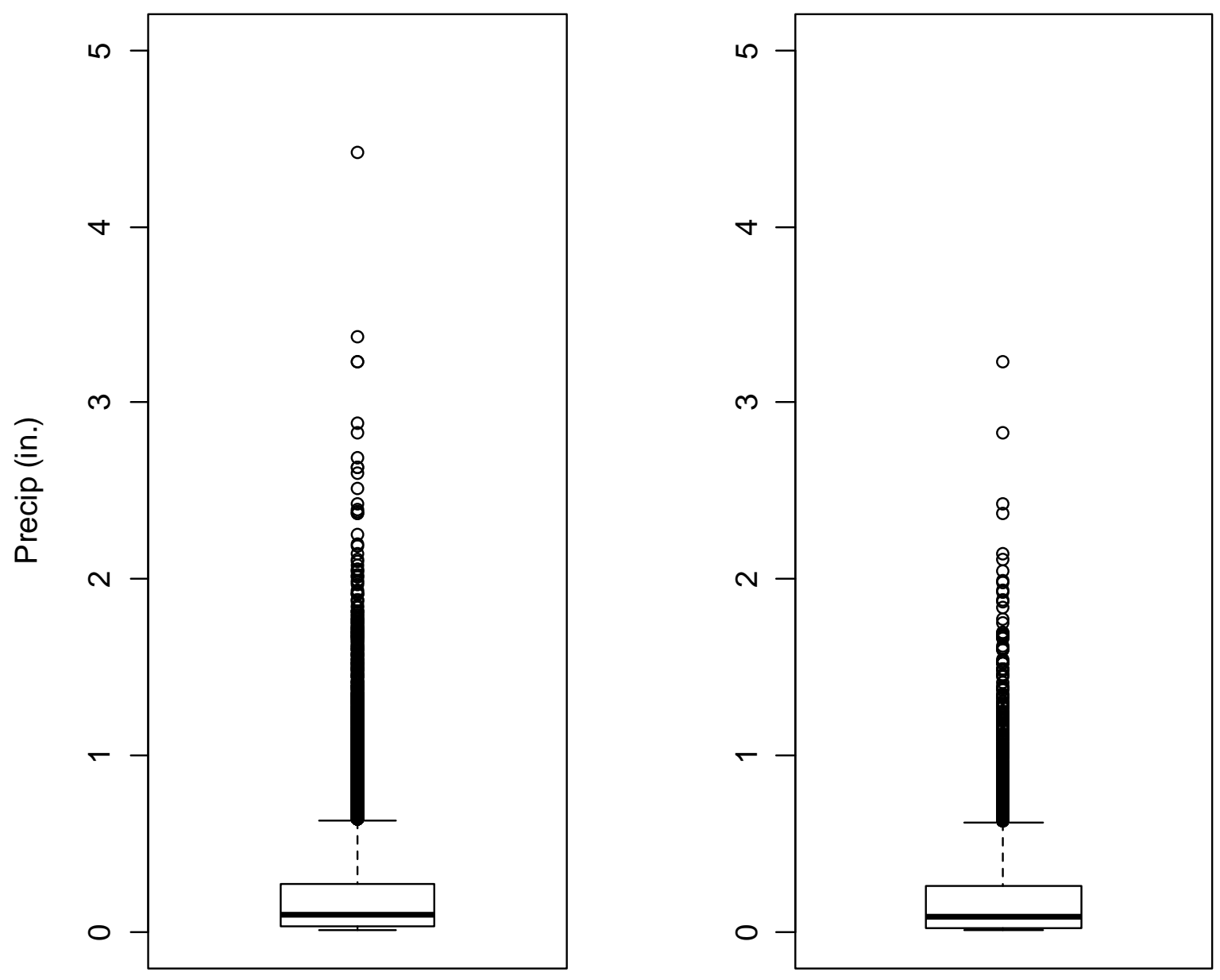

Figure 5: Precipitation (on days where precipitation>0) at First Connecticut Lake from 1930-2007 (left) and 1985-2004 (right). 


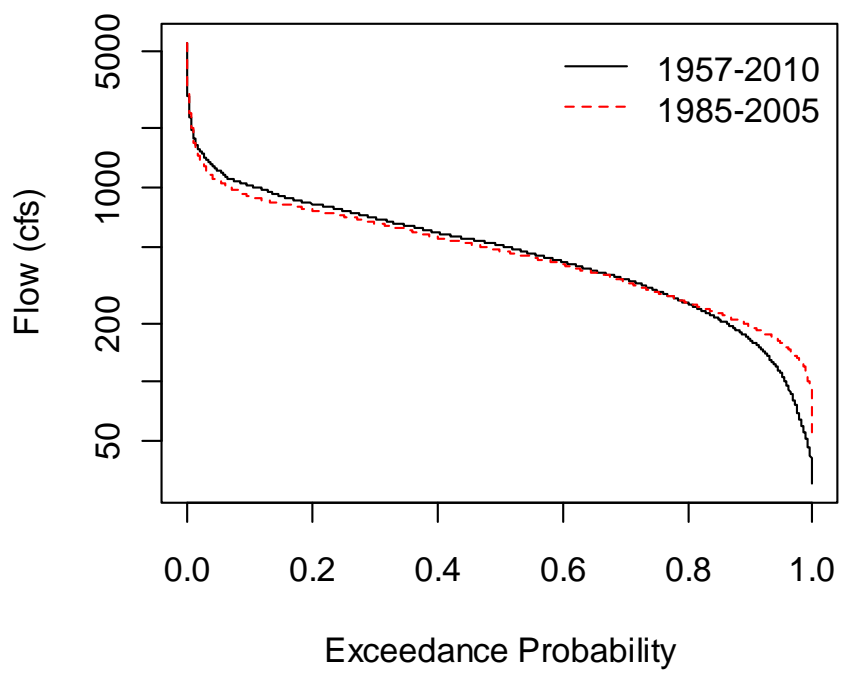

Figure 6: Flow duration curve at the Indian gage (below the confluence of the storage facilities and the Indian sub basin). The black line is the full period of record from 19572010 and the red line is the simulation period used in this study from 1985-2005.

\subsection{Ecological Flow Targets}

Ecological targets are used to restore the natural flow distribution to the river system. For the purposes of this study, The Nature Conservancy identified locations of particular ecological importance in the basin. For the upper third, these points included flood plain forests, mussels, and diadromous fish. Alteration in magnitude, timing, and duration of the regulated flows as compared to the natural distribution are important to the various species. Through discussions, the research team agreed the best way to restore a more natural flow regime is to base reservoir releases on natural flows and limit their alteration.

To implement this, the optimization model has a zone around the natural flow that incurs no penalty. For example, if this zone is set to $10 \%$, there is no penalty for releasing $90 \%$ to $110 \%$ of the natural flow. This allows the reservoirs to store or release extra water to serve their needs, in a sense, skimming higher flows and supplementing lower flows The penalty for releasing outside the "no penalty zone" grows piecewise-linear exponentially in four steps (Figure 7). The natural flows are those that would occur if no facilities were in place. This removed any potential 
bias that may be present in other methods of estimating natural flows. The natural flows were calculated by running the calibrated simulation model with all reservoir storage operations disabled.

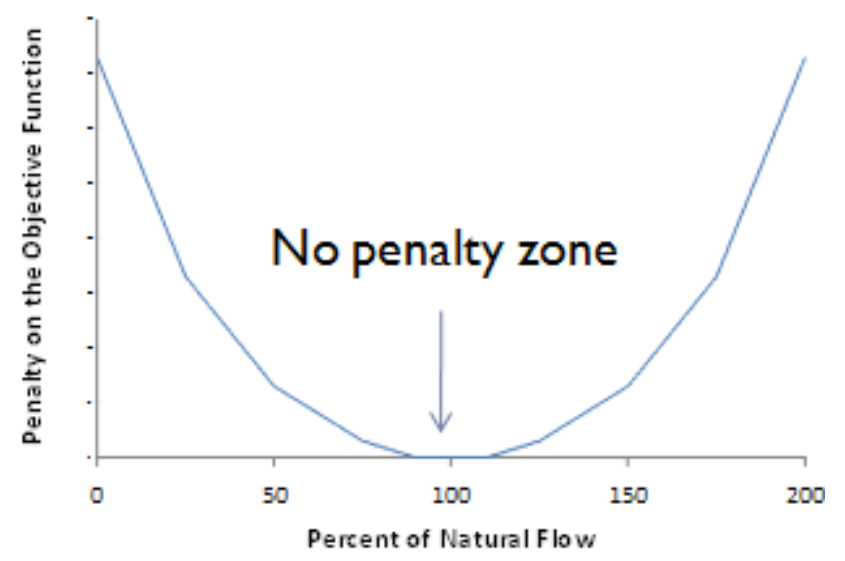

Figure 7: Piecewise linear exponential ecological flow penalty structure

This thesis examines the impacts of different penalty functions associated with maintaining natural flows and the necessary changes in operations required to adhere to these flows. This approach is still evolving in the Connecticut River study. Regulating potentially dangerous floods and properly inundating flood plain forests are modeling challenges still to be resolved. Floods posing risks of property damage or loss of life must be regulated beyond the no-penalty zone. Flood control will be particularly important with USACE flood control dams (Note: The storage facilities operate to mitigate high flows at the Indian gage, but there are no USACE flood control dams in the Upper Third). Also, inundating flood plain forests requires an exact flow that is determined from hydraulic modeling. Allowing a no-penalty zone may result in inadequately inundating the plain.

\subsection{Energy Prices}

Daily Historic energy prices from 2003-2007 were obtained from the Independent System Operator (ISO) of New England. The five years of energy price data were repeated 4 times for the 20 year reservoir operations model runs. The same energy prices were used when exploring potential future impacts from climate change. 


\section{Models of the Decision Support System}

\subsection{Hydrology Model}

Major reservoir construction in the Upper Connecticut began in 1930, ending the historic natural flow regime. The USGS gages in the watershed do not have records prior to 1930, which presents the need for a hydrology model to produce natural stream flow for model input. The hydrology model is used for two purposes: 1) to determine natural inflow into the reservoirs to provide a modeled view of the current system; and 2) to produce climate impacted streamflow from downscaled General Circulation Model (GCM) output.

The research team selected the Distributed Hydrology Soil Vegetation Model (DHSVM) as an appropriate tool to develop a watershed model. This model was co-developed at Princeton University and the University of Washington for hydrologic simulation (Wigmosta et al., 1994). DHSVM is a distributed hydrology model that spatially represents runoff, evapotranspiration, snow cover, and soil moisture (Wigmosta et al., 1994). DHSVM is designed to simulate a three hourly time-step for multi-year runs. It has been extensively used in the Pacific Northwest for various research efforts (Stork et al., 1998 and 1999; Whitaker et al., 2002 and 2003). Storck et al. (1998) utilized three DHSVM models to examine the effects of logging in the Pacific Northwest. Whitaker et al. (2003) found success in using DHSVM to simulate streamflow in the high altitude forested mountain regions of British Columbia. Battin et al. (2007) used DHSVM for a similar purpose as one of the goals of this project - to create streamflow from downscaled GCM meteorological data.

The DHSVM documentation recommends grid cell size on the order of magnitude of 100-400 meters and a total modeled area of less than 10,000 square kilometers. The hydrology model of the study area was built using 300 meter grid cells over a 7,600 square kilometer area. Nine meteorological stations provided temperature and precipitation. The model was calibrated over three years (1984-1987) and performance was evaluated over 20 years (1984-2004). Two tributaries, the Passumpsic River and the Upper Ammonoosuc River, with unregulated UGSS gaging stations were used to calibrate the model (Figure 8). The model output was aggregated from a three hourly time step to daily and calibrated in 5 ways: visual interpretation of the daily hydrograph (Figure 9), average monthly flows (Figure 10), average yearly flows (Figure 11), flow duration curves (Figure 12), and the Nash-Sutcliffe Coefficient. The calibrated hydrology 
model has a Nash-Sutcliffe value of 0.71 at the Passumpsic River calibration point and 0.75 at the Upper Ammonoosuc for the period of 1987 to 2004 (calibration period excluded).

The DHSVM input file has 3 major sections that require attention during calibration: constants, soil properties, and geological properties. The soil layers for the basin were obtained from University of Pennsylvania and the geological information from the USGS. The only parameters in the soil and geological properties that were adjusted were infiltration values that improved the mass balance of the system. Most of the calibration effort was spent on the constants section. The values of the calibrated constant parameters are found in Table 3 . The temperature lapse rates were calculated by examining temperatures at nearby stations at different elevations. The other parameters were adjusted from the default values to improve magnitude and timing of events.

Table 3: DHSVM constant parameters used in calibration.

\begin{tabular}{|c|c|}
\hline Parameter & Calibrated Values \\
\hline Rain Threshold $\left({ }^{\circ} \mathrm{C}\right)$ & -2.0 \\
\hline Snow Threshold $\left({ }^{\circ} \mathrm{C}\right)$ & -1.0 \\
\hline Snow Water Capacity $($ fraction$)$ & 0.008 \\
\hline Snow Melt Release Rate $(\mathrm{m} / \mathrm{s})$ & 0.001 \\
\hline Precipitation Lapse Rate $(\mathrm{m} / \mathrm{m})$ & 0.002 \\
\hline Temperature Lapse Rate $\left({ }^{\circ} \mathrm{C} / \mathrm{m}\right)$ & By Month \\
Jan & -0.014 \\
Feb & -0.014 \\
Mar & -0.014 \\
Apr & -0.00892 \\
May & -0.0071 \\
Jun & -0.00709 \\
Jul & -0.00782 \\
Aug & -0.0081 \\
Sep & -0.00778 \\
Oct & -0.00758 \\
Nov & -0.00842 \\
Dec & -0.014 \\
\hline
\end{tabular}

As seen in the daily hydrologic simulation over an uncalibrated time period in Figure 9, the model responds to most precipitation events. The model misses the magnitude of some of the daily extreme events, but the timing and signal are accurate. Over the historic record, the average 
monthly flows (Figure 10) are slightly lower in the spring and higher in the fall. The average annual flow in Figure 11 does not show any major discrepancies, indicating accurate accounting in the water balance.

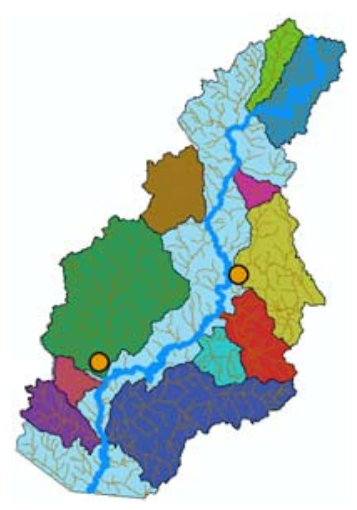

Figure 8: Hydrology model calibration points (indicated by gold circles). The two calibration points, Upper Ammonoosuc (upper right point) and the Passumpsic (lower left point) are each at the mouth of their respective rivers.
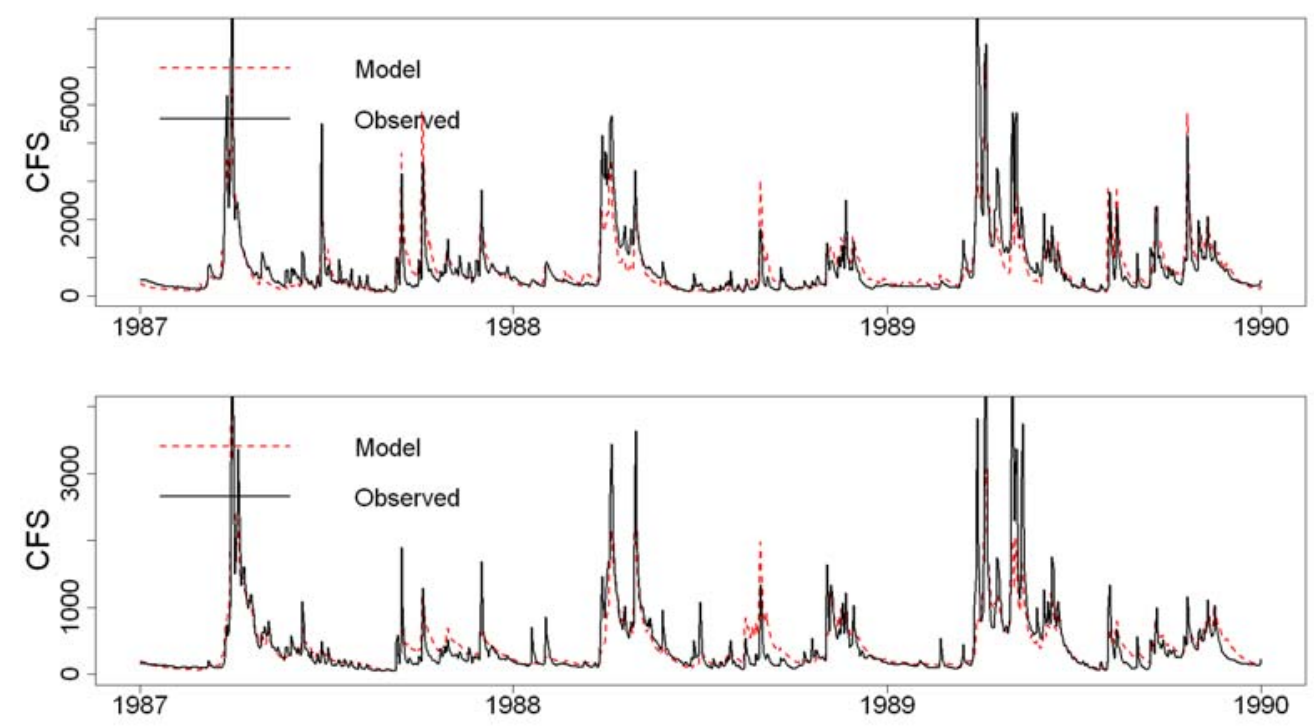

Figure 9: Three year daily time series in the validation period for the Passumpsic River (top) and the Upper Ammonoosuc River (bottom) 

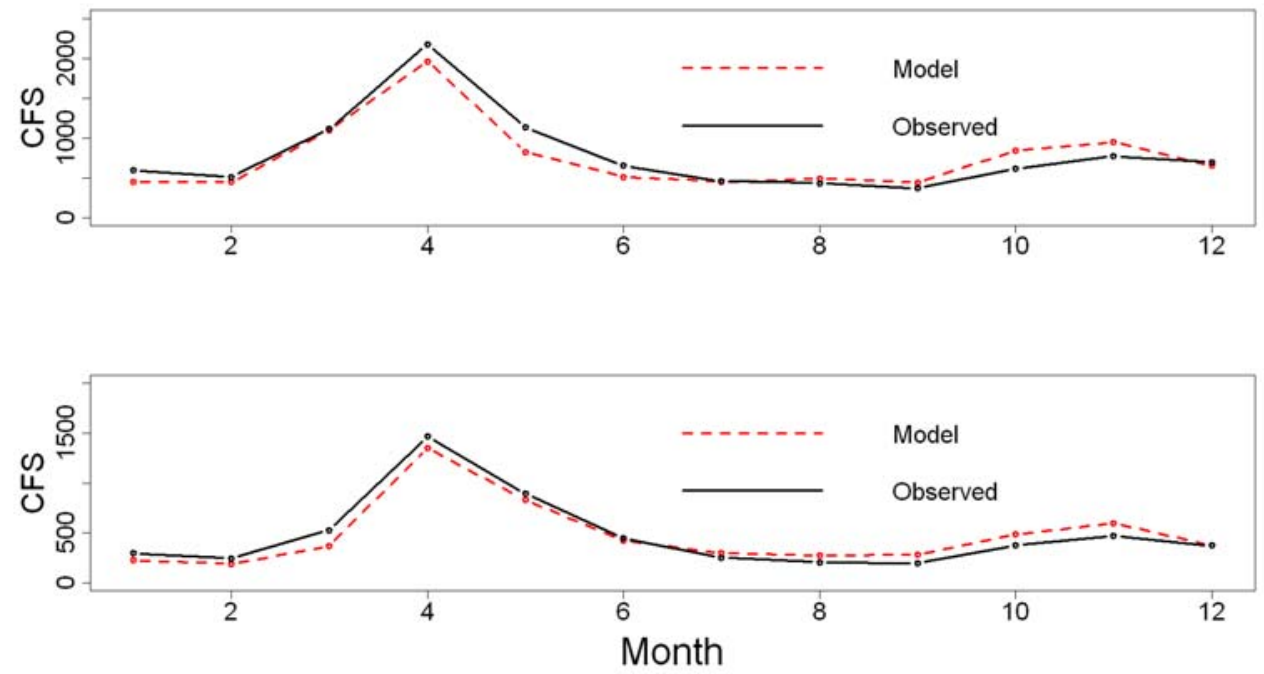

Figure 10: Passumpsic River (top) and Upper Ammonoosuc River (bottom) average monthly flows from the validation period of 1986-2004
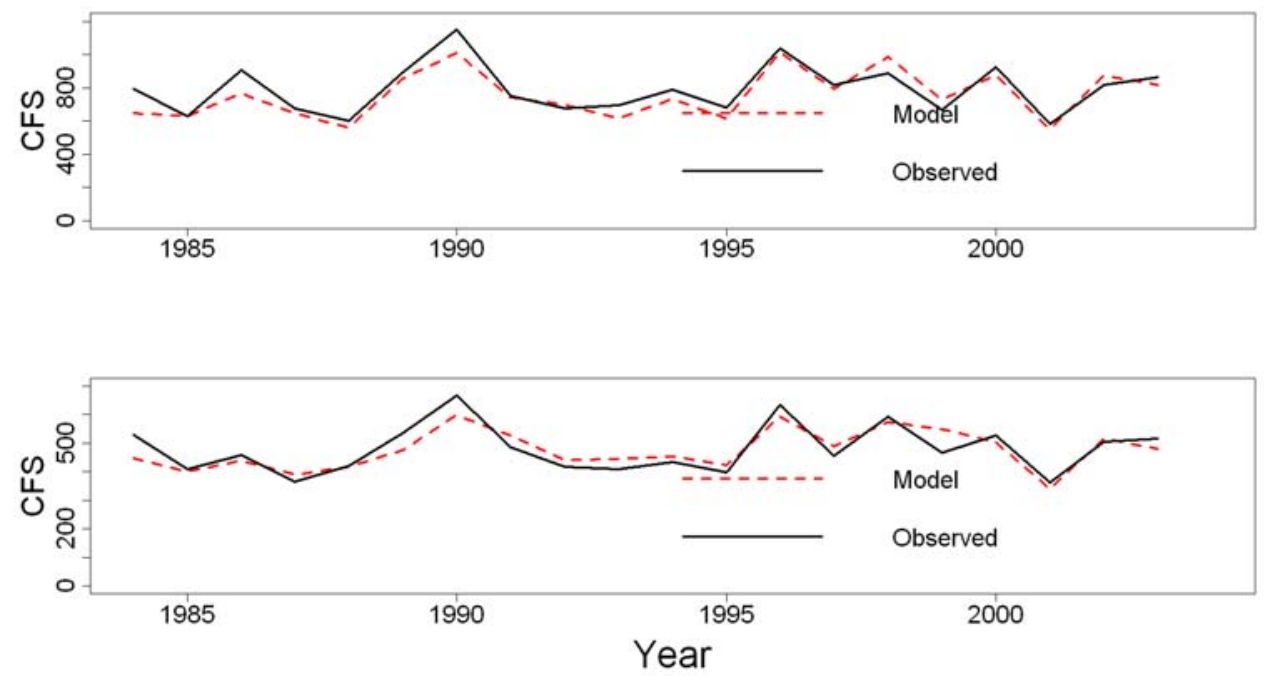

Figure 11: Passumpsic River (top) and Upper Ammonoosuc River(bottom) average yearly flows from 1984-2004 

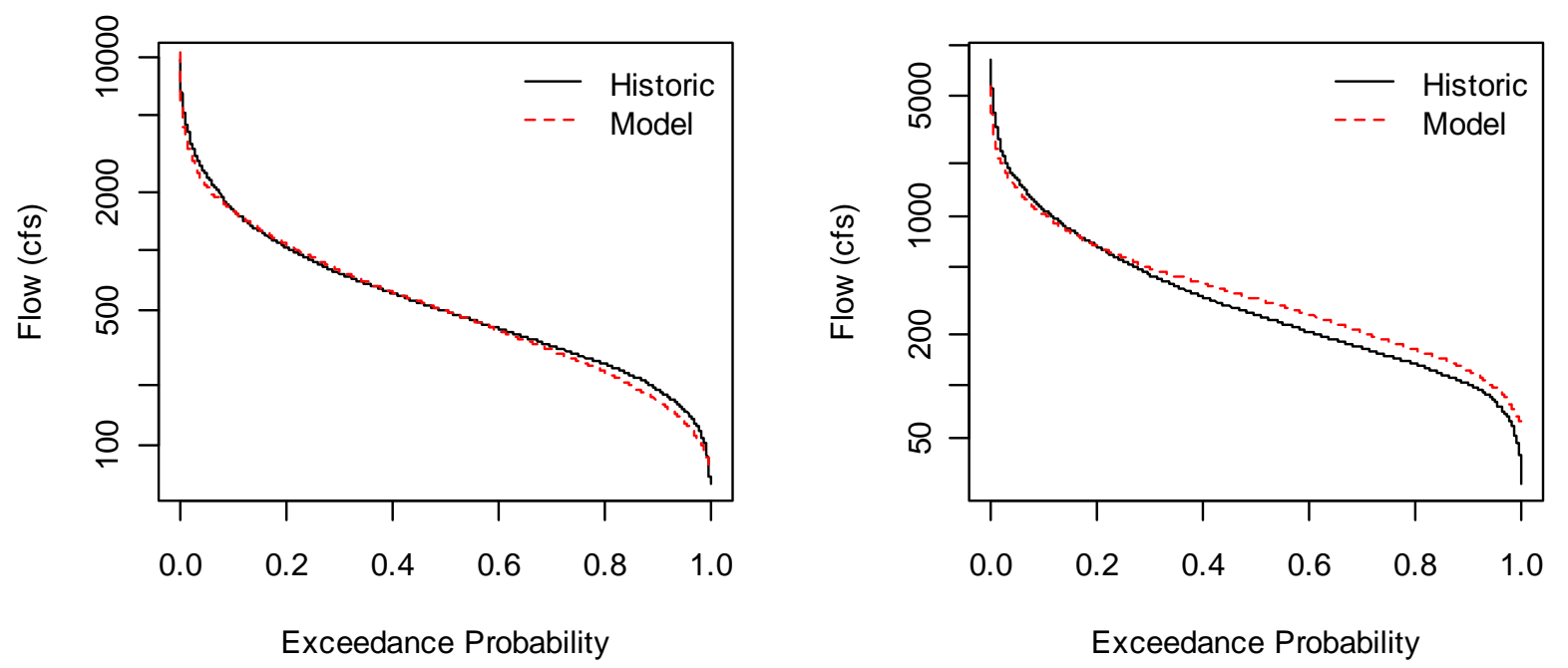

Figure 12: Flow duration curves for the Passumpsic (left) and Ammonoosuc (right) calibration points. The black line represents the historic flows and the red line represents the hydrology model flows.

\subsection{Simulation Model}

The reservoir simulation model is a key communication tool for interactions with project stakeholders (Stave, 2003). The simulation model is the project's representation of the physical system. The research team selected Stella 9.1 .2 by ISEE systems as the simulation software for the project. The Stella environment is object-oriented, allowing accurate replication of complex system interactions and allowing users to understand key model assumptions and feedback. The reservoir simulation model includes logical arguments that govern the operations and visually depicts flows, reservoirs, and releases. The modeling environment, combined with a simple and direct user interface, allows individuals to run the model, view results, and change parameters and assumptions. This ease of development, updating, and execution encourages stakeholder engagement. Although Stella is not strictly a reservoir simulation software package, it has been widely used in the water resources sector (Palmer et al., 2002; Simonovic, 2002; Xu et al., 2002; Lettenmaier et al., 1999).

The modeling process began with dam operator interviews to acquire operational data on the 6 reservoirs in the system (for details, see Section 2.1). Interaction and insight were the goal of the subsequent meetings - the simulation model was presented to demonstrate how the information provided at previous meetings was being used to replicate the system. This type of stakeholder engagement served two purposes. First, the operators could verify that the modelers 
accurately interpreted the information and that operating rules were being properly translated into mathematical terms. Secondly, the stakeholders were involved early in the process and encouraged to articulate ways in which they would use the model. Including stakeholders in the early stages of model development improved the model accuracy and the stakeholder's willingness to contribute.

The model operates on a daily time step and calculates reservoirs' releases and storages as well as flows at eco-nodes. All reservoirs are modeled following a similar framework. Target storages, which fluctuate throughout the year drive the model. The simulation model calculates the releases necessary to meet a target storage given the current reservoir storage and the inflow. The target release is compared against a hierarchy of logical statements representing the reservoir rules such as minimum release requirements, maximum releases, turbine capacity, existing ecological considerations, etc. Since the documented reservoir rules cannot completely detail day-to-day operations, the model releases were calibrated to historic flow at USGS gages to capture operations that may not be included in the documentation. Calibration mainly consisted of capturing weekday peaking of the reservoirs to capitalize on higher weekday energy prices. Historical reservoir storages were not provided, which forced model calibration to be done solely with releases.

\subsection{Optimization Model}

The optimization model was constructed using the commercially available linear programming packing LINGO (Version 11.0). The model operates on a daily time-step and calculates decision variables such as reservoir releases, storages, and flows in rivers. The releases were calculated to minimize the objective function, which consisted of deviations from storage targets, and deviations from ecological flow targets as well as terms to maximize income (Equation 1).

To decrease model runtime, the model runs at 5-year intervals (i.e. 20 years is modeled as four five-year runs). Continuity was preserved by constraining the model storage to its target value on the first and last day of each execution. The constraints on the reservoirs were: storage capacity, reservoir connectivity, minimum/maximum release, and maximum power generation. The reservoir connectivity constraints established the proper flow of water through reservoirs, confluences, and eco-nodes and preserve mass balance. Time lags between reservoirs are 
discussed in Appendix C. As mentioned in Section 2.1, many of the minimum release requirements were dependent on the inflow. Flow data was preprocessed before being imported to the model to avoid using binary variables and the associated increase in runtime. If the inflow on a given day was less than the minimum release, the inflow value was imported into the model as the minimum release requirement for that day.

$$
\begin{gathered}
M I N= \\
W T_{S C L} * \sum_{i=1}^{N}\left|S T_{S C L_{i}}-T A R G_{S C L_{i}}\right|+ \\
W T_{F C L} * \sum_{i=1}^{N}\left|S T_{F C L_{i}}-T A R G_{F C L_{i}}\right|+ \\
W T_{M O R 1} * \sum_{i=1}^{N}\left|S T_{M O R_{i}}-T A R G_{M O R_{i}}\right|+ \\
W T_{M O R 2} * \sum_{i=1}^{N} S T_{M O R M A X_{i}}+S T_{M O R M I N_{i}}+ \\
W T_{E C O} * \sum_{i=1}^{N}\left|F L O W_{E C O_{i}}-T A R G_{E C O_{i}}\right|+ \\
W T_{I N C} * \sum_{i=1}^{N} I N C_{i}
\end{gathered}
$$

Subject To (typical constraints):

$$
\begin{gathered}
S T_{\text {res }_{i}} \leq \text { Capacity }_{\text {res }} \\
R E L_{\text {res }_{i}} \geq \text { MINRE }_{\text {res }} \\
F L O W_{\text {IND }_{i}} \leq F L O W_{\text {FLOOD }} \\
S T_{R E S_{1}}=S T_{R E S_{N}} \\
F L O W_{T_{\text {TUB }}}<T U R B_{C A P}
\end{gathered}
$$

Where:

$N=$ number of days in the model run

$W T_{S C L}=$ Weighting coefficient for SCL's target storage objective

$S T_{S C L_{i}}=$ Model calculated storage at SCL for day $i$

$T A R G_{S C L_{i}}=$ Target Storage for day $i$

$W T_{F C L}=$ Weighting coefficient for FCL's target storage objective

$S T_{F C L_{i}}=$ Model calculated storage at FCL for day $i$

$T A R G_{F C L_{i}}=$ Target Storage for day $i$ 
$W T_{M O R 1}=$ Weighting coefficient for MOR's target storage objective

$S T_{M O R_{i}}=$ Model calculated storage at MOR for day $i$

$T A R G_{M O R_{i}}=$ Target Storage for day $i$

$W T_{M O R 2}=$ Weighting coefficient for MOR's upper and lower limit target storage objective

$S T_{\text {MORMAX }}=$ Storages exceeding MOR's upper storage target

$S T_{\text {MORMIN }_{i}}=$ Storages below MOR's lower storage limit

$F L O W_{E C O_{i}}=$ Flow at an ecological node for day $i$

$T_{A R G_{E C O}}=$ Target flow at an ecological node for day $i$

$W T_{I N C}=$ Weighting coefficient for income objective (must be negative to maximize income)

$I N C_{i}=$ Income on day $i$

$S T_{\text {resi }}=$ reservoir storage on day $i$

Capacity $_{\text {res }}=$ reservoir capacity

$R E L_{r e s_{i}}=$ reservoir release on day $i$

$M I N R E L_{\text {res }}$ = minimum release on day $i$

$F L O W_{I D N_{i}}=$ Flow at the Indian gage on day $i$

$F L O W_{F L O O D}=$ Flood control flow $(10,000 \mathrm{cfs})$

$S T_{\text {res }_{N}}=$ Storage on the last day of model run

$F L O W_{T_{U R B}}=$ Flow through the turbine on day $i$

$T U R B_{C A P}=$ Maximum flow through the turbine

\section{Equation 1: Optimization model objective function.}

One of the most challenging components of a multi-objective optimization problem is assigning the proper weighting coefficients to each objective. The weights serve two purposes: normalizing the unit discrepancies and prioritizing competing objectives. The objective function sums flows, storages, and dollars; all measured in disparate units. The order of magnitude of typical values offer a starting point for estimating the weights, but some trial and error is required.

The trial and error process occurs during the modeling portion where the simulation model rules are translated into linear programming as discussed in Section 2. This is a crucial step in the modeling process because it assures the linear program will be optimizing the same system as the simulation model. To accomplish this, the model's objective function only minimized deviations from target storages and maximized income generated. These rules guided historic operations, so with the correct weighting factors the storage and release daily time series should be similar to the simulation model and historic values. 
The optimal solution depends on the priority assigned to each objective term. Many of the objectives conflict - for example, deviations from target storage must be increased to generate more income and income must be sacrificed to meet an ecological flow. The optimization model quantifies what one objective must sacrifice to improve another. Trade-off curves show the range of optimal operating policies for competing objectives, and will be discussed further in the results section (Section 5).

\section{Generating Climate Impacted Streamflow}

\subsection{General Circulation Models}

Exploring the possible effects of climate change is an ongoing task in the Connecticut River Project and a final approach was not established prior to the completion of this thesis. The final climate change analysis will include 5 GCMs and 2 emissions scenarios (A2 and B1), totaling 10 climate change conditions. The A2 scenario models limited global cooperation and efforts to reduce emissions, while the B1 scenario depicts a globally cooperative society that is consciously working to limit emissions.

This thesis shows some preliminary results of changes in streamflow according to an ensemble of the 5 selected GCMs for the A2 and B1 emissions scenarios. Reservoir operations under the changed hydrologic conditions are also examined.

The GCM selection was based on the findings of Ahlfeld (2006) in which the author tested the ability of GCMs to replicate historic precipitation in North America. Ahlfeld used the CPC Merged Analysis of Precipitation data (CMAP) from January 1, 1979 to December 31, 1999 to compare the GCM output. The GCMs deviations from the CMAP data were calculated on a yearly and seasonal average. The seasonal averages were segmented at three month intervals: December-January-February, March-April-May, June-July-August, and SeptemberOctober-November. The following GCMs had the best results for the eastern North America and will be used in this study:

- $\quad$ GISS-AOM (NASA/Goddard Institute for Space Studies-USA)

- $\quad$ CGCM3 (Canadian Centre for Climate Modeling \& Analysis - Canada) 
- MRI-CGCM (Meteorological Research Institute - Japan)

- PCM (National Center for Atmospheric Research - USA)

- CCSM3 (National Center for Atmospheric Research - USA)

Individual GCM projections for temperature and precipitation can be found in Appendix D.

\subsection{Downscaling}

Temperature and precipitation from the GCM data were needed as input to the hydrology model at meteorological station resolution. Mauer (2007) provides GCM output downscaled and bias corrected from various sizes to $1 / 8^{\text {th }}$ degree. This data set was used as the starting point for downscaling. The delta method is used to downscale the $1 / 8^{\text {th }}$ degree data to the meteorological station level. The delta method applies GCM projected changes in temperature and precipitation to the historic record. This accounts for the trends suggested by the GCM while maintaining the historic climatic variability. This method has been widely used, especially in studies requiring sub-monthly data (Lettenmaier et al., 1999; Snover et al.,; 2003, Elsner et al.,; 2010).

The delta method also allows direct comparison to the historic data. For this study, 19852004 is used as the current conditions for the hydrology and reservoir simulation and optimization models. To compare how the natural hydrology and regulated streamflow will shift under climate change, the same historic record is used but with the appropriate GCM shift. GCM trends centered around 2000, 2040, and 2080 are used in this study. Ideally, the 2000-GCM scenarios match the current conditions model, indicating the GCM accurately represents the past, thus giving it credibility into the future. If the 2000 scenario does not match historic, it shows the error that can be taken into account when examining the 2040 and 2080 future cases.

\section{Results}

The results of this research pursue four themes, establishing the credibility of the model by comparing its results to historic operations, optimizing the system for environmental flows, optimizing the system for power generation, and optimizing the system for flood control. The 
goal is to demonstrate the trade-offs that exist between these various operating objectives, but equally important, to note those situations in which significant progress toward one or more of these goals can be achieved without significant loses to the others. This classic trade-off analysis has been illustrated by many (Cohon, 1986; Loucks, 1992; Lund, 1997) and is used once again here to help define the range of possible operating policies in this basin and to serve as a point of departure for future studies.

\subsection{Modeling the Status Quo}

In water resources planning, the status quo is defined as the state of a water system currently and through time without the implementation of new planning. In the upper Connecticut River watershed, the important components of the status quo include rivers, basins, facilities, existing environmental targets (minimum instream flow requirements), operations, and energy price fluctuation.

The presentation of results focuses on flows at Eco-Node 1, the first eco-node below the storage facilities. There is no regulation or regulated tributary inflow between Eco-Node 1 and Eco-Node 2, indicating the level of natural flows achieved at 1 will be the same as 2 and thus can be viewed as the same target. Results from Eco-Node 3, located at the outlet of the system, can be found in Appendix E. Eco-Node 3 is affected by all the reservoirs in the system, but the drainage from the natural tributaries dampens the regulated signal (Figure 13). Under current operations, Eco-Node 1 deviates from the natural flow distribution significantly more than EcoNode 3. 


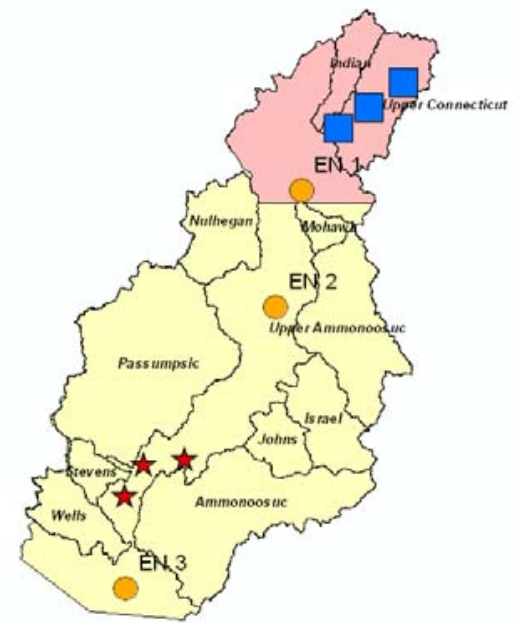

Figure 13: Drainage areas of Eco-Node 1 (red) and Eco-Node 3 (yellow).

Although each reservoir is modeled uniquely in the simulation and optimization models, the results are presented here, for the sake of clarity, as a single cumulative storage, consisting of the combined storages of the three storage facilities - SCL, FCL and LFR. This is used to illustrate the impacts on reservoir storage of meeting ecological flow targets. The model reservoir's target storage and storage capacity is the sum of the three facilities.

Before exploring ways to improve flows for ecological targets, the status quo is established. Currently, the operational objective of a hydropower system is assumed to be to maximize total income, while remaining within the bounds of any licenses and agreements. In New England, the average monthly energy prices (Figure 14) are highest in the winter and summer months due to the high energy use associated with heat and air conditioning. High energy prices entice the operators to release more water through the turbines to increase generation and revenue. The reservoir operations, specifically the target storage, are designed to increase flows during the winter and summer through reservoir draw downs. In the winter and summer, the storage facilities release excess water to supplement water to the downstream generating units to maintain an increased flow and head levels. The fall and spring seasons have lower energy prices and therefore the reservoirs refill during this period. The operational scheme can be seen in Figure 15. 


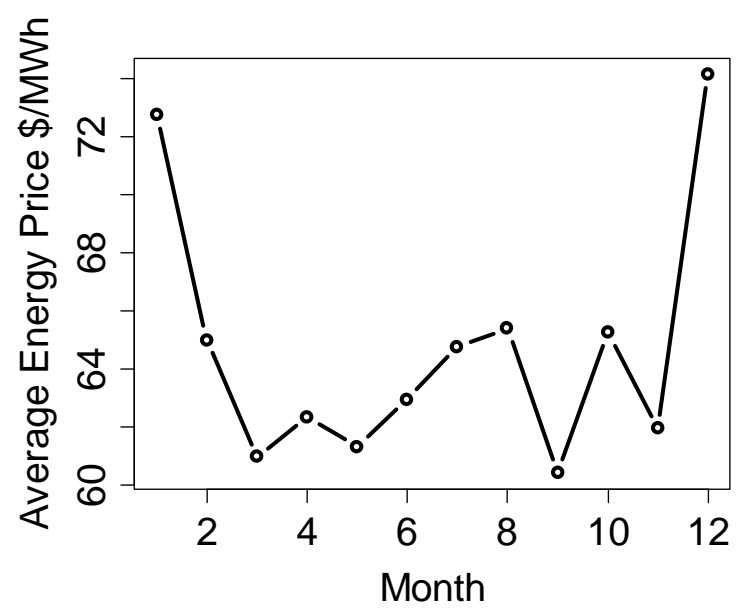

Figure 14: Average monthly energy prices used in simulation and optimization model (ISO New England, 2003-2007).

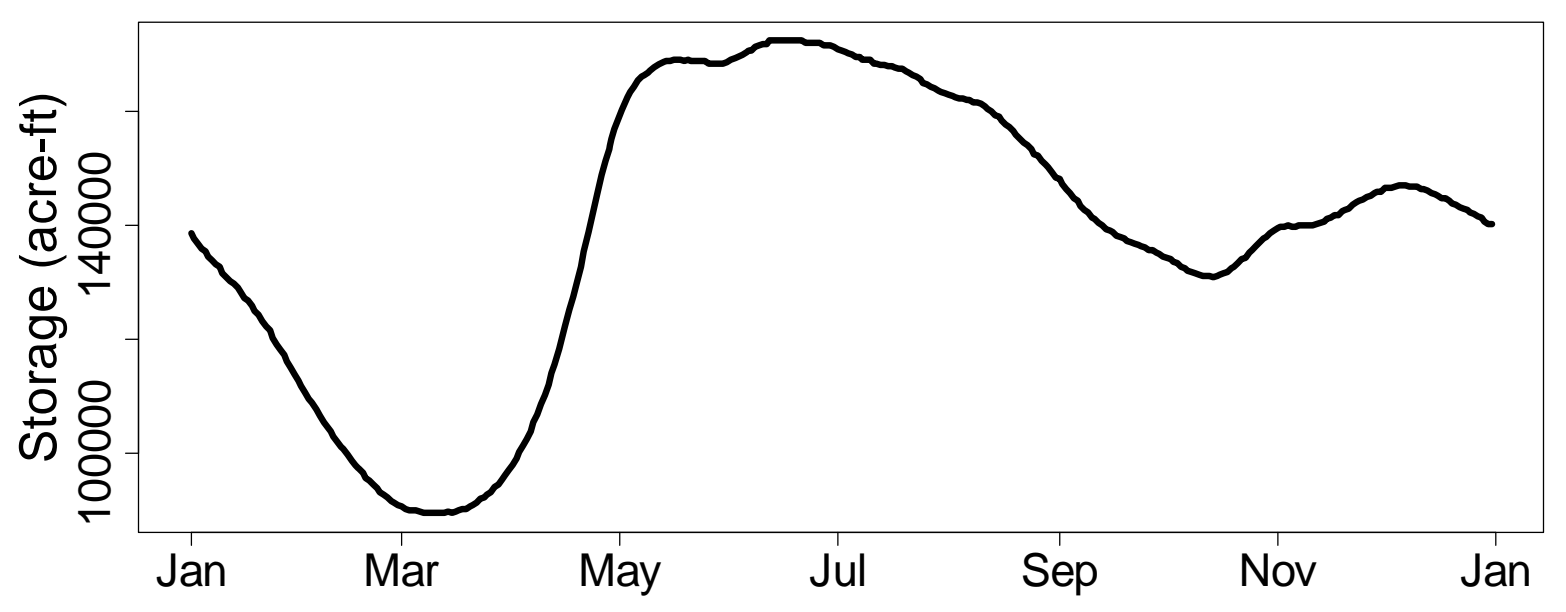

Figure 15: Target storage for the combined storage system in the Upper Connecticut Basin (Second CT Lake, First CT Lake, and Lake Francis).

\subsubsection{Simulation Model Monthly Flow Duration Curves}

The operation of reservoirs in the upper Connecticut River basin has significant impacts on the monthly flows during much of the year. Monthly flow duration curves of the simulation model compared to the natural flow regime show the impacts of the current operations (Figure 16). The most significant deviations from the natural flows occur in January and February. During this time, streamflows are significantly higher due to reservoir releases than would occur 
naturally. This is a result of the winter drawdown that starts at the beginning of January and continues until the beginning of March. Flows are also higher in August and September due to the summer drawdown. The summer drawdown has a slower rate and does not reach as low a level, thus the deviations are not as severe as in the winter. The reservoirs use the naturally higher flows in April, May, and June to refill, causing lower than natural flows. This also occurs in November when reservoirs are refilled. Again, the summer draw down is less severe, so the fall refill does not cause as significant deviations as the spring refill. Under current operations, March and October do not significantly deviate from the natural flow distribution. 


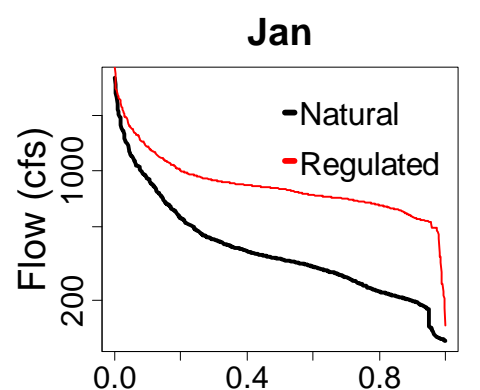

Exceedance Probability

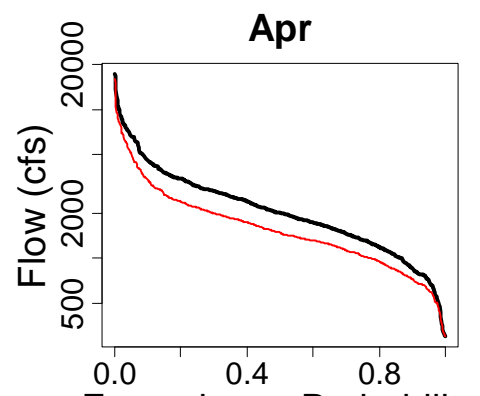

Exceedance Probability
Feb

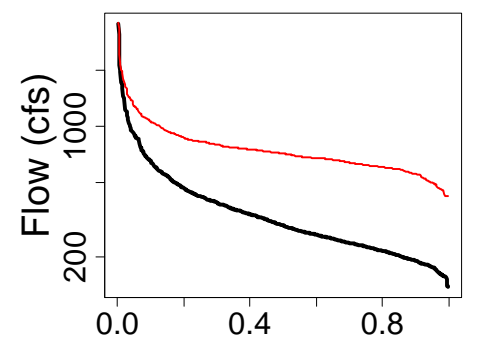

Exceedance Probability

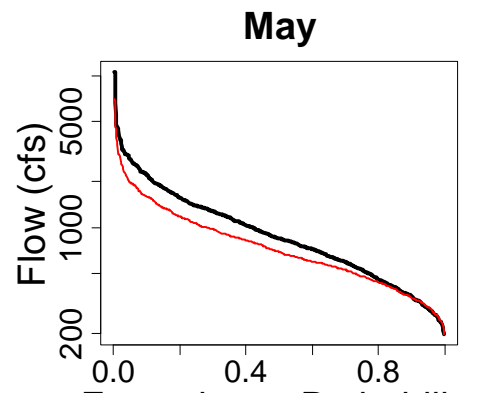

Exceedance Probability

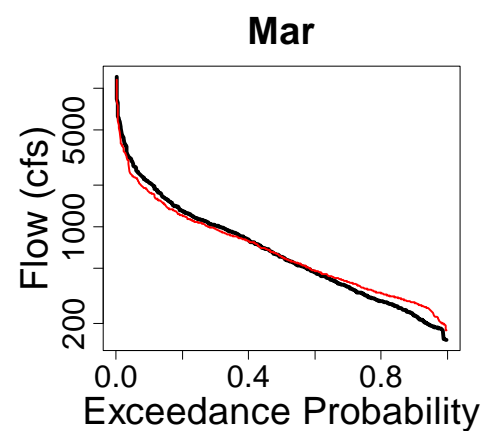

Jun

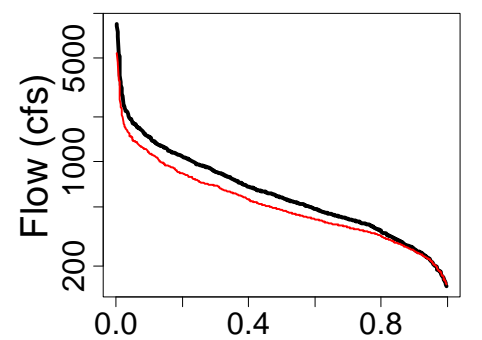

Exceedance Probability
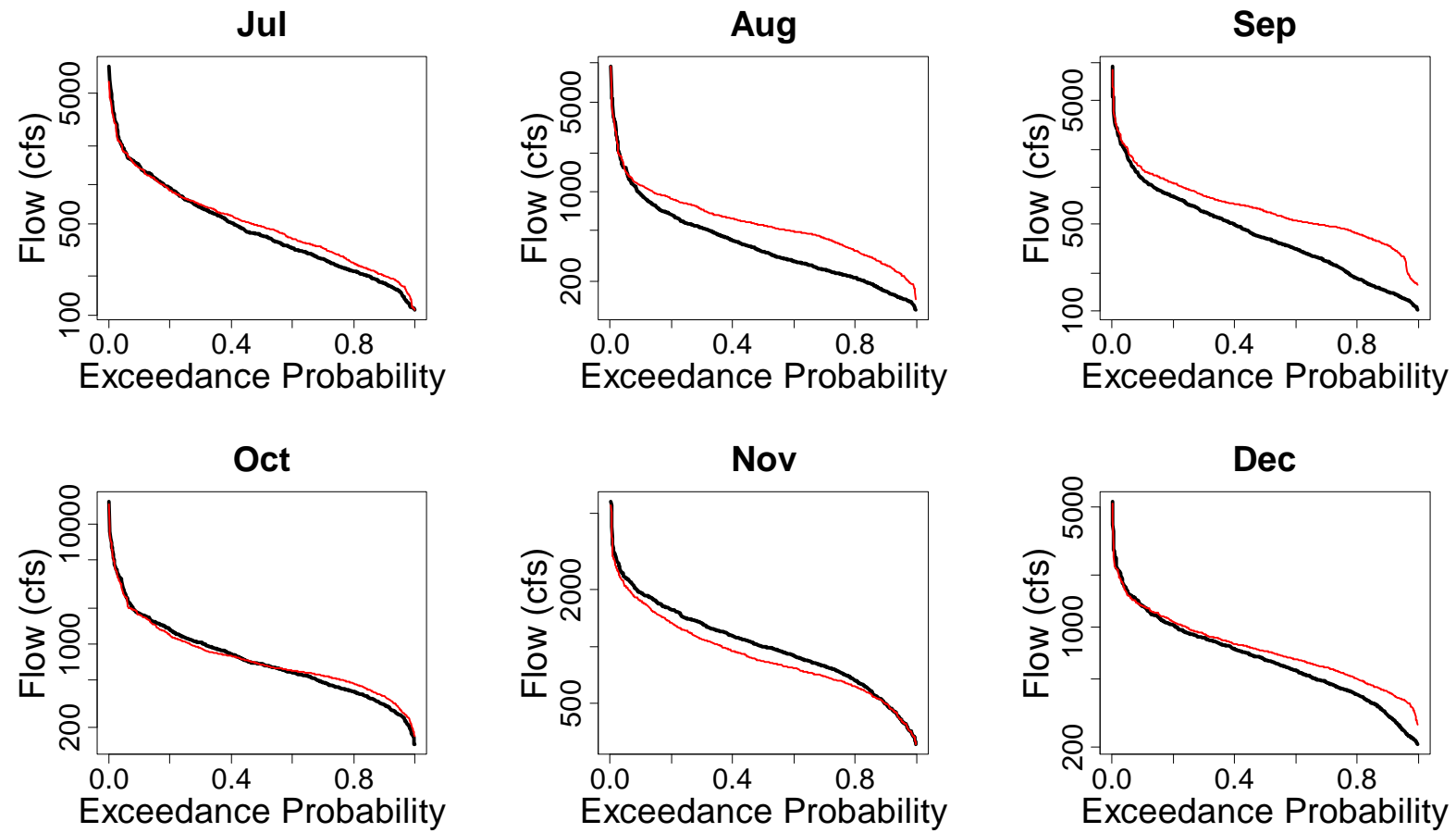

Figure 16: Simulation model monthly flow duration curves with current operations at EcoNode 1 below the 3 storage facilities. The red line represents the simulation model and the black solid line is the natural flow in the river if the reservoirs passed all inflow. (Note the $y$-axis is a logarithmic scale) 


\subsubsection{Optimization Model Monthly Flow Distributions}

Unlike the simulation model, which replicates current operating policies through a series of rule curves and rules of thumb, the optimization model seeks to maximize system income through the production of hydropower while minimizing deviations from target storages. With the proper weighting (Table 4), the optimization model generates results very similar to the simulation model (Figure 17). In the Current Conditions scenario, the reservoirs follow their target storage while making deviations to capitalize on periods of higher energy prices. The time series of storages in Figure 18 demonstrates this behavior. The target storage is a guide for pool elevation, but energy prices and streamflow dictate exactly how much water is captured or released. The perfect foresight of all future energy prices and inflows produces slightly different results than the simulation model, but the same trends can be seen: higher than natural releases in the winter and summer and storing flows in the fall and spring. The optimization model's ability to perfectly forecast future energy prices results in the rapid changes in storage in Figure 18; in day-to-day operation, this variation would be gradual deviations away from the target storage followed by a gradual return.

Table 4: Objective function coefficient weights for current operations.

\begin{tabular}{|cc|}
\hline Objective & Weighting Coefficient \\
\hline SCL Storage & 1 \\
\hline FCL Storage & 1 \\
\hline LFR Storage & 1 \\
\hline MOR Storage & 1 \\
\hline MOR Storage Extremes & 10,000 \\
\hline Ecological Targets & 0 \\
\hline Income & 85,000 \\
\hline
\end{tabular}




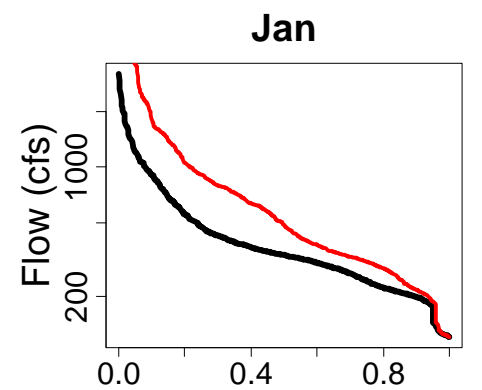

Exceedance Probability

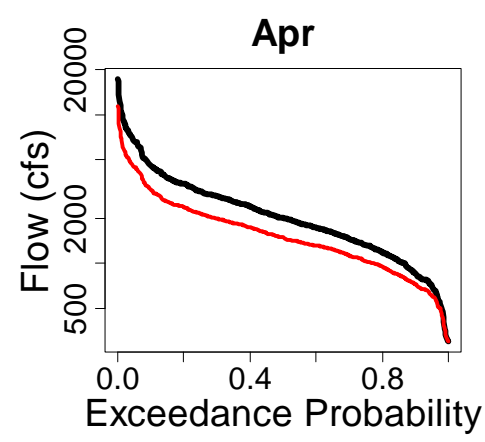

Jul
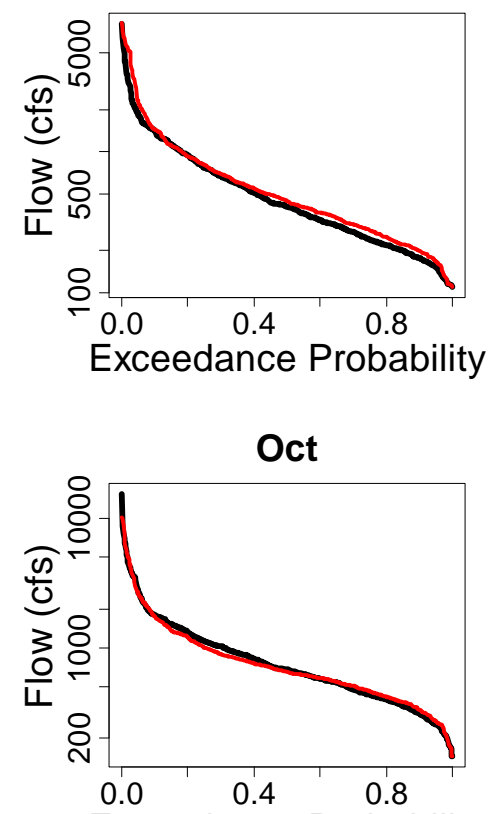

Exceedance Probability

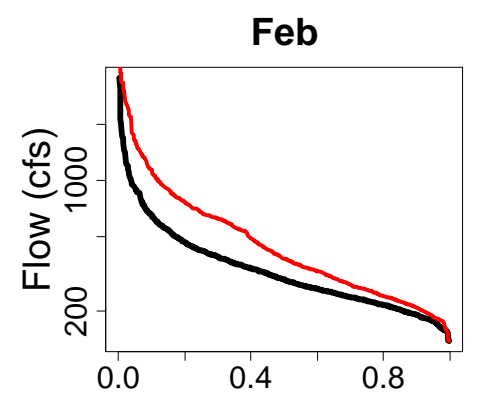

Exceedance Probability
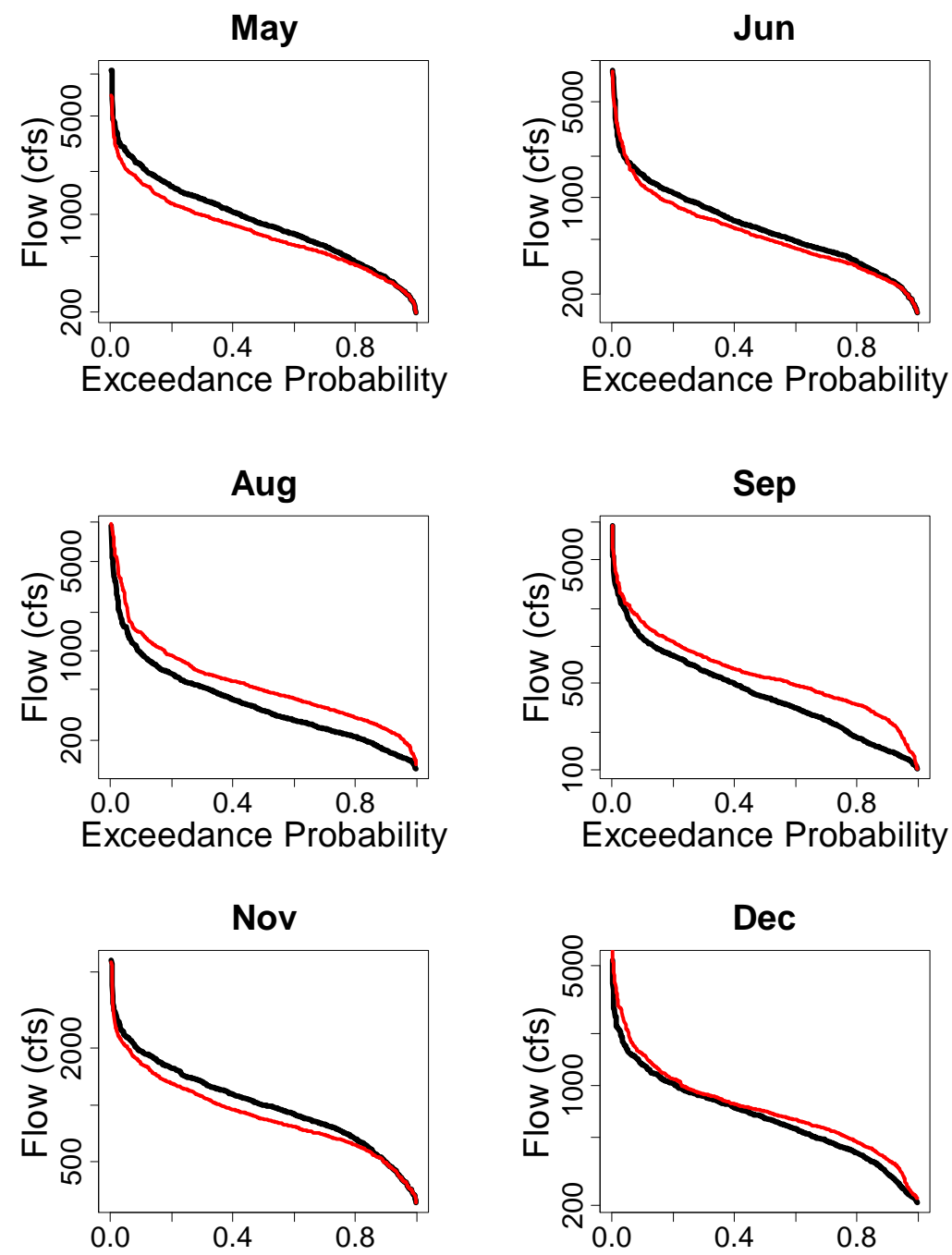

Exceedance Probability

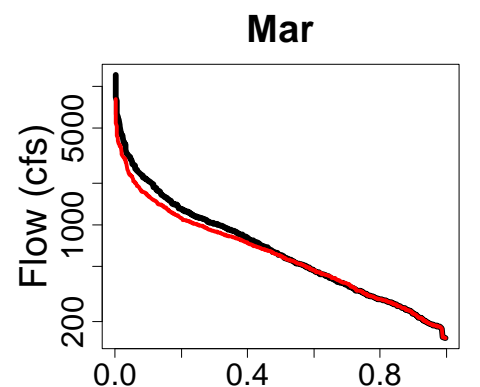

Exceedance Probability
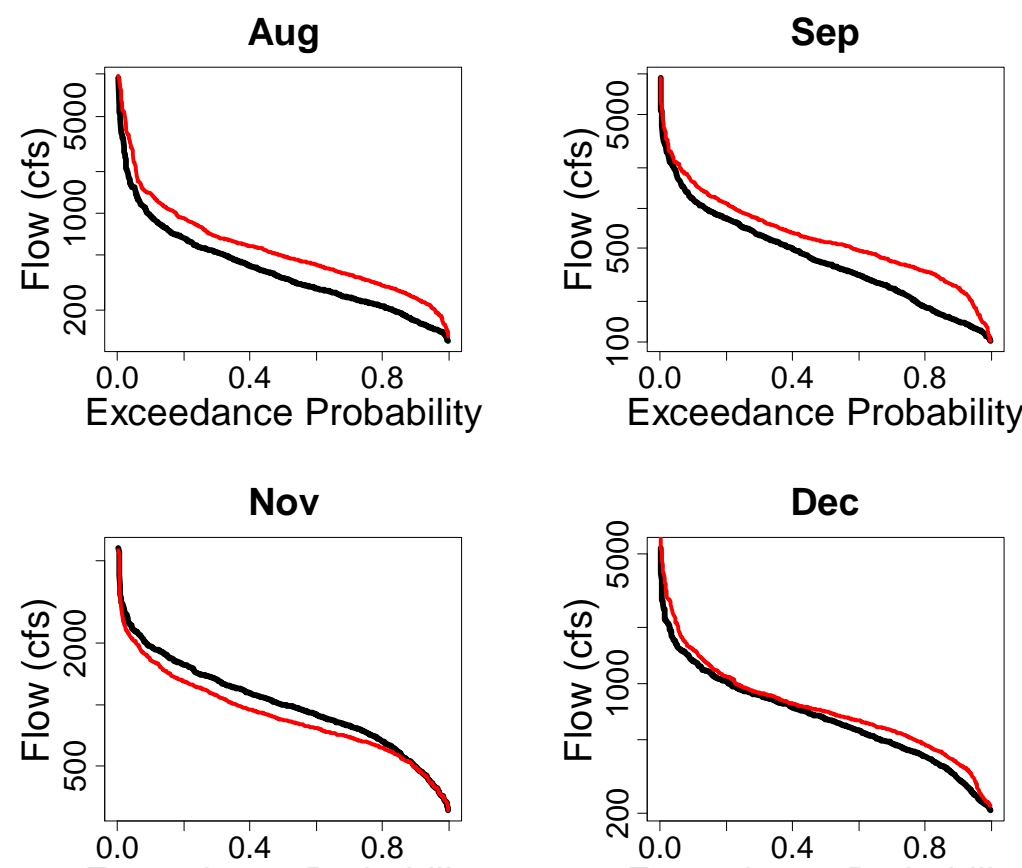

Exceedance Probability

Figure 17: Optimization model monthly flow duration curves at Eco-Node 1 with ecological targets not considered. The objective function forces the reservoirs to follow their target storages while maximizing income. The red line represents the optimization model and the black solid line is the natural flow in the river if the reservoirs passed all inflow. 


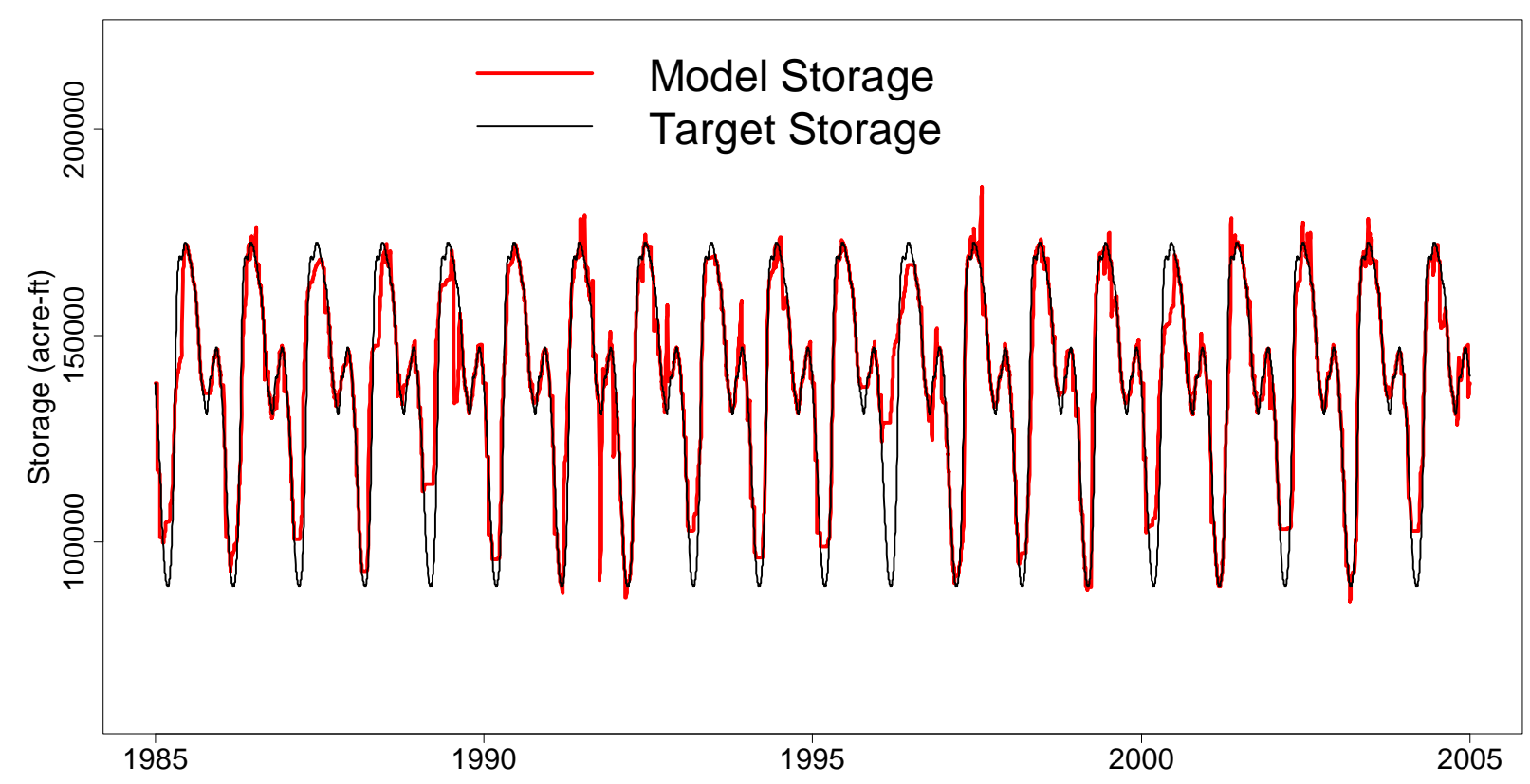

Figure 18: Optimization model combined system storage that corresponds to the monthly flow duration curves in Figure 17. The objective function forces the reservoirs close to the target storage while allowing deviations to maximize income.

\subsubsection{Income from Current Operations}

In this thesis, simulation and optimization output are not directly compared, but rather various runs of the optimization model are analyzed. However, it is important to note that actual income generated falls in the range between the simulation and optimization models. With the current operational guidelines (eco-targets not considered), the simulation model produced an average of $\$ 44$ million/year over the 20 year model run and the optimization model generated $\$ 55.3$ million/year. The simulation model is driven solely by the target storage and has no foresight or knowledge of energy prices. As previously discussed, the target storage curves are designed to release more water during typical high energy price times, and this is all the simulation model uses. On the contrary, the optimization has perfect foresight and knowledge. The penalty function that negatively weights deviation from the target storages is all that prevents the model from completely dictating releases based on income. In actual operations, real time energy prices and stream flow are known. Forecasts of streamflow and energy prices 
are also available, although forecasts are never perfect. This information is used to determine operations and falls between the no foresight or knowledge (simulation model) and perfect knowledge (optimization model).

\subsection{Results: Operating to Improve Ecological Flows}

As discussed in Section 2.4, the research team determined that limiting the percent difference between natural and regulated flows at the eco-nodes was the best option to restore the natural magnitude, timing, and duration of flows. The initial ecological targets provide a 10\% “penalty free zone” in which reservoirs can store or release water. Altering flows from what they would be naturally by more than $10 \%$ incurred a penalty that increased exponentially, and which was estimated in a piecewise fashion. Although little biological justification existed for the choice, the $10 \%$ value provided an initial point to examine the costs and effects on flows and storages for different no penalty zones. When the ecological flows are weighted heavily with respect to other reservoir objectives (Table 5), the model replicates the natural flow regime. As can be seen in Figure 19, the model uses the $+/-10 \%$ allowance to alter the natural flow in a similar pattern to the current conditions in Section 5.1. (increasing flows during high energy price times and storing water during low energy price times). The releases are virtually identical to the natural, but it is apparent the reservoir uses the allowance to release more water in the winter/summer and refill in the spring/fall. This scenario is considered the best case for the ecosystems; the flow distribution is nearly identical to that in the natural state with no large deviations.

Table 5: Objective function weighting coefficients for operating to improve ecological flows

\begin{tabular}{|cc|}
\hline Objective & Weighting Coefficient \\
\hline SCL Storage & 1 \\
\hline FCL Storage & 1 \\
\hline LFR Storage & 1 \\
\hline MOR Storage & 1 \\
\hline MOR Storage Extremes & 10,000 \\
\hline Ecological Targets* & $10,000,000$ \\
\hline Income & 85,000 \\
\hline
\end{tabular}

*The heavy weight on ecological targets essentially makes them constraints 


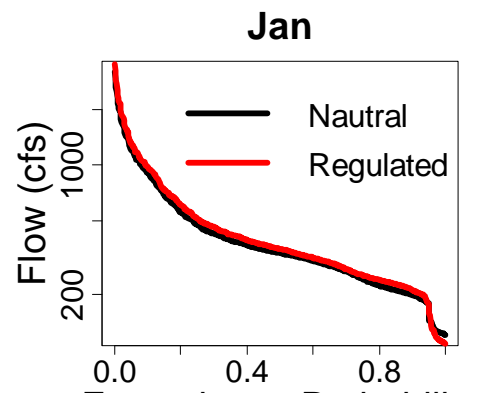

Exceedance Probability
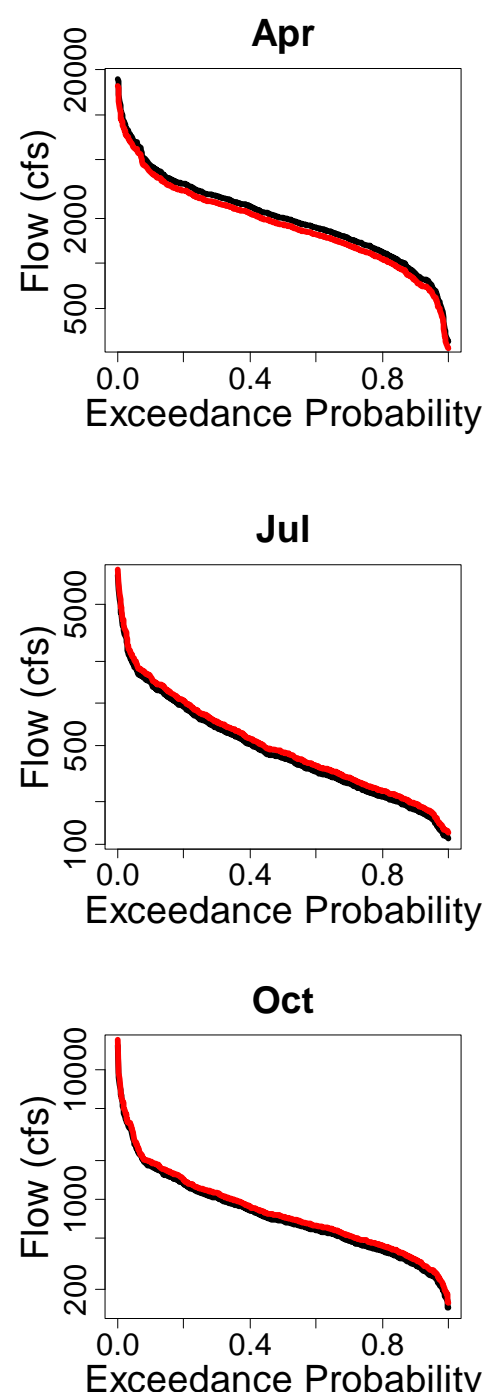

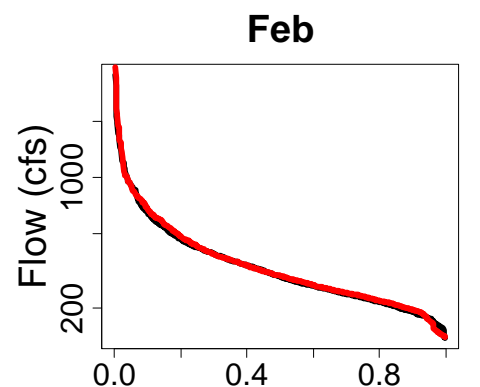

Exceedance Probability
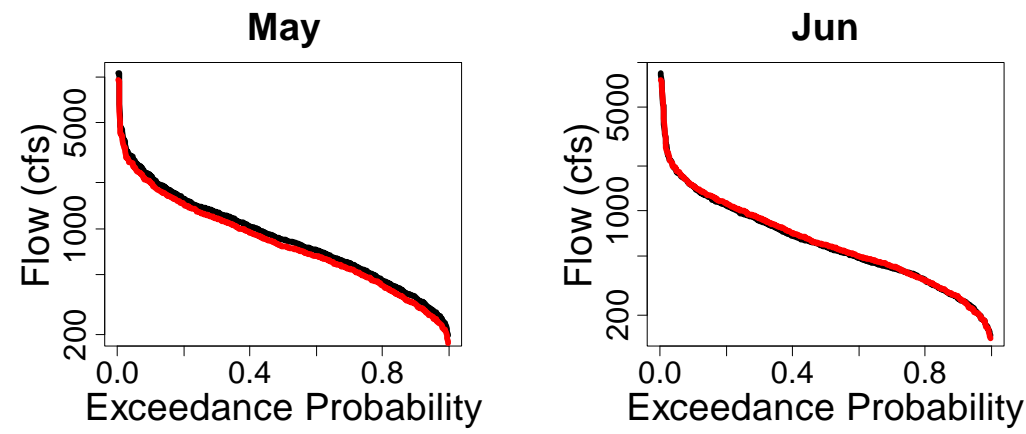

Exceedance Probability
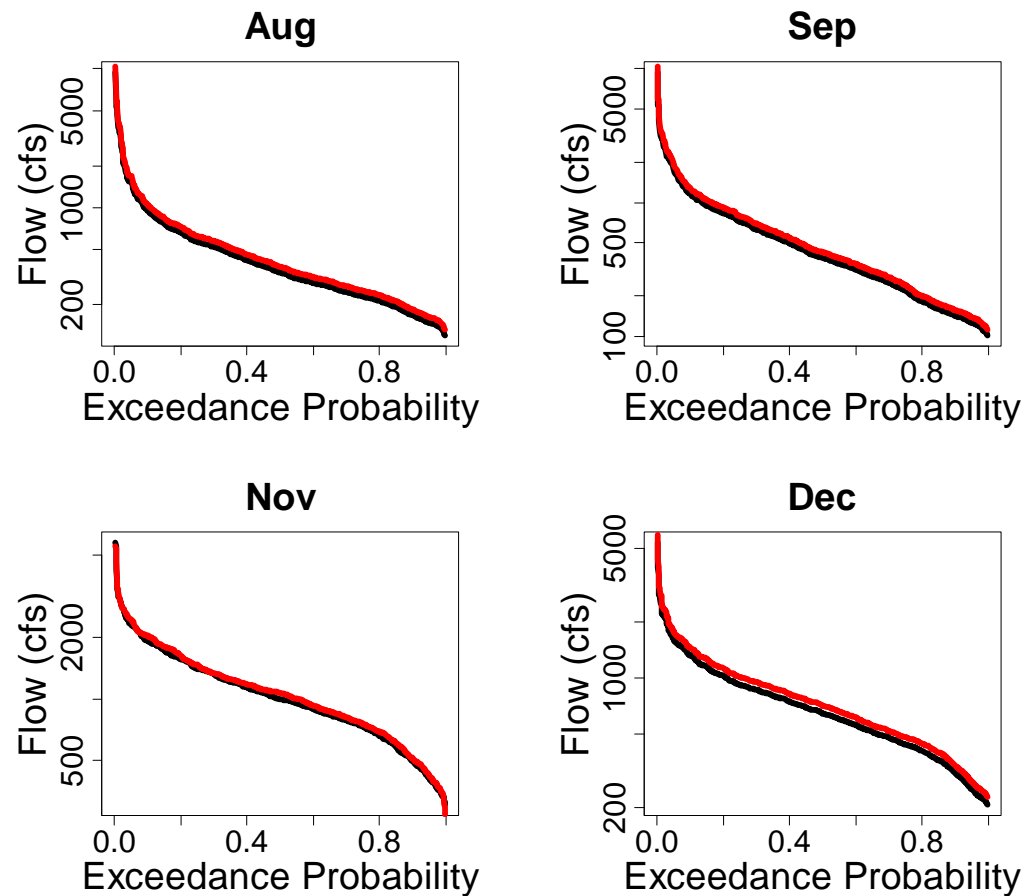

Figure 19: The optimization model results at Eco-Node 1 with ecological targets being heavily weighed to be with $+/-10 \%$ of the inflow.

Figure 20 shows the impact of restricting the releases to be within $10 \%$ of the inflow on system storage. The winter drawdown is most affected by the restriction; in the 20 year 
optimization run, deviation from traditional target draw downs is significant each year. The refill target is also frequently missed, but not as drastically.

It is important to note that if all deviations from the natural flow regime were prohibited, the system storage would not vary. Figure 20 shows the extent of the target storage that can be reached with the limited $10 \%$ alteration. Storage levels at different allowable alterations are explored in Section 5.2.4 in Figure 26.

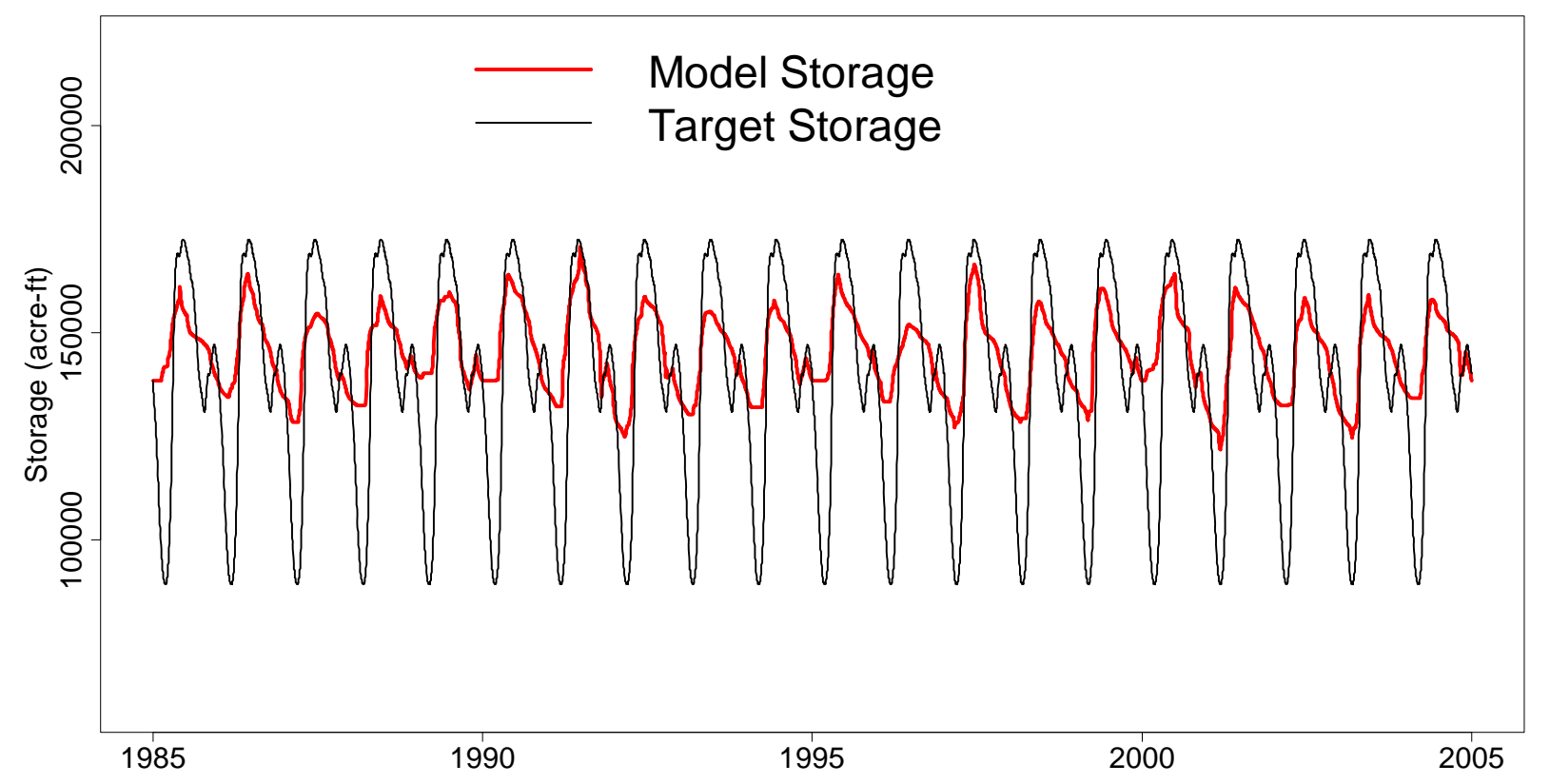

Figure 20: Optimization model results for the Upper Connecticut system storages associated with meeting within $10 \%$ of the inflow at Eco-Node 1.

\subsubsection{Economic Cost of the Ecological Flows}

Figure 19 and Figure 20 illustrate that an ecological target of within 10\% of the natural flows is physically feasible. However, it is informative to determine the cost of this ecological target to the reservoir operations. Under current conditions (no ecological considerations) the reservoir system generated $\$ 55.3$ million/year in the optimization model. Releasing within $10 \%$ of the natural flow will be considered the best condition for ecological flows. Restricting the reservoirs more than this value would severely limit their ability to operate to meet their needs, and therefore will not be considered. At a 10\% allowance from the natural flow, the reservoirs 
generated \$52.5 million/year in the optimization model. This suggests that strict adherence to the ecological targets cost \$2.8 million/year.

If \$2.8 million/year is deemed too expensive, other alternatives can be evaluated to find a suitable compromise between ecological and hydropower objectives. Figure 21 shows the tradeoff between different flow requirements and the average annual income generated. Figure 21a shows income from model runs that allow $10 \%$ to $400 \%$ alteration. Figure $21 \mathrm{~b}$ highlights income from the $10 \%$ to $100 \%$ alteration range. To generate $\$ 55.3$ million/year, as in the current conditions optimization run, the reservoirs must be allowed to alter the inflow up to $400 \%$ (i.e. release 4 times the natural flow). By examining the differences in reservoir storages and flow duration curves (discussed later in this section), it is evident the flow is only altered by $400 \%$ on days with extremely opportune energy prices. Since real-time operations could never react as precisely to energy prices as an optimization model, the remainder of this analysis focuses on this $10 \%-100 \%$ maximum allowable alteration range.

As seen in Figure 21b, the average annual income generated continually decreases as freedom to alter inflows decreases. However, the rate of decrease increases at approximately a $40 \%$ maximum allowable alteration to inflow, indicating a smaller differential cost beyond this point. 


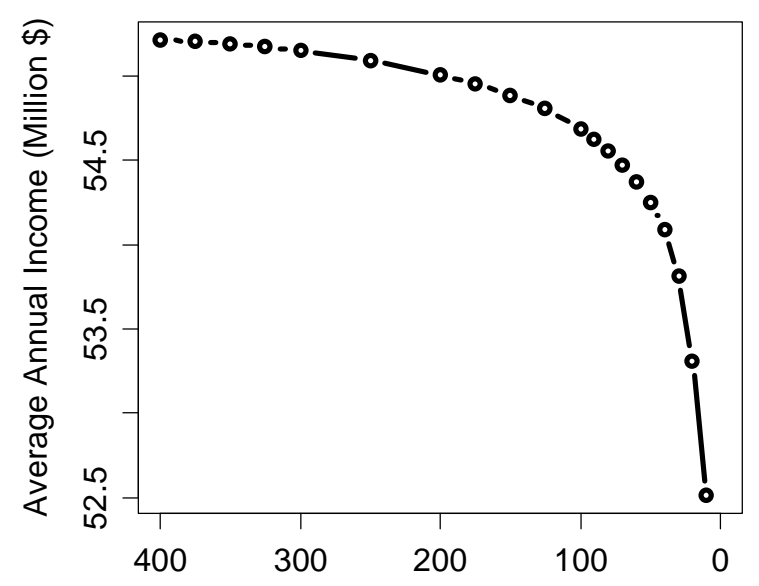

Maximum Allowable \% Alteration to Inflow (+/-)

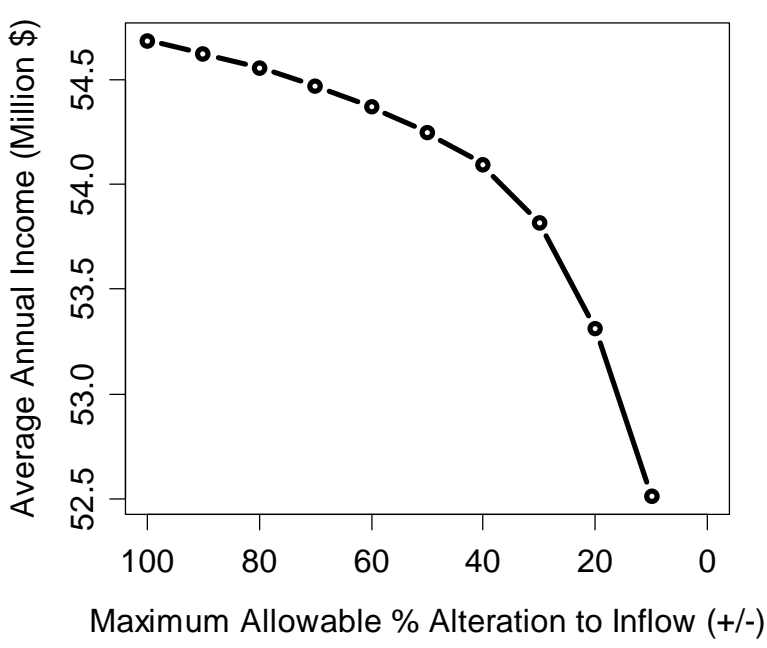

Maximum Allowable \% Alteration to Inflow (+/-)

Figure 21: Trade-off curve for the flows at Eco-Node 1 comparing average annual income to the maximum percent alteration. The figure on the left (18a) compares the full range of maximum allowable alterations. The figure on the right (18b) is the same data, but only showing $10 \%-100 \%$ maximum allowable alteration.

\subsubsection{Effects on the Q10, Q50, and Q90 at Different Allowance Levels}

Research conducted by The Nature Conservancy (Richter, 2003) indicates the Q10 (flows with a 90\% exceedance probability), the Q50 (median), and Q90 (flows with a 10\% exceedance probability) are particularly important when evaluating the ecological health of a river. Figure 22 compares the three quantiles as a percent of the natural quantile. For example, $150 \%$ would indicate 1.5 times the natural quantile is flowing at Eco-Node 1; 100\% would mean the flows released do not alter the quantile; and 50\% would indicate releases result in half of the natural quantile. A horizontal line indicates the releases do not alter the quantile as the allowable alteration increases.

Because of the winter drawdown, January releases increase all three quantiles as compared to the natural flow as the allowable alteration increases. The Q10 and Q50 increase linearly from $10 \%$ to $100 \%$ allowable alteration. The effect on the Q90 remains constant after a $70 \%$ allowance. The three quantiles all increase at a similar pace in February. A portion of the high flows in March are regulated, but the regulation does not increase as the allowable alteration increases. The Q10 and Q50 are regulated, but the extent of regulation does not increase after a $30 \%$ allowable window. The opposite is seen in April when the reservoirs store water. The low 
flows are unregulated, and so Q10 is not changed, while the Q50 and Q90 are lower than would naturally occur. Like in March, operations in April only require a 30\% allowable alteration window. The same pattern is observed in May and June, but a smaller fraction of water is stored as compared to April. The three quantiles are regulated in July, but the high flows are the least affected. The magnitude of regulation does not increase after a $40 \%$ allowable alteration window. In August and September the three regulated quantiles are higher than natural. The low flows continue to increase as the allowable alteration increases, but the median and high flows remain constant after a $40 \%$ allowable alteration. October and November show minimal regulation in all three quantiles. In December, the high flows are not heavily regulated; the median flows are slightly regulated but remain constant after a $40 \%$ allowable alteration; and the low flows increase until a 70\% allowable alteration. In summary, Figure 22 shows there are only a few times in which the current operations require an allowable alteration greater than $40 \%$. In many instances, the reservoirs can operate according to current rules without altering the flow greater than $40 \%$ from the natural. 
Jan

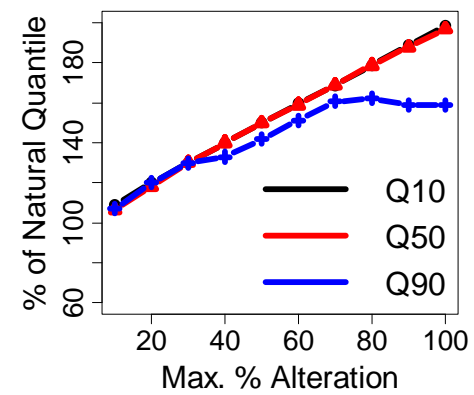

Apr

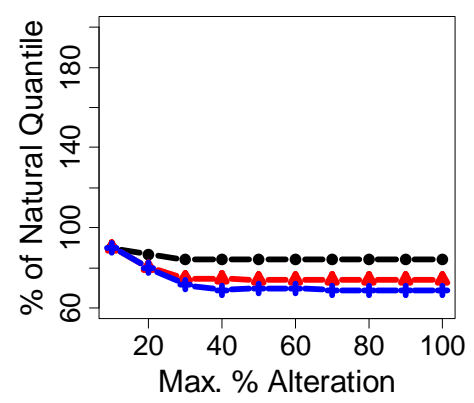

Jul

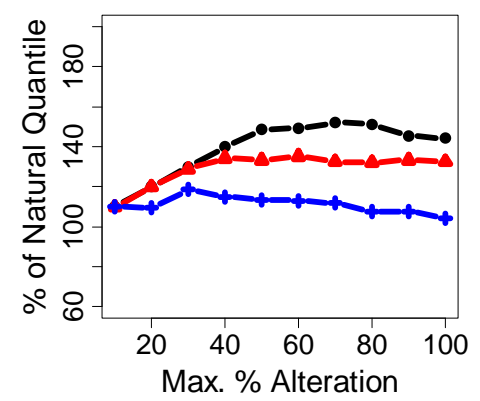

Oct

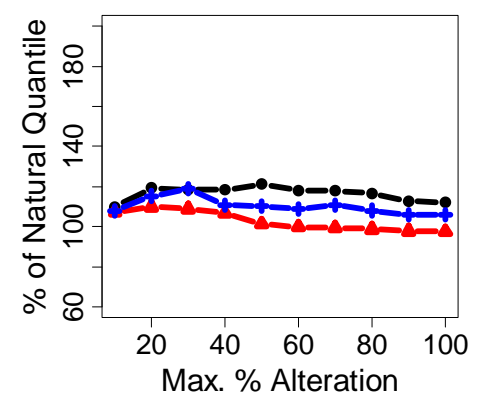

Feb

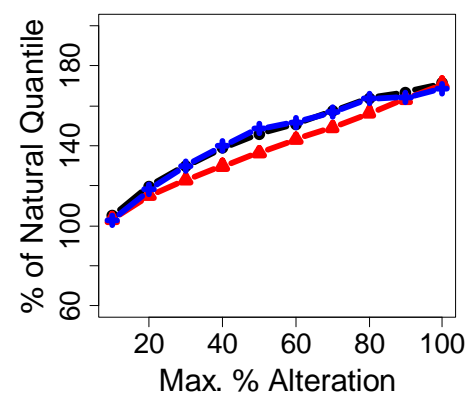

May

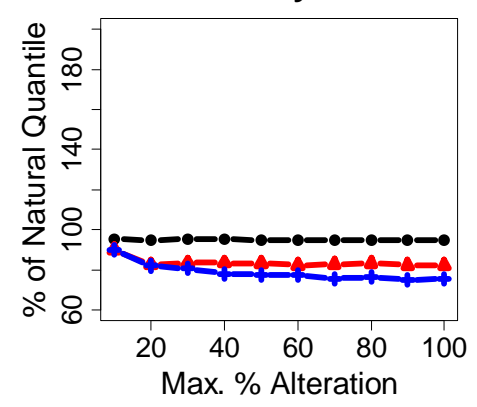

Aug

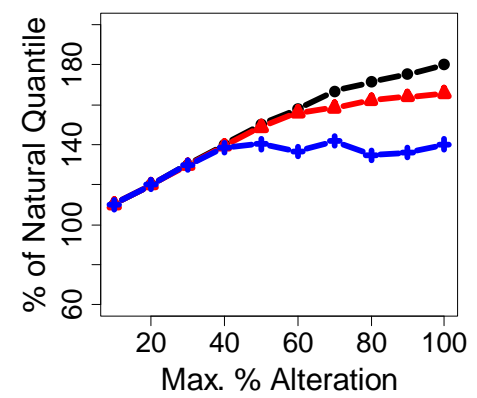

Nov

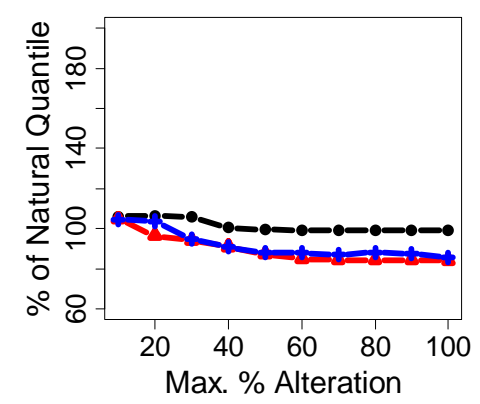

Mar

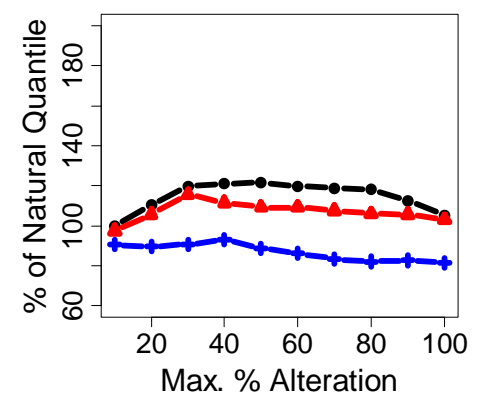

Jun

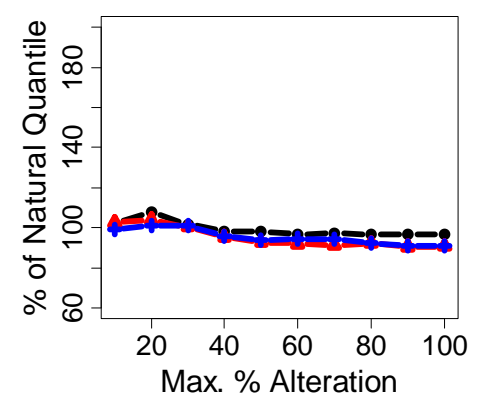

Sep

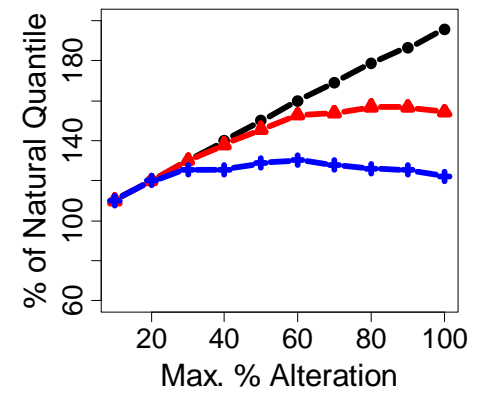

Dec

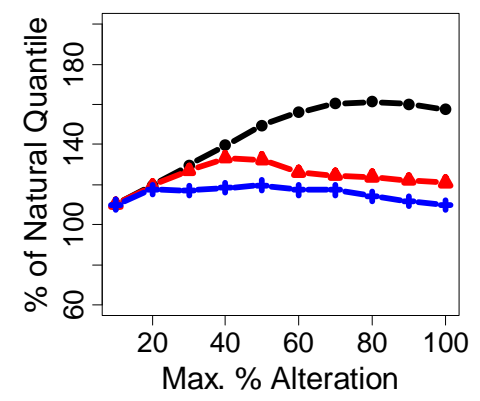

Figure 22: Monthly changes in the Q10, Q50, and Q90 compared to the natural flow distribution as the maximum allowable \% alteration increases. 


\subsubsection{Monthly Flow Duration Curves at Selected Alteration Levels}

The monthly flow duration curves for 3 maximum allowable alterations $-10 \%, 40 \%$, and $100 \%,-$ are compared to natural flows and current operations in Figure 23. The results seen in Figure 22 are evident in Figure 20 - in most months there is not much additional regulation when allotted greater than a $40 \%$ alteration allowance. As previously shown, the $10 \%$ maximum allowable alteration to inflow (the red line) essentially produces natural flow duration curves in all months. December, January, and February are the only months in which the reservoirs use the additional allowance from $40 \%$ to $100 \%$, to increase flows. The current operation according to the optimization model, which requires a $400 \%$ alteration, increases the high flows beyond the $100 \%$, but brings the lower flows closer to the natural. In April, the reservoirs store water, but alter the flows the same whether allotted a $40 \%$ or $100 \%$ alteration window, confirming what was observed in Figure 22 - the current operations do not alter the natural flow regime beyond $40 \%$. May and June have the least regulation for all allowance ranges. As in the winter, regulation in July, August, and September causes an increase in flows, however, there is not as much additional regulation from a $40 \%$ to $400 \%$ allowance. October has minimal regulation. November stores some water to prepare for the winter drawdown, but there is minimal additional regulation from a $40 \%$ to $400 \%$ allowance. December begins the winter drawdown, releasing more water than natural, but does not significantly increase releases from a $40 \%$ to $400 \%$ window. 


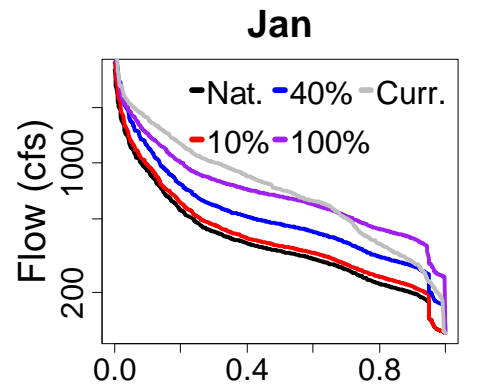

Exceedance Probability

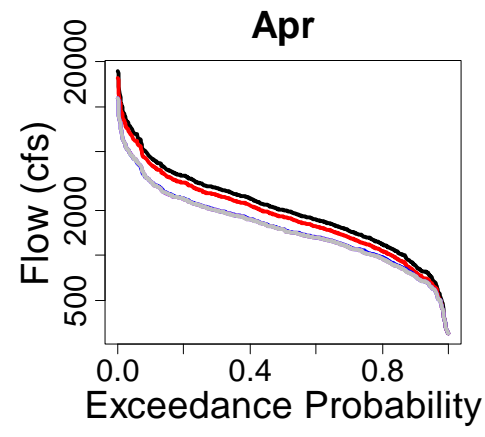

Jul

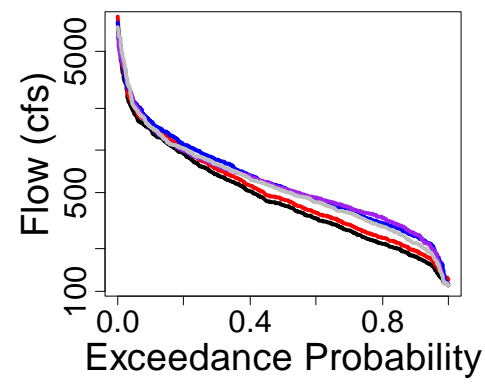

Oct

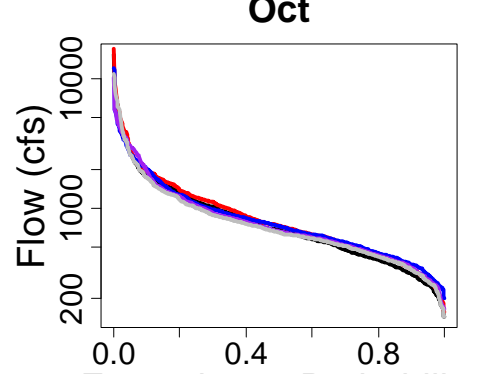

Exceedance Probability
Feb

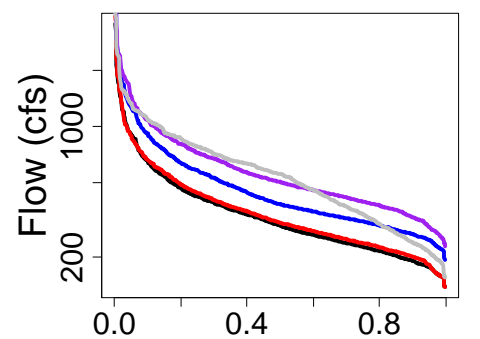

Exceedance Probability

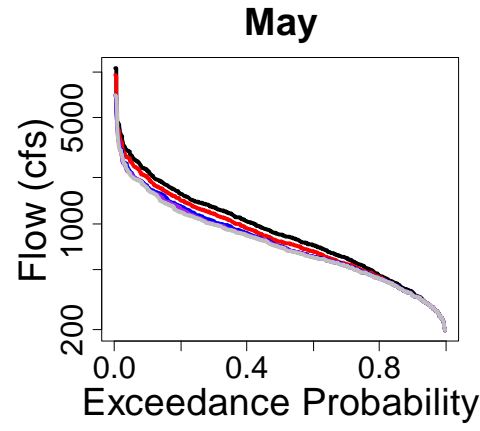

Aug

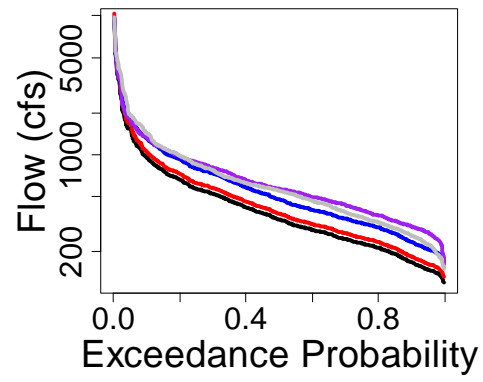

Nov

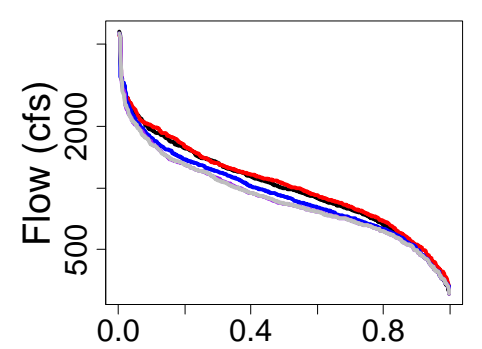

Exceedance Probability

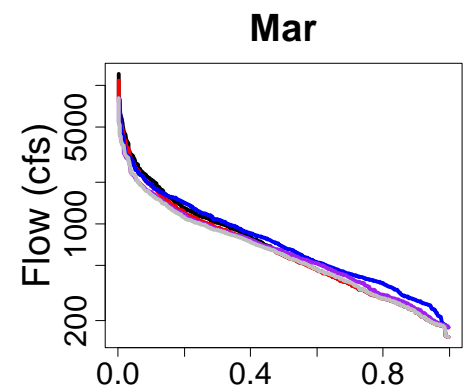

Exceedance Probability

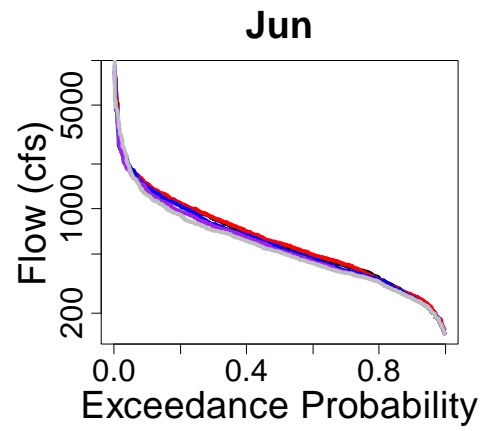

Figure 23: Monthly flow duration curves for points along the trade-off curve. The black line represents the natural flow duration curve. Different alteration levels of $10 \%, 40 \%$, and $100 \%$ are represented by red, blue, and purple lines. The gray line is the current operations. 


\subsubsection{Effects on System Storage at Select Alteration levels}

Figure 24 shows system storage levels at the maximum allowable alteration levels explored in the previous section $-10 \%, 40 \%, 100 \%$, and $400 \%$ (current operations). As illustrated in Figure 20, at 10\% allowable alteration, the system consistently misses the winter drawdown and most of the refills. At $40 \%$ allowable alteration, the drawdown levels are obtained 4 out of the 20 years, and the refill levels are obtained 19 of the 20 years. In the 16 years when the drawdown is missed, failure to meet the target is far less drastic than with a $10 \%$ allowance. By $100 \%$ allowable alteration, the reservoir's ability to reach drawdown and refill are the same as the current operations (400\%). The only difference is the magnitude of the deviations away from the target to capitalize on high energy prices. The system is able to generate an additional $\$ 0.6$ million/year by having more freedom to spike releases on days when the energy price is high. 

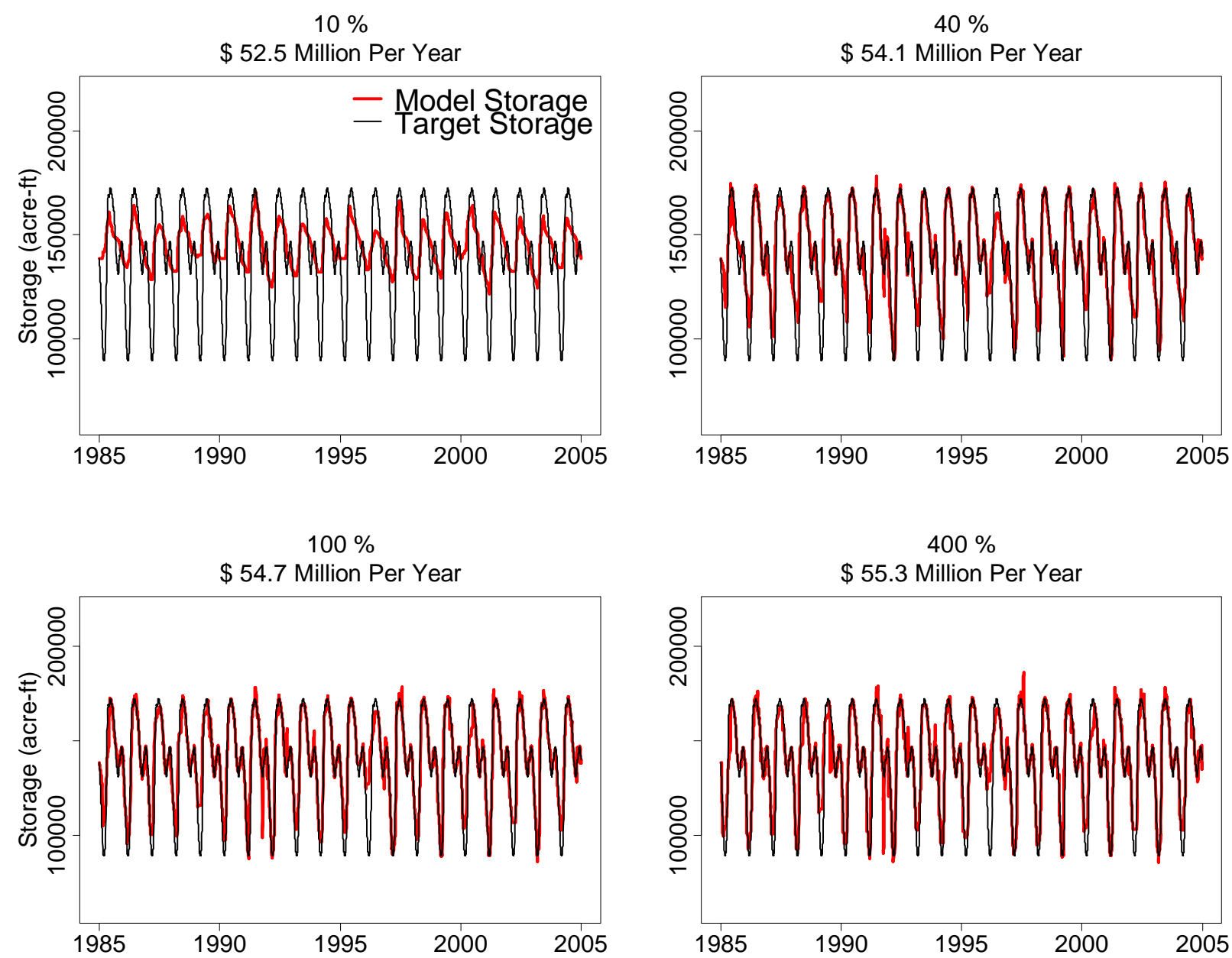

Figure 24: System storage levels at select points along the trade-off curve. The maximum allowable percent alteration to inflow (+/-) along with the cumulative system income is shown above each graph.

\subsubsection{Ecological Flow at Eco-Node 1 Operation Recommendations}

The previous analysis can inform stakeholders during discussions of possible operational adjustments to improve flows at Eco-Node 1. The Nature Conservancy has indicated a 10\% alteration to natural flow is acceptable for restoring the natural flow distribution. As previously mentioned, the set of potential operations being considered will be in the $0-100 \%$ allowable alteration range. The research question remains as to the true value of restoring all of the natural stream variability. Should extreme events be treated differently outside of the allowable alteration range? Allowing reservoirs to capture extreme high flow events may be a dramatic help in meeting refill targets. Similarly, if natural conditions produce severe droughts, it is 
unclear whether reservoirs should supplement the natural flow or adhere to an allowable alteration. In future work, environmental benefits of extreme events will be investigated further.

From $10 \%$ to $40 \%$ maximum allowable alteration, there is a $\$ 1.6$ million/year revenue loss, while from $40 \%$ to $100 \%$ there is a $\$ 0.6$ million/year revenue loss. There is little additional revenue gained from increasing the maximum allowable range beyond $40 \%$ thus the recommended operating range is between $10 \%-40 \%$ maximum allowable alteration. From the trade-off curve in Figure 21a, the income decreases approximately linearly from $40 \%$ to $10 \%$ allowable alteration. This linear relationship implies the gain in ecological benefits is directly proportional to the decrease in income and the final decision is based on how much revenue reservoir owners can forgo for ecological benefits.

To implement operational policies to better attain the ecological targets at Eco-Node 1, Lake Francis is critical. Because it is the third reservoir in the series, the flow released from Lake Francis must be within the allowable alteration. The upstream reservoirs, Second Connecticut Lake and First Connecticut Lake, have more operational flexibility as long as Lake Francis can meet the requirement. To do this, the target storages of the reservoirs, especially Lake Francis, must be adjusted. As seen above in Figure 24, the most important adjustment is the magnitude of the winter drawdown. This will then require less of a refill, which will improve the spring flows.

\subsection{Results - Operating for Hydropower}

In this section, alternatives to the current operations (Section 5) are evaluated to find systematic operational changes in the storage facilities that increase system revenue. Only the storage facilities are being considered because Moore has rigid storage constraints that are not flexible. This prevents the optimization model from using Moore in any systematic changes. Instead, only small, spikes in storage are seen as a result of the perfect foresight of energy prices and inflow. The storage facilities investigated in Section 5.2 to improve flows at Eco-Node 1 are more flexible and are considered in this section as well.

Over the 20 year historic period, the system generates an average of $\$ 55.3$ million/year under current operations. To explore potential trade-offs, the weight placed on income reservoir target levels are incrementally decreased from current operations to generate income beyond the current status. The weight on Moore's storage is held constant. Since the optimization model has 
perfect foresight of future flows and energy prices, there are many sudden spikes and drops in storage. These types of operations cannot be implemented in day-to-day operation. However, consistent alterations in reservoir level, such as a changing in timing or magnitude of drawdown/refill, can be incorporated into the operating policy.

\subsubsection{Trade-off Between Current Target Storage and System Income}

Figure 25 shows the trade-off between the annual revenue and the deviations from current storage targets. Under the current operations, the average daily deviation from the target storage is 9,000 acre-feet. The maximum amount of income generated for the system is $\$ 56.7$ million/year, which results in a 77,000 acre-ft daily deviation from target storage. In the latter scenario, the optimization model uses the perfect foresight of flows and energy prices and is not limited by any target reservoir levels.

The trade-off curve shows the set of non-inferior solutions, that is, the solutions for which improvement in one objective can only be attained by a decrease in another objective. However, the selection of the best compromise solution (Cohon, 1978) will depend on the final relative weighting of each objective. For the weighting scheme used in this analysis, the set of solutions to be considered ranges from 9,000 to 29,000 acre-ft average daily deviation. Technically, there is always some income gain; however, the income gained from 29,000 to 77,000 acre-ft daily deviation is minimal compared to the gain observed from 9,000 to 29,000 acre-ft average daily deviation. From 9,000 to 29,000 acre-ft average daily deviation the system generates an additional \$1.2 million/year, while from 27,000 acre-ft to 77,000 acre-ft the system generates only an additional $\$ 0.4$ million/year. 


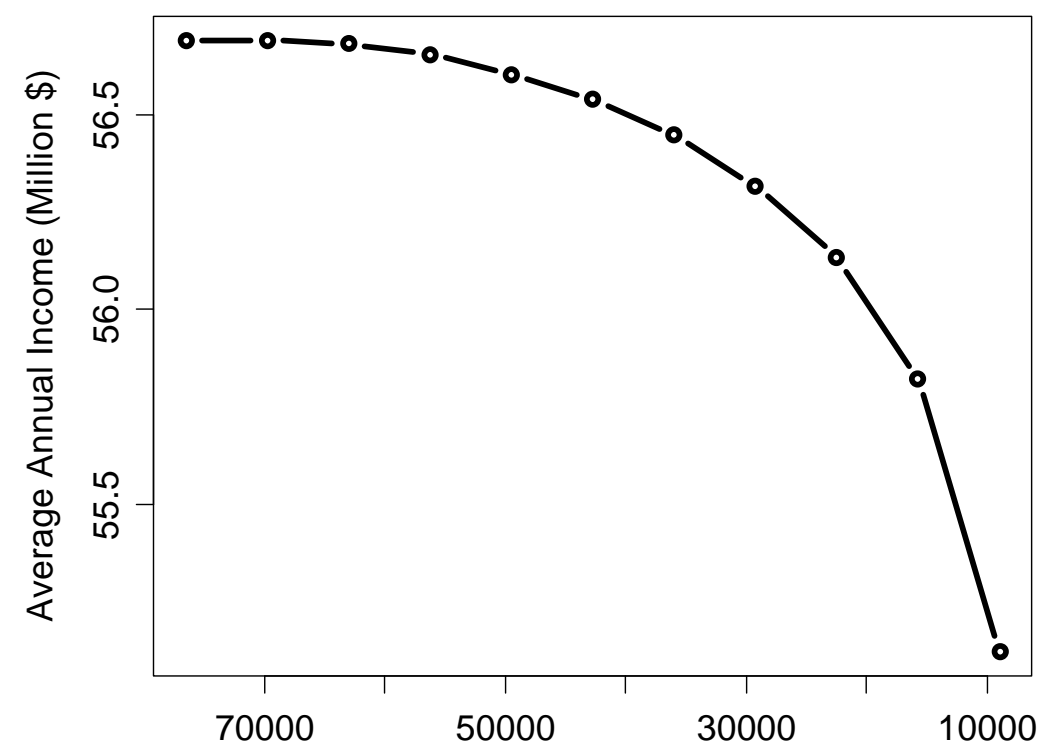

Average Daily Deviation from System Storage Target (acre-ft)

Figure 25: Trade-off between average annual system income and the average daily deviation from system storage target

\subsubsection{Reservoir Storage at Different Income Levels}

Figure 26 illustrates the deviations from current storage levels for four points along the trade-off curve. As the weight on current target storage decreases, the oscillations in storage increase in some years. To increase revenue, the reservoir is filled more than current operations and drawn down further in some years. As the existing target storage becomes less of a driving factor, the drawdown/refill magnitudes continue to increase, and there is a noticeable change in the drawdown. By an average daily deviation of 29,000 acre-ft the system's spring refill is significantly higher and the winter drawdown is lower in almost every year.

The timing of the refill and drawdown remains constant until the 22,000 acre-ft average daily deviations. Beyond this point the timing begins to shift later in the season. The end of the drawdown (i.e. the time the reservoir reaches the lowest level) remains constant. The optimization model stores water longer, and then releases it at a faster rate to reach the drawdown. 

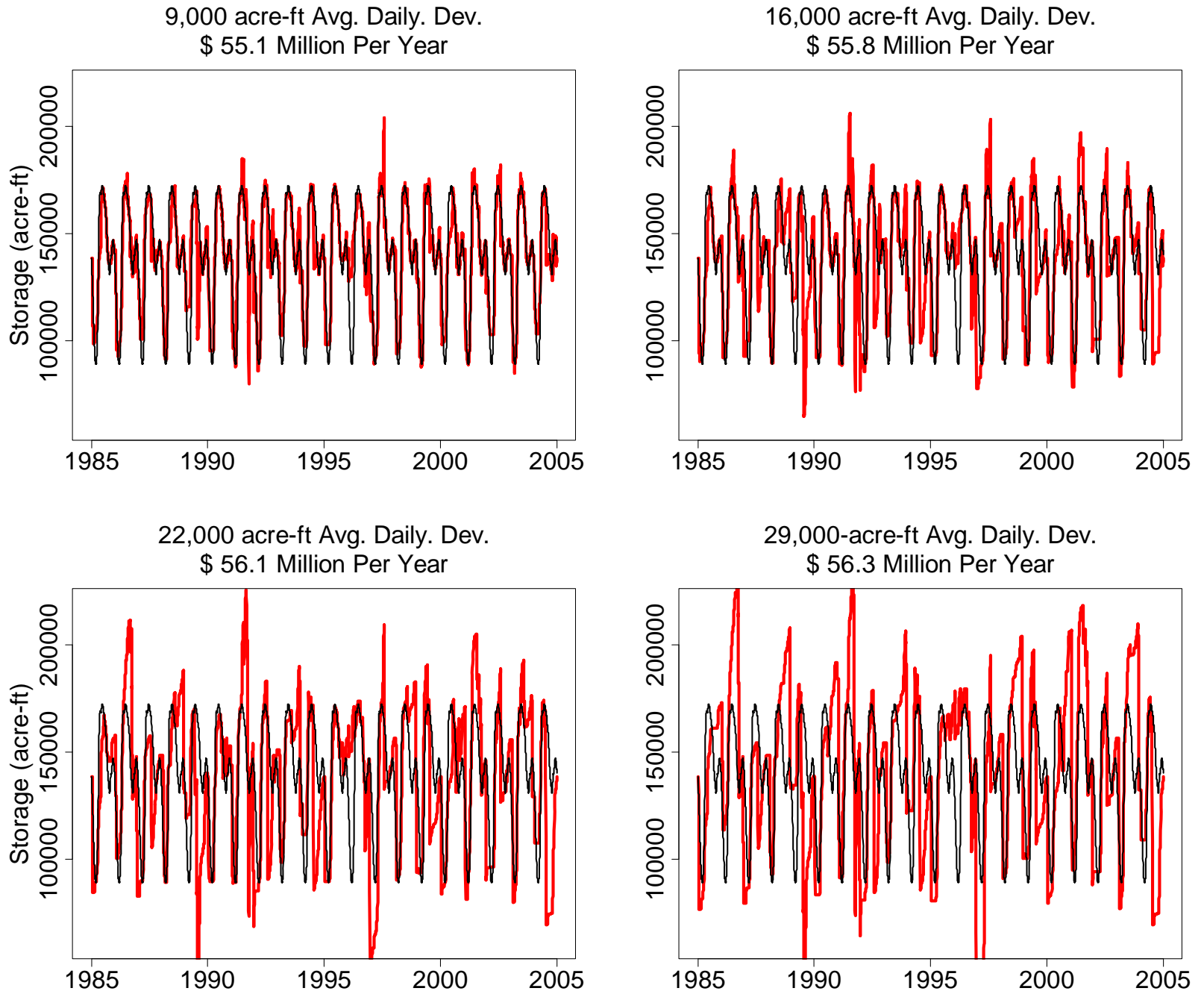

Figure 26: Storage Levels of the combined reservoir storage system (SCL, FCL, and LFR) for four points along the trade-off curve in Figure 25. The red line is the model storage and the black line is the target storage.

\subsubsection{Operational Recommendations for Storage Facilities to Increase System}

\section{Income}

As previously mentioned, the major facilities in the Upper Third of the basin are privately owned and operated to maximize profit. The operations of the reservoirs are designed to fulfill that goal by storing water during lower energy cycles and releasing it when energy is more valuable. In current operations, the reservoirs deviate from their target storage to maximize profit, thus indicating their day-to-day operations are fairly close to optimal for maximizing income. Figure 26 shows that having a larger winter drawdown in most years, which would require a larger refill, would yield more revenue for the system. However, this is not done every 
year in Figure 26, indicating that to truly optimize reservoir operations forecasts would be required. Forecasting streamflow a season in advance can inform operators when it is beneficial to have a larger drawdown and refill. Seasonal streamflow forecasting is beyond the scope of this thesis but is under investigation in the larger research effort.

\subsection{Results - Operating for Flood Control}

The Upper Third system has one flood control target at the confluence of the Indian River, requiring flows to remain less than $10,000 \mathrm{cfs}$. The Indian River is unregulated so any flood control must come from the storage facilities in the Upper Third of the system. Table 6 shows the flow statistics at the Indian gage under the current operational scheme with flood control removed as a constraint. Under normal operations, without considering the downstream flood target, the maximum flow at the Indian gage is $12,410 \mathrm{cfs}$. In the 20 year model run, this is the only time the flow exceeds 10,000 cfs. Including the Indian gage flood checkpoint as a target or a constraint in the model has negligible impact on income and storages.

Table 6: Flow Statistics at the Indian gage during current operations

\begin{tabular}{|c|c|c|c|c|c|}
\hline Min & 25th Percentile & Median & Mean & 75th Percentile & Max \\
\hline 46.34 & 172.2 & 284.9 & 447.5 & 448.3 & 12410 \\
\hline
\end{tabular}

Flood control is not a dominating issue in this study area; however, it will become important in other portions of the basin. There are many USACE flood control dams on major tributaries in the lower portion of the watershed that will be included in the effort to improve ecological flows. In the areas designated as potential flood hazards, there will be a trade-off between ecological benefits and flood control risk that will be examined.

\section{Climate Change Impacts on the Upper Third System}

This section investigates the effects of climate change on the Upper Third system. Changes in temperature, precipitation, and streamflow are explored. The hydrology model uses the downscaled meteorological data from the GCMs discussed in Section 4 to generate streamflow to all model input nodes. This is compared to streamflow driven by historic meteorological data to discern how streamflow will change due to climate change. The reservoir 
optimization model is used to determine the effect climate change will have on ecological targets and profits under the current reservoir operating rules. The optimization model structure and weighting scheme is held constant as in the base case examined in Section 5.

As mentioned in Section 4, the larger Connecticut River Project is using 5 GCMs and 2 emissions scenarios (A2 and B1) to investigate the effects of climate change. This thesis uses an ensemble mean of the 5 selected GCMs for the A2 and B1 scenario. This creates two climate scenarios that are used in the analysis: one A2 scenario and one B1 scenario. Each is the ensemble average of the 5 selected GCMs. Future work will study the effects under the individual climate models and prescribe operational adjustments to mitigate the effects of climate change.

\subsection{Climate Impacted Conditions - A2 Emissions Scenario}

Figure 27 shows the monthly average temperature, precipitation, and unregulated streamflow at the outlet of the Upper Third, beneath the Wells River confluence for the A2 ensemble. Output from the hydrology model driven by historic meteorology data is considered historic streamflow. The climate change scenarios show the monthly average meteorological and streamflow data for 20 years centered around 2000, 2040, and 2080. For example, the changed observed in the A2 ensemble GCM from 1990-2010 is applied to the historic record and labeled as the GCM-A2-2000 scenario. As previously discussed in Section 4.2, the delta downscaling method preserves the climatic variability of the time period and shifts the temperature and precipitation according the chance observed in the GCM.

The GCM-A2-2000 scenario produces virtually identical temperature as the historic record, indicating no significant error. There is a steady increase in temperature through the 3 GCM time periods. The increase from 2040 to 2080 is greater than 2000 to 2040. This would be expected since the A2 scenario projections are based on continually increasing carbon emissions into the future. Figure 28 graphically displays the changes.

The GCM-A2-2000 scenario has a positive precipitation error as compared to the historic

data in all months except January and September. The largest precipitation error is in April - the GCM-A2-2000 scenario over estimates precipitation by 0.19 inches. The average error is 0.075 inches. GCM-A2 estimates an increase in precipitation in most months moving into the future. 
Average precipitation and temperature increases from the 3 time periods are in Table 7, located in the next section.

The meteorological shifts cause changes in the annual hydrograph of the river. The most noticeable changes are the lowering of the spring peak and the increase in winter streamflow. For the A2 scenario, these shifts intensify with time. The combination of the increased winter precipitation and temperature cause higher winter flows. Because more precipitation is falling as rain instead of snow, there is less melt in the spring which produces a lower spring peak. The A2 scenario does not project significant change in streamflow in the summer and fall seasons. 
Selected GCM A2 Ensemble
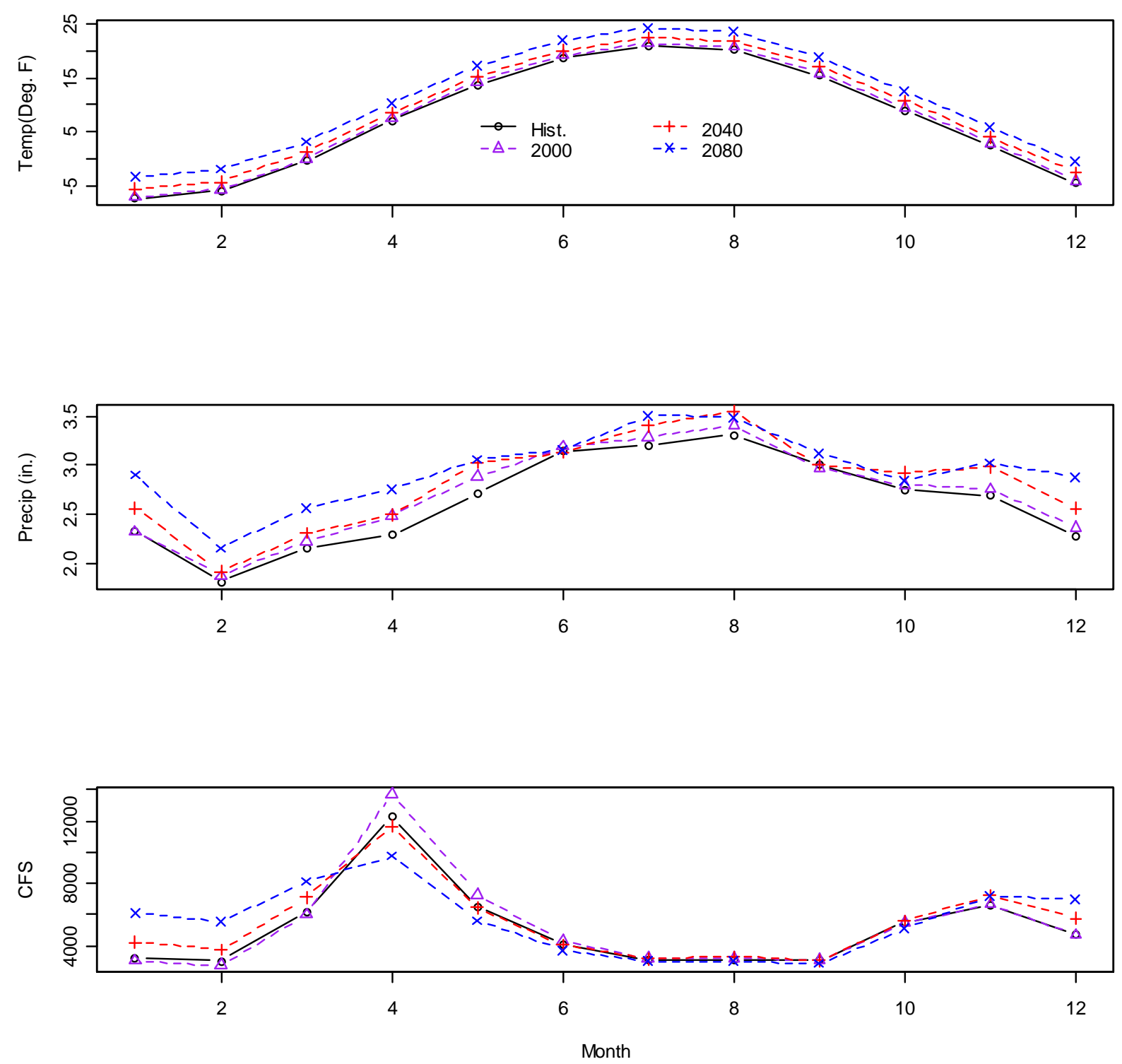

Figure 27: Temperature (top), precipitation (middle), and streamflow (bottom) at the outlet of the outlet of the Upper Third of the Connecticut River. Historic meteorological data (black) and the 5-GCM Ensemble A2 scenarios centered around 2000 (purple), 2040 (red), and 2080 (blue). 
Selected GCM A2 Ensemble Comparison to Historic
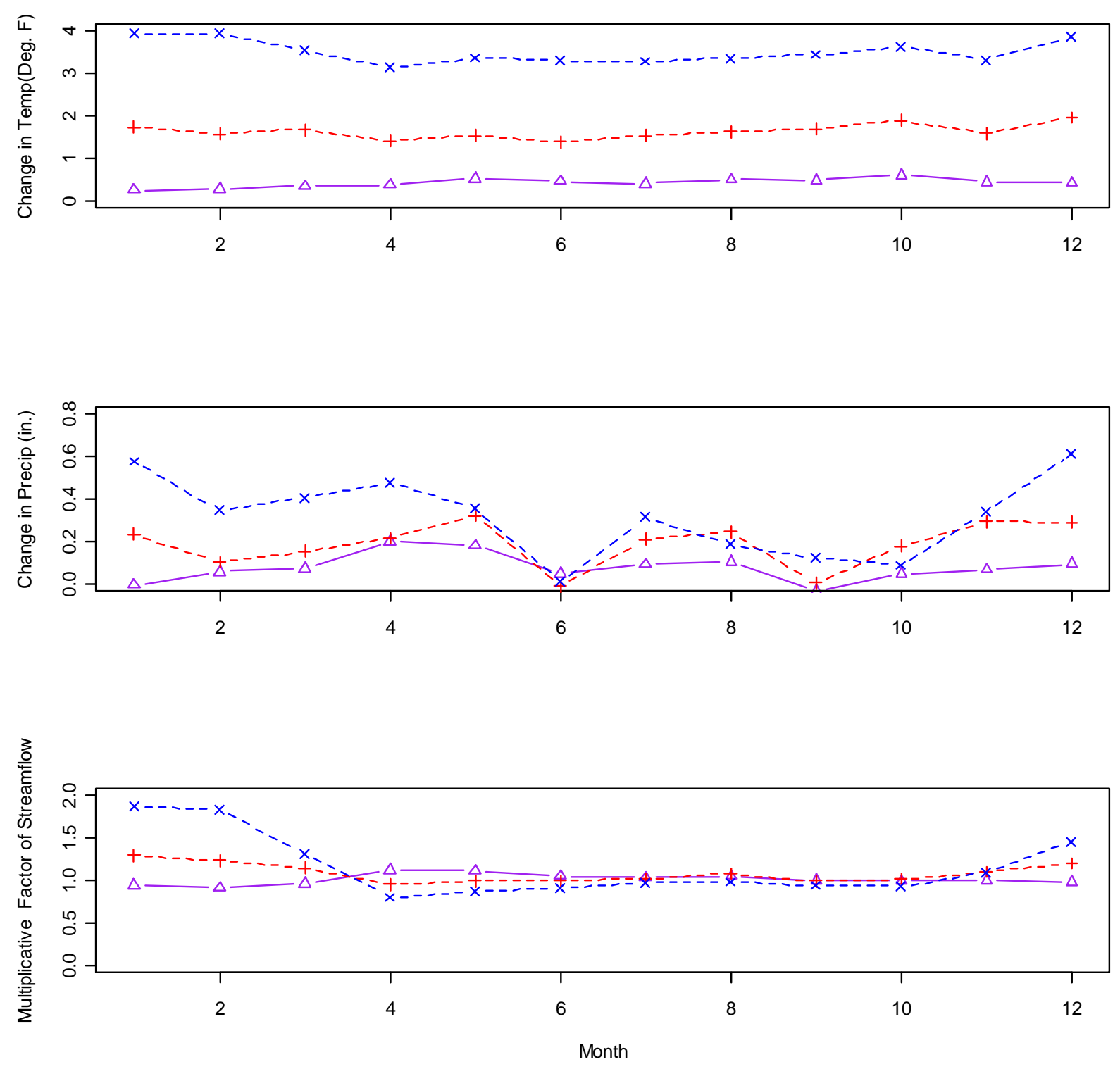

Figure 28: Change in temperature (top), precipitation (middle), and streamflow(bottom) projected by the 5-GCM Ensemble A2 Scenarios centered around 2000 (purple), 2040 (red), and 2080 (purple). The 2000 change should match the GCM and shows bias.

\subsection{Climate Impacted Conditions - B1 Emissions Scenario}

Figure 29 shows the meteorological and hydrological shifts projected by the B1 emissions scenario. Like the GCM-A2-2000, the GCM-B1-2000 produces average monthly temperatures virtually identical to the historic record. The temperature increases with time in the B1 scenario, but at less severe rates than the A2 scenario. There is little temperature increase 
from 2040 to 2080 in GCM-B1. Similarly, B1 also projects increases in precipitation with time, but, again, not as severe as the A2. The precipitation and temperature changes cause the same type of change in streamflow as observed in the A2 scenario, but of less magnitude. The spring peak lessens with time, but not drastically. There is very little shift in the peak from 2040 to 2080. The winter flows increase with time, but less severely than in the A2 scenario. Figure 30 shows the changes as compared to historic values for the B1 scenario. A summary of the A2 and B1 changes can be found in Table 7. 
Selected GCM B1 Ensemble
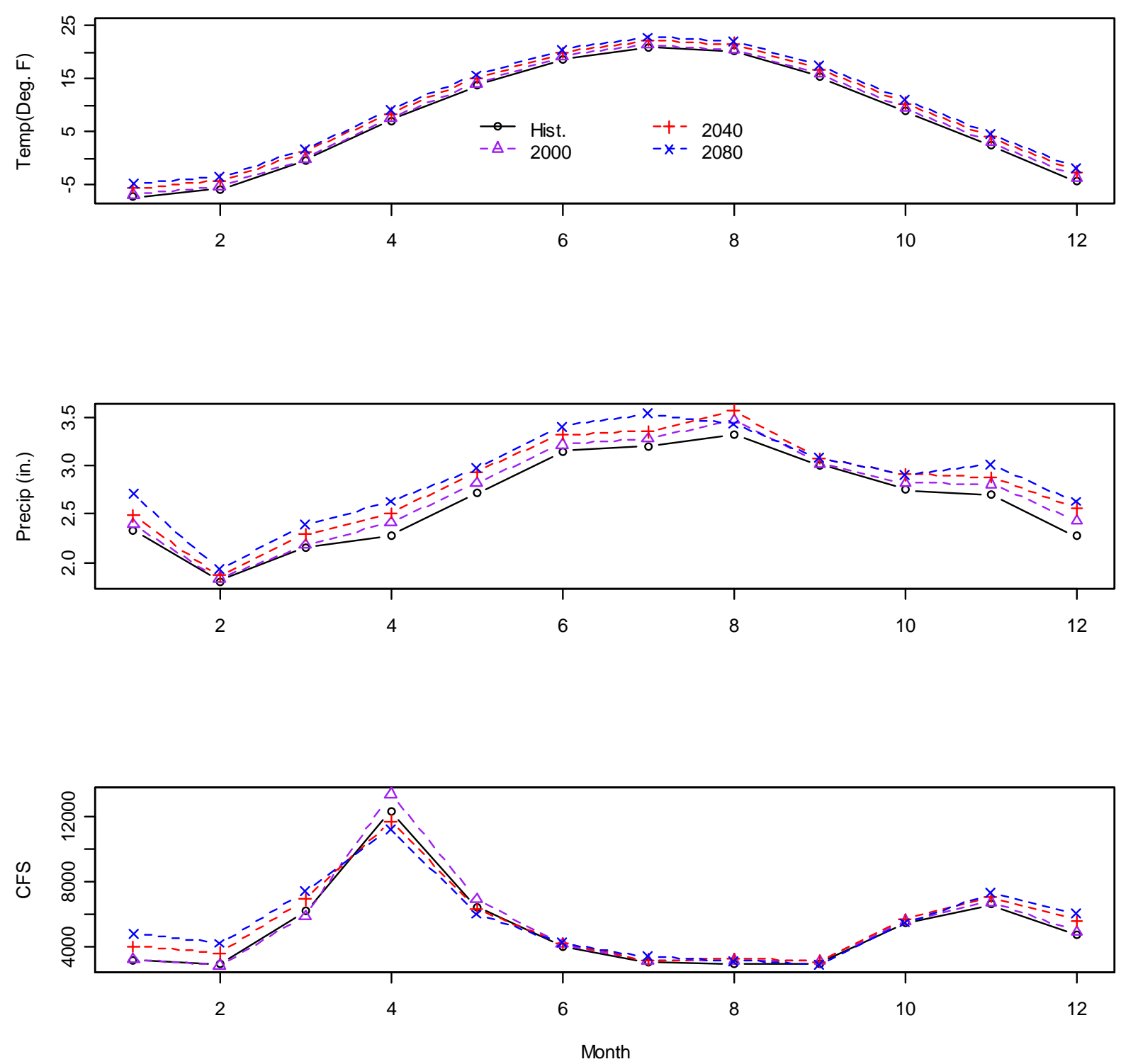

Figure 29: Temperature (top), precipitation (middle), and streamflow (bottom) at the outlet of the outlet of the Upper Third of the Connecticut River. Historic meteorological data (black) and the 5-GCM Ensemble B1 scenarios centered around 2000 (purple), 2040 (red), and 2080 (blue). 
Selected GCM B1 Ensemble Comparison to Historic
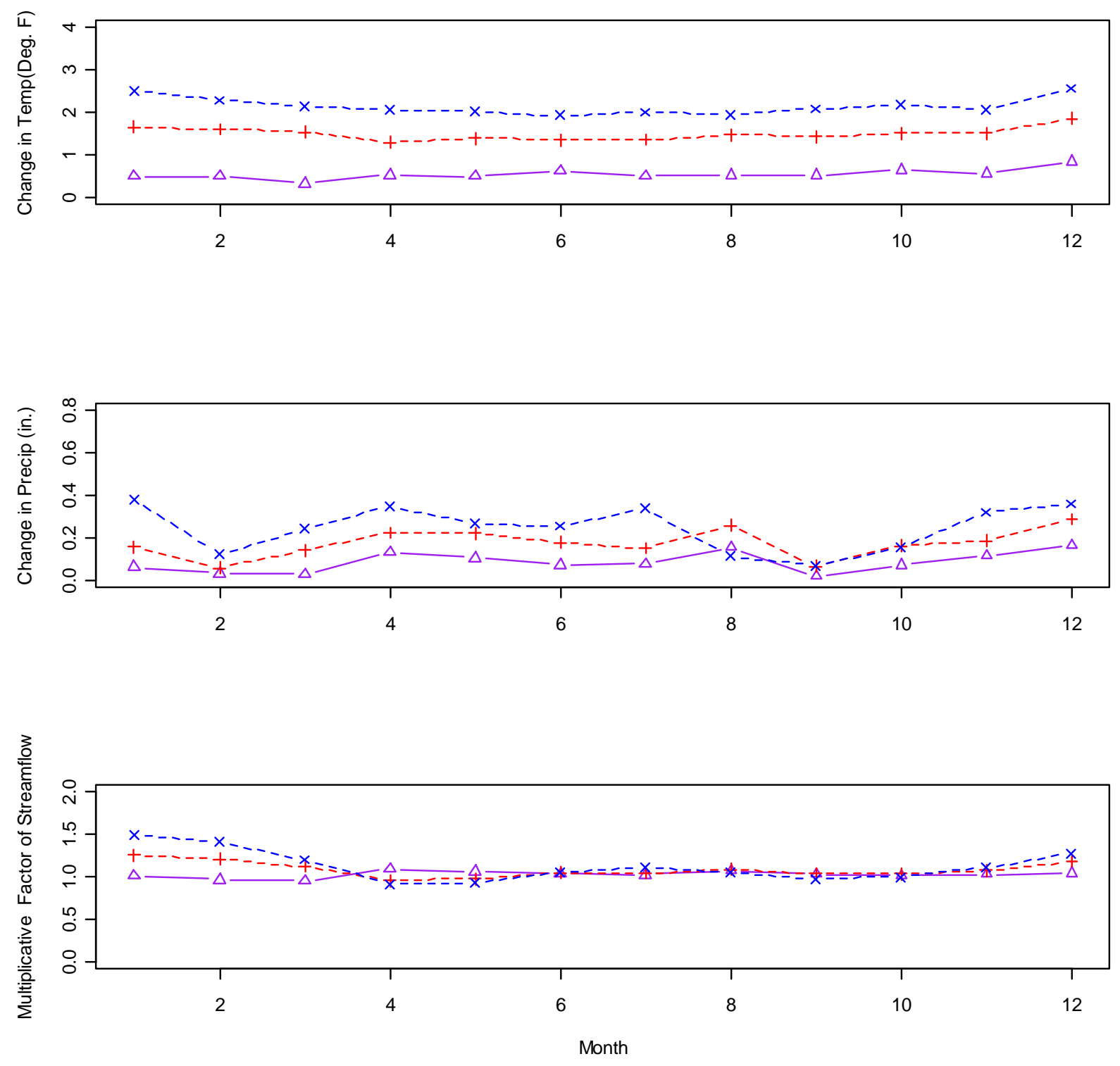

Figure 30: Change in temperature (top), precipitation (middle), and streamflow(bottom) projected by the 5-GCM Ensemble B1 Scenarios centered around 2000 (purple), 2040 (red), and 2080 (purple). The 2000 change should match the GCM and shows bias. 
Table 7: The A2 and B1 GCM Ensemble comparison of temperature and precipitation changes

\begin{tabular}{|c|cc|cc|cc|cc|}
\hline & \multicolumn{2}{|c|}{ Temp $\left({ }^{\circ}\right.$ F) } & \multicolumn{2}{|c|}{ Precip (in) } & \multicolumn{2}{|c|}{ Jan Flows (cfs) } & \multicolumn{2}{|c|}{ Apr Flows (cfs) } \\
& $\underline{A 2}$ & $\underline{B 1}$ & $\underline{A 2}$ & $\underline{B 1}$ & $\frac{A 2}{B 1}$ & $\underline{B}$ & $\underline{A 2}$ & $\underline{B 1}$ \\
\hline Error* & 0.4 & 0.6 & 0.1 & 0.1 & -180 & 43 & 1451 & 1072 \\
\hline $\begin{array}{l}\text { Change from } \\
\text { 2000 to 2040 }\end{array}$ & 1.2 & 1.0 & 0.1 & 0.1 & 1136 & 785 & -2014 & -1618 \\
\hline $\begin{array}{l}\text { Change from } \\
\text { 2040 to 2080 }\end{array}$ & 1.9 & 0.7 & 0.1 & 0.1 & 1873 & 756 & -1918 & -477 \\
\hline
\end{tabular}

*the error is calculated as the difference between the GCM-2000 and historic values

\subsection{Monthly Flow Duration Curves}

The aquatic ecosystems in the Upper Third of the Connecticut River have coped with the impacts of regulation for approximately 70 years. The changing climate due to greenhouse gas emissions will compound the altered hydrograph into the future. As seen in Figure 27 and Figure 29, the largest effect of the warming climate is less snowpack and more winter precipitation. This causes an increase in winter streamflow and a decrease in spring streamflow. Figure 31 shows the effects on the monthly flow duration curves if the reservoirs maintain their current operations throughout the projected GCM-A2 emissions scenario hydrologic change. In December, January, February, and March, the reservoirs are able to maintain their current operations while releasing the excess water to capitalize on the winter's high energy prices. The 2000-GCM-A2 scenario is virtually identical to the current conditions, as would be expected. The increase in winter flows is forecasted in the GCM-A2-2040, and even more significantly in the GCM-A2-2080. April, May, and June show the opposite effect. Moving into the future, there is less spring flow . The lower snow melt causes less water to be available, requiring a larger percentage to be stored to meet the spring refill targets. Climate change does not affect the regulated flow duration curve in the summer and fall. This coincides with the results of Section 6.1, which showed little change to streamflow in the summer and fall.

Figure 32 shows the similar results for the GCM-B2 scenario, but the rate of increase in deviation from natural conditions decreases from 2040 to 2080. The winter flow duration curves correspond to Figure 29 - the winter flows still increase with time, but the rest of year has far 
less deviation. Besides December, January, February, and March, the regulated flows under the B1 emissions scenario do not change with time.
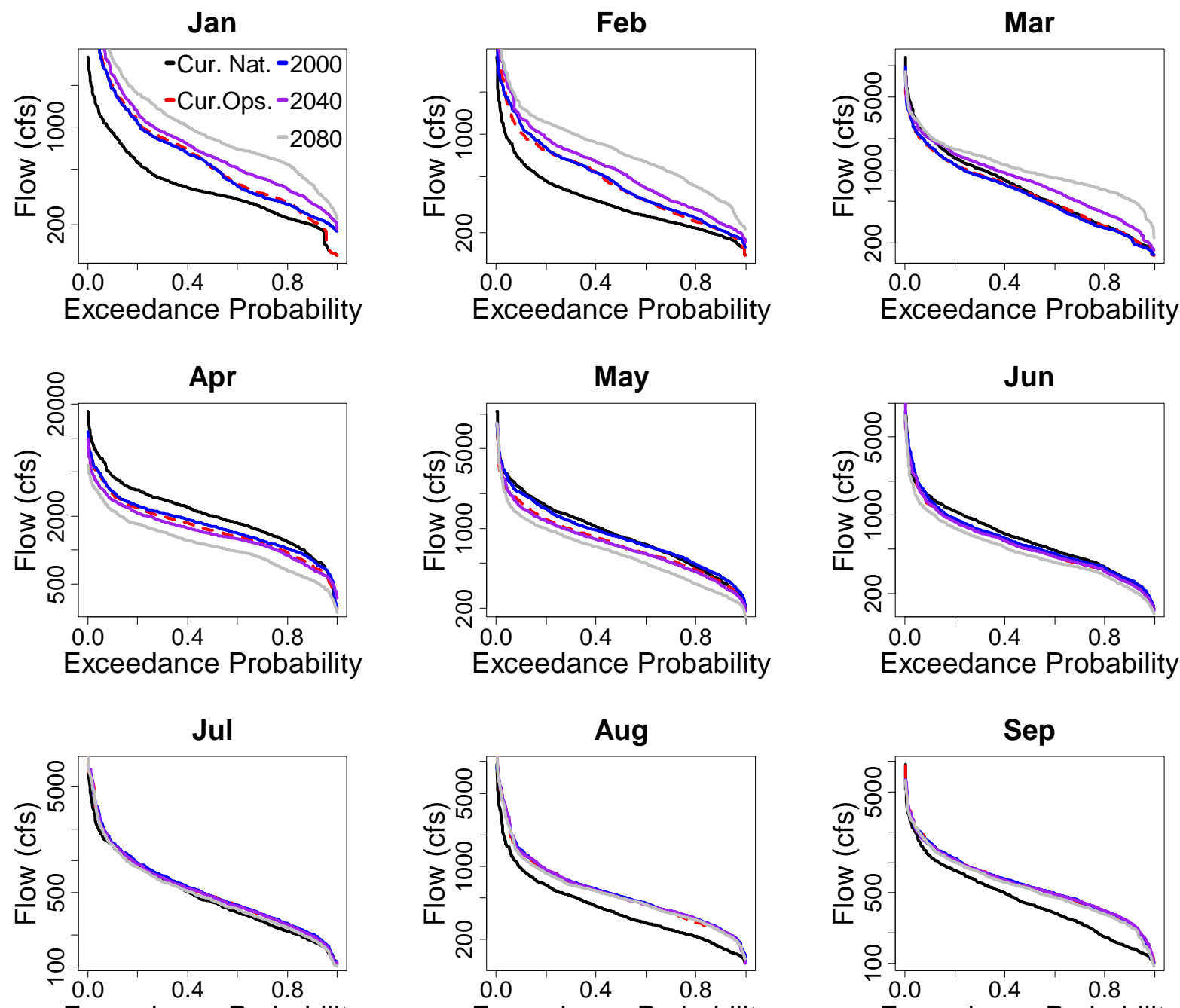

Exceedance Probability

Exceedance Probability
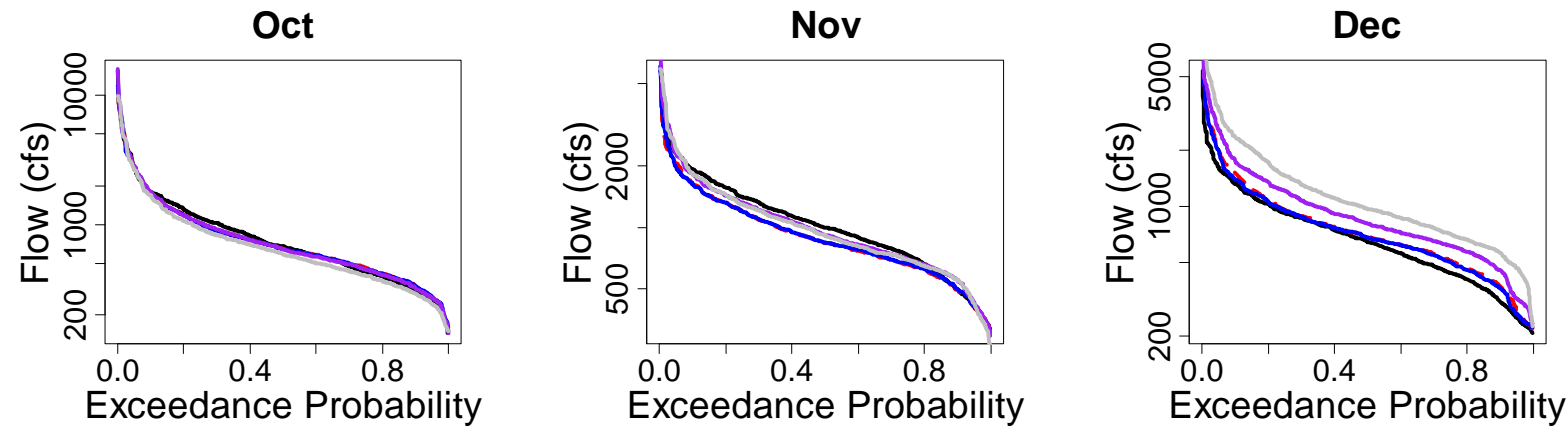

Figure 31: Optimization model monthly flow duration curves at Eco-Node 1. The black (current, natural flow) and red (current operations) are the same as in Figure 17. The blue, 
purple, and gray lines represent the A2 GCM ensemble under current operations for hydrologic conditions centered around 2000, 2040, and 2080.

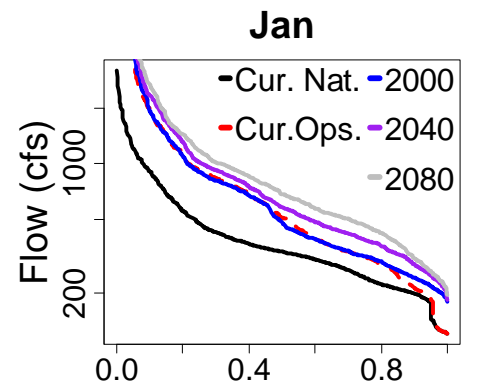

Exceedance Probability

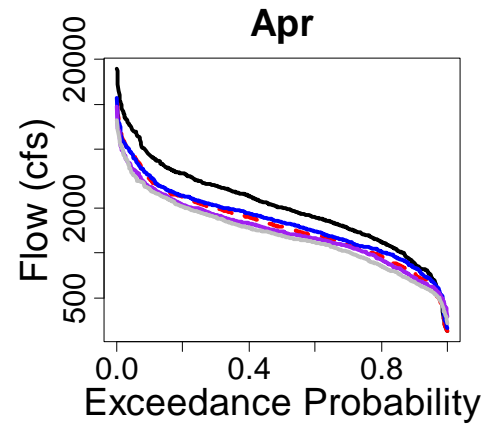

Jul

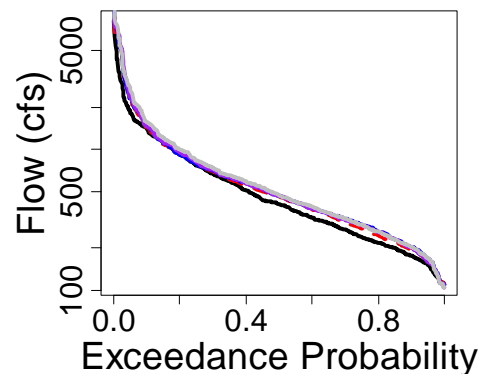

Oct

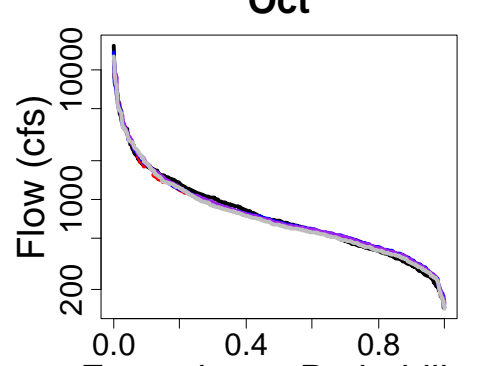

Exceedance Probability

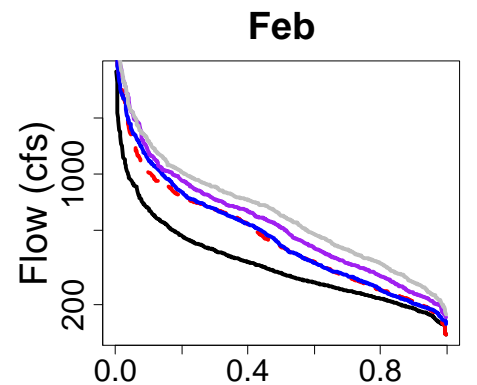

Exceedance Probability

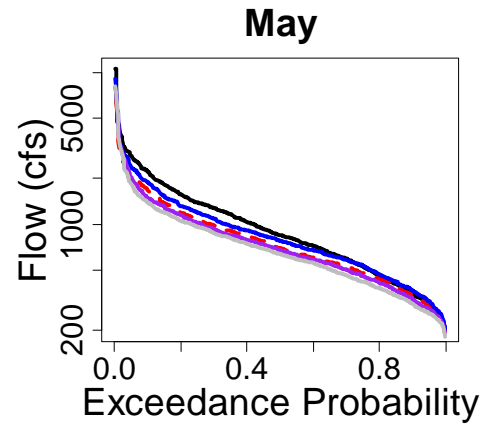

Aug

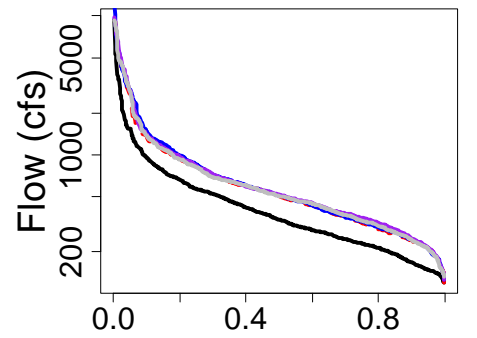

Exceedance Probability

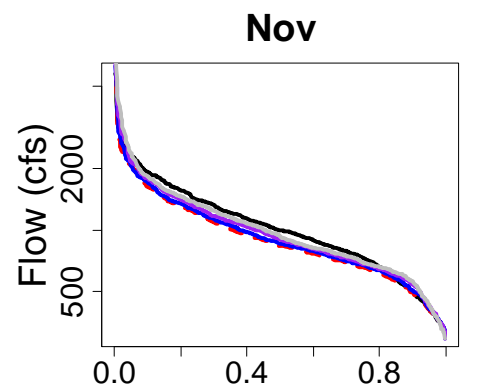

Exceedance Probability

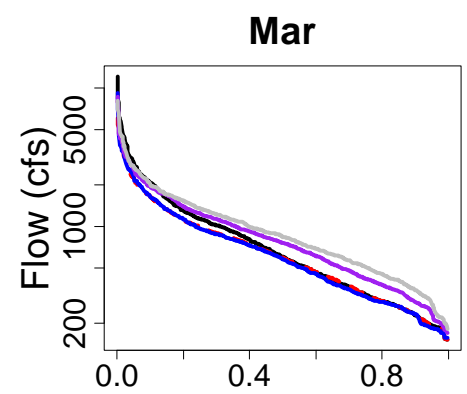

Exceedance Probability
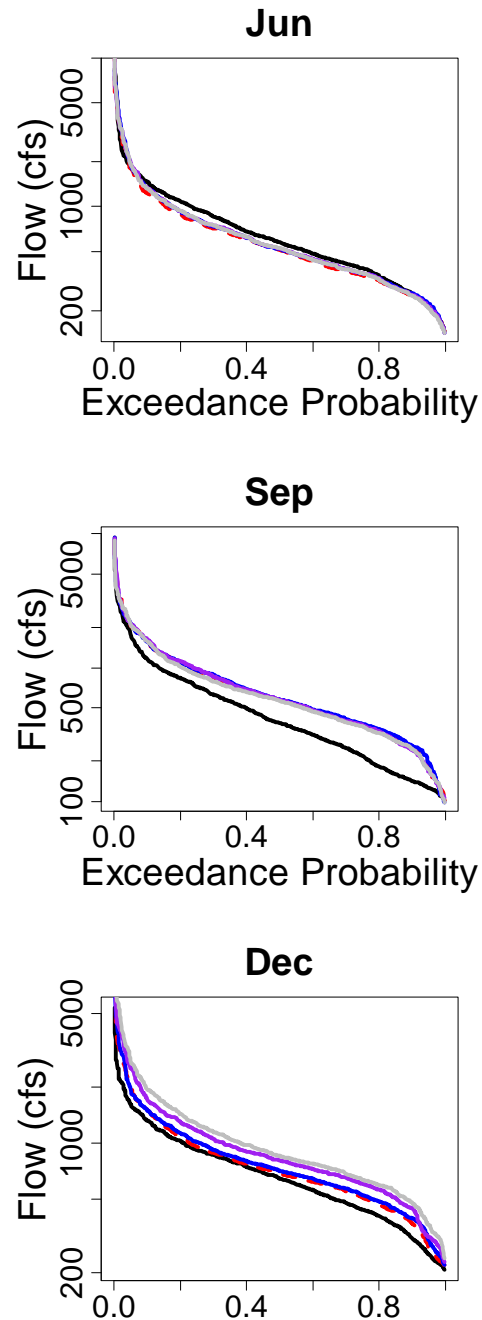

Exceedance Probability

Figure 32:Optimization model monthly flow duration curves at Eco-Node 1. The black (current, natural flow) and red (current operations) are the same as in Figure 17. The blue, 


\section{purple, and gray lines represent the B1 GCM ensemble under current operations for}

hydrologic conditions centered around 2000, 2040, and 2080.

\subsection{Average Annual System Income}

Figure 33 shows an increase in system revenue into the future under the A2 emissions scenario. This is expected based on the results in Section 6.3 which showed the reservoirs releasing more water during the winter. The reservoirs release more water without sacrificing their target storage because the winter flow is higher. The trend in the system income is the important observation to note, not necessarily the exact amount. The GCM-2000-A2 scenario shows an average annual system income of \$56.6 million/year, which is \$1.3 million/year more than current conditions, indicating a possible GCM error. However, the average annual system income continues to grow into the future, up to \$59.7 million/year in the GCM-2080 scenario, indicating income is likely to increase under current operations in the 5 GCM Ensemble A2 scenario.

Maintaining the current operations under climate change increases system income, but compounds the original problem of the altered flow regime. To mitigate the effects of climate change, system operations must be reexamined and adjusted. It might possible to maintain historic income levels, while operating to limit the effects of climate change. For example, if the reservoirs lower the winter drawdown, the income could remain constant because the changing climate provides more water in the winter. The alteration from the natural flow would not increase with climate change. Prescribing the operational adjustments to mitigate the effects of climate change is under investigation in the larger Connecticut River Project. 


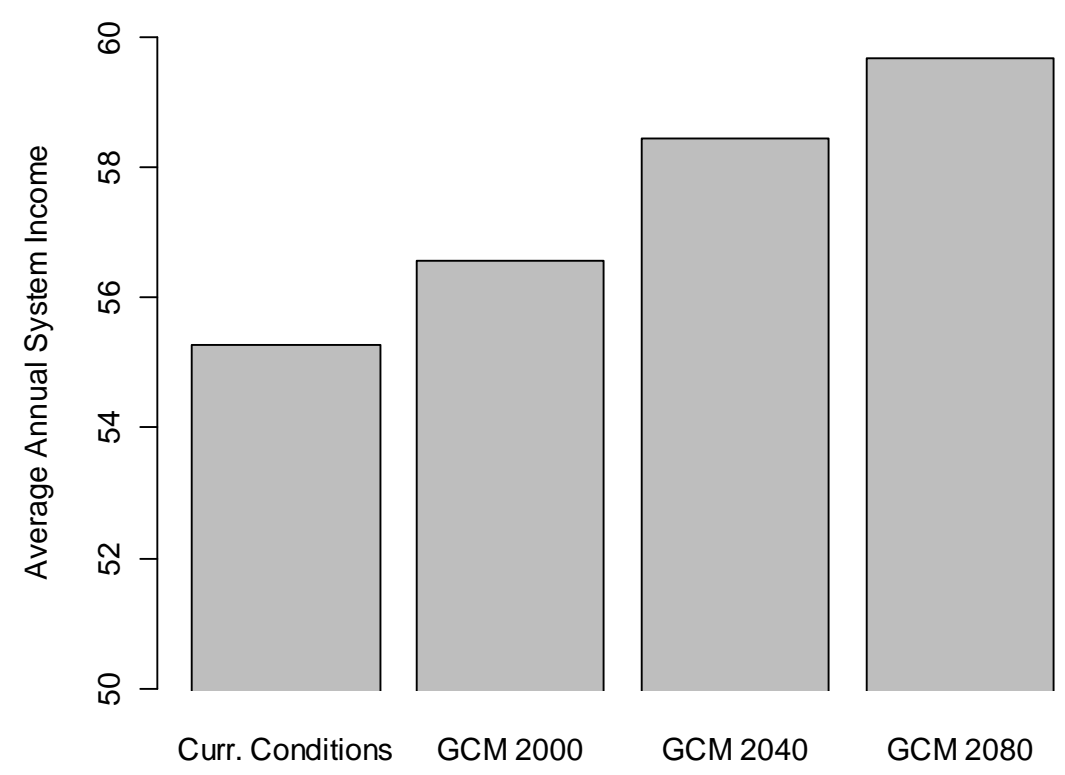

Figure 33: Average annual system income for the current conditions and the A2 Ensemble GCM for the time periods centered around 2000, 2040, and 2080

Since the winter flows increase in the B1 scenario as well, there is a similar growth in average annual system income. Table 8 compares the income generated from the A2 and B1 scenarios.

Table 8: Average annual income generated under the $A 2$ and $B 1$ emissions scenarios. (Note: little income difference between A2 and B1 climate chance scenarios)

\begin{tabular}{|ccccc|}
\hline \multicolumn{4}{|c|}{ Average Annual Income (\$M) } \\
& \multicolumn{2}{|c|}{$A 2$} & & $B 1$ \\
\hline Current & $\$$ & 55.28 & $\$$ & 55.28 \\
$\mathbf{2 0 0 0}$ & $\$$ & 56.56 & $\$$ & 56.85 \\
$\mathbf{2 0 4 0}$ & $\$$ & 58.44 & $\$$ & 58.30 \\
$\mathbf{2 0 8 0}$ & $\$$ & 59.67 & $\$$ & 59.67 \\
\hline
\end{tabular}

\subsection{Flood Control}

As discussed in Section 5.4, there are not any USACE flood control reservoirs in the Upper Third; the only flood control is maintaining flows under 10,000 cfs at the confluence of the Indian River. The analysis done in Section 5.4 is repeated to determine if the flow exceeds the threshold without any consideration in the objective function. The optimization model only 
minimizes deviations from target storage and maximizes income; the 10,000 cfs flood target is not included. The flow events exceeding 10,000 cfs increase into the future under the A2 scenario, but not by a drastic amount. By 2080, there are still only 5 flow events in 20 years that exceed 10,000 cfs. The B1 scenario also does not pose any flood threat at the Indian gage.

\section{Table 9: Number of times the Indian Gage flood control target is exceeded without considering flood control in the objective function for the current operations and the A2 GCM ensemble.}

\begin{tabular}{|c|c|c|}
\hline \multicolumn{3}{|c|}{ \# of Times Exceeding 10,000 cfs } \\
\hline & A2 & B1 \\
\hline Current & 1 & 1 \\
\hline 2000 & 2 & 3 \\
\hline 2040 & 5 & 1 \\
\hline 2080 & 5 & 4 \\
\hline
\end{tabular}

\section{Conclusions}

The study of the Upper Third of the Connecticut River Basin has resulted in a hydrology model, simulation model, optimization model, and a preliminary framework to prescribe operations to improve ecological targets to move forward in the larger research effort. This thesis examined the effects of regulation from the storage facilities on a monthly basis and provided insight into how to better manage the facilities. Under current operations, the system is operating optimally for hydropower production; the reservoir's target levels are designed to follow the energy price signal in the region and maximize income. The simulation model that replicates the system shows heavy regulation of the river from the drawdowns and refills. The reservoirs increase the natural flow in the winter and summer months to capitalize on the high energy prices and then replenish the reservoir by storing water during the spring and fall, causing lower than natural flows.

This study tested operational alternatives to improve flows for ecological targets by using the system optimization model to assign an allowable alteration to natural flows. The study selected a $10 \%$ allowable alteration as the ideal condition to improve ecological conditions. The optimization model suggested a cost of $\$ 2.8$ million/year to achieve these flows. To provide a 
foundation for future stakeholder discussions and negotiations, this study explored the economic and physical effects of allowable alterations from $10 \%$ to $100 \%$. The results indicated the allowable alteration range to be further discussed among stakeholders is in the range of $10-40 \%$. Below $10 \%$, the reservoirs cannot fulfill their core purpose and above $40 \%$ the economic benefits are not great enough to justify the deviations from natural flow indicators such as the Q10, Q50, and Q90.

The ensemble of the 5 selected GCMs for this study indicated hydrologic changes in the basin in the winter and spring. Higher temperatures and increased precipitation cause an increase in winter flows. Less precipitation falling as snow reduces the water stored in the basin and lowers the spring flows. The GCMs indicated climate change will not significantly affect the precipitation and temperature in the summer and fall months. Under current operations, climate change will compound the problem of the altered hydrograph. The higher than natural flows in the winter caused by the reservoir drawdown will increase from the excess water in the system due to climate change . The opposite is true for the spring - the lower than natural flows caused by the reservoir refill will be even lower from the decrease in snowpack due to climate change. If reservoir operations are not adjusted, the negative impacts felt by the eco-system from regulation will be increased. However, by adjusting the reservoir operational rules the reservoir system may potentially use the excess flow in the system during the winter to generate the same income using the higher climate change flows rather than a reservoir drawdown, thus mitigating the effects of climate change. This thesis only explored the effects of climate change and build a foundation for future work that is required to test operational adjustments and their effectiveness at mitigating climate change.

Along with modeling alternative operational policies to mitigate the effects of climate change, future work on the larger Connecticut River Project will expand the study area to the entire basin. There is more variety of reservoir functions in the lower portion of the basin. USACE flood control dams and municipal drinking water supply reservoirs will be included in the analysis to improve ecological flows. The decisions support system will also be combined with the project's forecasting effort to provide water managers a tool to dynamically manage systems rather than adhering to static rules. The final product of the project will include the complete analysis for all ecological points of interest; recommended operating policies for all major reservoirs; and operational adjustments necessary to mitigate the effects of climate change. 


\section{References}

Battin, James, Matthew W. Wiley, Mary H. Ruckelshaus, Richard N. Palmer, Elizabeth Korb, Krista K. Bartz, and Hiroo Imaki. 2007. Projected impacts of climate change on salmon habitat restoration. Proceedings of the National Academy of Sciences 104 (16) (April 17): 6720-5.

Brown, Casey and James Hansen. 2008. Agricultural Water Management and Climate Risk. Report to the Bill and Melinda Gates Foundation. IRI Tech. Rep. No. 08-01. International Research Institute for Climate and Society, Palisades, New York, USA. 19 pp.

Christensen, Niklas S., Andrew W. Wood, Nathalie Voisin, Dennis P. Lettenmaier, and Richard N. Palmer. 2004. The effects of climate change on the hydrology and water resources of the colorado river basin. Climatic Change 62 (1): 337-63.

Elsner, Marketa, Lan Cuo, Nathalie Voisin, Jeffrey Deems, Alan Hamlet, Julie Vano, Kristian Mickelson, Se-Yeun Lee, and Dennis Lettenmaier. 2010. Implications of 21st century climate change for the hydrology of washington state. Climatic Change 102 (1): 225-60.

Hamlet, Alan, Se-Yeun Lee, Kristian Mickelson, and Marketa Elsner. 2010. Effects of projected climate change on energy supply and demand in the pacific northwest and washington state. Climatic Change 102 (1): 103-28.

Hayhoe, Katharine, Cameron Wake, Thomas Huntington, Lifeng Luo, Mark Schwartz, Justin Sheffield, Eric Wood, et al. 2007. Past and future changes in climate and hydrological indicators in the US northeast. Climate Dynamics 28 (4): 381-407.

Lee, Se-Yeun, Alan F. Hamlet, Carolyn J. Fitzgerald, and Stephen J. Burges. 2009. Optimized flood control in the columbia river basin for a global warming scenario. Journal of Water Resources Planning and Management 135 (6) (November/December 2009): 440-50.

Lettenmaier, Dennis P., Andrew W. Wood, Richard N. Palmer, Eric F. Wood, and Eugene Z. Stakhiv. 1999. Water resources implications of global warming: A U.S. regional perspective. Climatic Change 43 (3): 537-79.

Loucks, D. P. 1995. Developing and Implementing Decision Support Systems: A Critique and a Challenge. JAWRA Journal of the American Water Resources Association 31 (4): 571-82.

Lund JR, Palmer RN. Water resources system modeling for conflict resolution, Water Resources. 1997. Update, n. 108. Universities Council on Water Resources (UCOWR). Carbondale, Illinois, US.

Maurer, E. P., L. Brekke, T. Pruitt, and P. B. Duffy. Fine-resolution climate projections enhance regional climate change impact studies. 2007. Eos Trans. AGU. 88(47), 504. 
Milly, P. C. D., Julio Betancourt, Malin Falkenmark, Robert M. Hirsch, Zbigniew W. Kundzewicz, Dennis P. Lettenmaier, and Ronald J. Stouffer. 2008. Climate Change: Stationarity is dead: Whither water management? Science 319 (5863) (February 1): 573-4.

Ngo, Long Le, Henrik Madsen, and Dan Rosbjerg. 2007. Simulation and Optimization Modeling Approach for Operation of the Hoa Binh Reservoir, Vietnam. Journal of Hydrology 336 (34) (4/7): 269-81.

Opperman, J. J., R. Luster, B. A. McKenney, M. Roberts, and A. W. Meadows. 2010. Ecologically functional floodplains: Connectivity, flow regime, and Scale1. JAWRA Journal of the American Water Resources Association 46 (2): 211-26.

Palmer, R. N., W. J. Werick, A. Mac Ewan, and A. W. Woods. Modeling water resources opportunities, challenges and trade-o

ffs: The use of shared vision modeling for negotiation and conflict resolution. Tempe, AZ, USA.

Payne, Jeffrey T., Andrew W. Wood, Alan F. Hamlet, Richard N. Palmer, and Dennis P. Lettenmaier. 2004. Mitigating the effects of climate change on the water resources of the columbia river basin. Climatic Change 62 (1): 233-56.

Richter, Brian D., Ruth Mathews, David L. Harrison, and Robert Wigington. 2003. Ecologically Sustainable Water Management: Managing River Flows for Ecological Integrity. Ecological Applications 13 (1) (02/01): 206-24.

Simonovic, Slobodan P. 2002. World water dynamics: Global modeling of water resources. Journal of Environmental Management 66 (3) (11): 249-67.

Snover, Amy K., Alan F. Hamlet, and Dennis P. Lettenmaier. 2003. Climate-change scenarios for water planning studies: Pilot applications in the pacific northwest. Bulletin of the American Meteorological Society 84 (11) (11): 1513-8.

Stave, Krystyna A. 2003. A system dynamics model to facilitate public understanding of water management options in las vegas, nevada. Journal of Environmental Management 67 (4) (4): 303-13.

Storck, P., L. Bowling, P. Wetherbee, and D. Lettenmaier. 1998. Application of a GIS-based distributed hydrology model for prediction of forest harvest effects on peak stream flow in the pacific northwest. Hydrological Processes 12 (6): 889-904.

Thiessen, Ernest M., and Daniel P. Loucks. Computer Assisted Negotiation of Multi-Objective Water Resources Conflicts.1992. Vol. - 28. - Blackwell Publishing Ltd.

Vorosmarty, Charles J., Pamela Green, Joseph Salisbury, and Richard B. Lammers. 2000. Global water resources: Vulnerability from climate change and population growth. Science 289 (5477) (July 14): 284-8. 
Westphal, Kirk S., Richard M. Vogel, Paul Kirshen, and Steven C. Chapra. 2003. Decision support system for adaptive water supply management. Journal of Water Resources Planning and Management 129 (3) (May/June 2003): 165-77.

Whitaker, A., Y. Alila, J. Beckers, and D. Toews. 2003. Application of the distributed hydrology soil vegetation model to redfish creek, british columbia: Model evaluation using internal catchment data. Hydrological Processes 17 (2): 199-224.

Wiley, Matthew W., and Richard N. Palmer. 2008. Estimating the impacts and uncertainty of climate change on a municipal water supply system. Journal of Water Resources Planning \& Management 134 (3) (05): 239-46.

Wurbs, Ralph A. 1993. Reservoir-system simulation and optimization models. Journal of Water Resources Planning and Management 119 (4) (July/August 1993): 455-72.

Xu, Z. X., K. Takeuchi, H. Ishidaira, and X. W. Zhang. 2002. Sustainability analysis for yellow river water resources using the system dynamics approach. Water Resources Management 16 (3): 239-61. 


\section{Appendix A: Detailed Reservoir Information}

\subsection{Second Connecticut Lake}

Table 10A: Second Connecticut Lake information

\begin{tabular}{|c|c|}
\hline NAT ID: & NH00187 \\
\hline FER ID: & N/A \\
\hline CT RIVER ID: & NH_194.07 \\
\hline Dam Type: & Earth \\
\hline Year Built & 1935 \\
\hline Height (ft): & 28 \\
\hline Length (ft): & 568 \\
\hline Max Storage (acre-ft): & 12,500 \\
\hline Generating Capacity: & N/A \\
\hline
\end{tabular}

Table 11A: Second Connecticut Lake minimum releases

\begin{tabular}{|c|c|}
\hline Time of year & Flow (cfs) \\
\hline $6 / 1-9 / 30$ & 22.5 or inflow \\
\hline $10 / 1-5 / 31$ & 45 or inflow \\
\hline
\end{tabular}

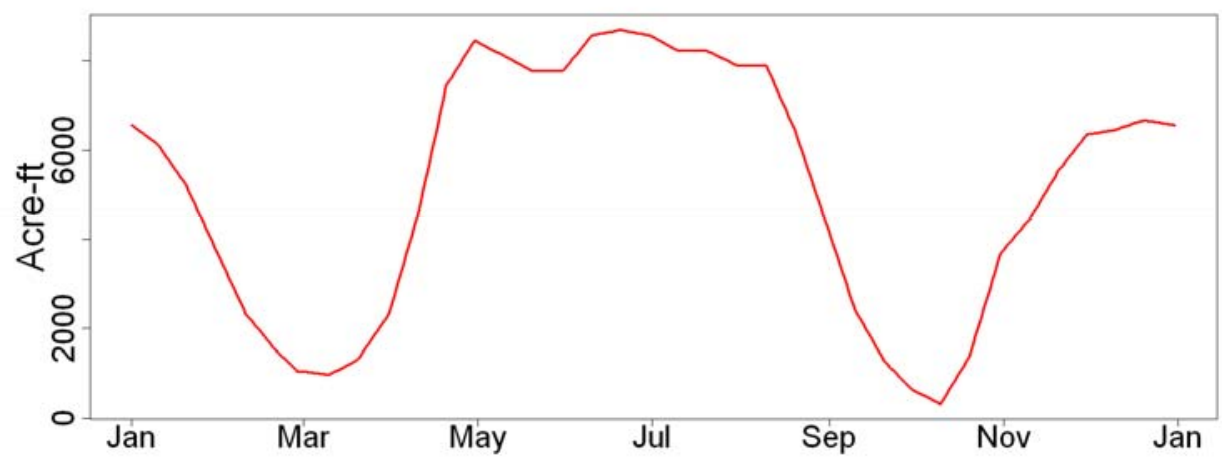

Figure 34A: Second Connecticut Lake Target Storage 


\subsection{First Connecticut Lake}

Table 12A: First Connecticut Lake information

\begin{tabular}{|c|c|}
\hline NAT ID: & NH00186 \\
\hline FER ID: & N/A \\
\hline CT RIVER ID: & NH_194.02 \\
\hline Dam Type: & Concrete \\
\hline Year Built & 1930 \\
\hline Height (ft): & 56 \\
\hline Length (ft): & 1117 \\
\hline Max Storage (acre-ft): & 114000 \\
\hline Generating Capacity: & N/A \\
\hline
\end{tabular}

Table 13A: First Connecticut Lake minimum releases

\begin{tabular}{|c|c|}
\hline Time of year & Flow (cfs) \\
\hline $6 / 1-9 / 30$ & 41.5 or inflow \\
\hline $10 / 1-5 / 31$ & 83 or inflow \\
\hline
\end{tabular}

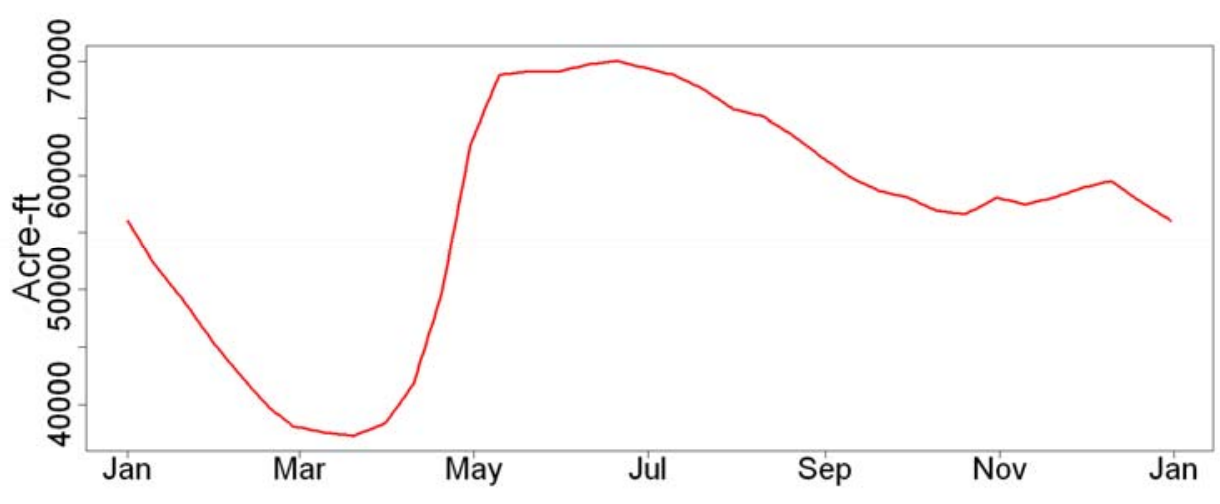

Figure 35A: First Connecticut Lake Target Storage 


\subsection{Lake Francis (Murphy Dam)}

Table 14A: Lake Francis information

\begin{tabular}{|c|c|}
\hline NAT ID: & NH00185 \\
\hline FER ID: & N/A \\
\hline CT RIVER ID: & NH_194.12 \\
\hline Dam Type: & Earth/Concrete \\
\hline Year Built & 1935 \\
\hline Height (ft): & 106 \\
\hline Length (ft): & 2200 \\
\hline Max Storage (acre-ft): & 132000 \\
\hline Generating Capacity: & N/A \\
\hline
\end{tabular}

Table 15A: Lake Francis minimum releases

\begin{tabular}{|c|c|}
\hline Time of year & Flow (cfs) \\
\hline $6 / 1-9 / 30$ & 85 or inflow \\
\hline $10 / 1-5 / 31$ & 170 or inflow \\
\hline
\end{tabular}

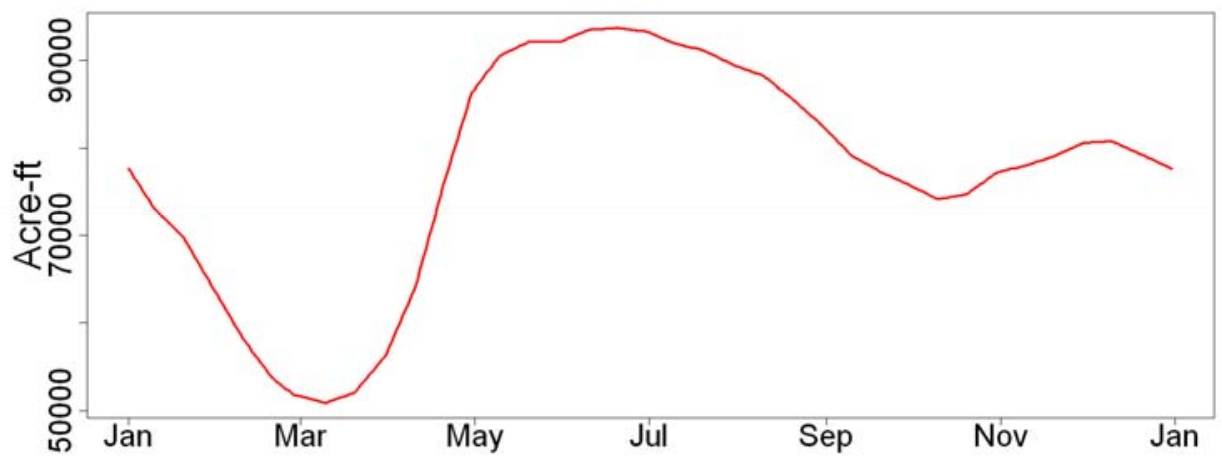

Figure 36A: Lake Francis Target Storage 


\subsection{Moore Reservoir}

Table 16A: Moore information

\begin{tabular}{|c|c|}
\hline NAT ID: & NH00414 \\
\hline FER ID: & P-2077 \\
\hline CT RIVER ID: & NH_227.10 \\
\hline Dam Type: & Concrete \\
\hline Year Built & 1957 \\
\hline Height (ft): & 144 \\
\hline Length (ft): & 2920 \\
\hline Max Storage (acre-ft): & 223722 \\
\hline Generating Capacity (MW): & 192 \\
\hline
\end{tabular}

Table 17A: Moore minimum releases

\begin{tabular}{|c|c|}
\hline Time of year & Flow (cfs) \\
\hline All year & 320 \\
\hline
\end{tabular}

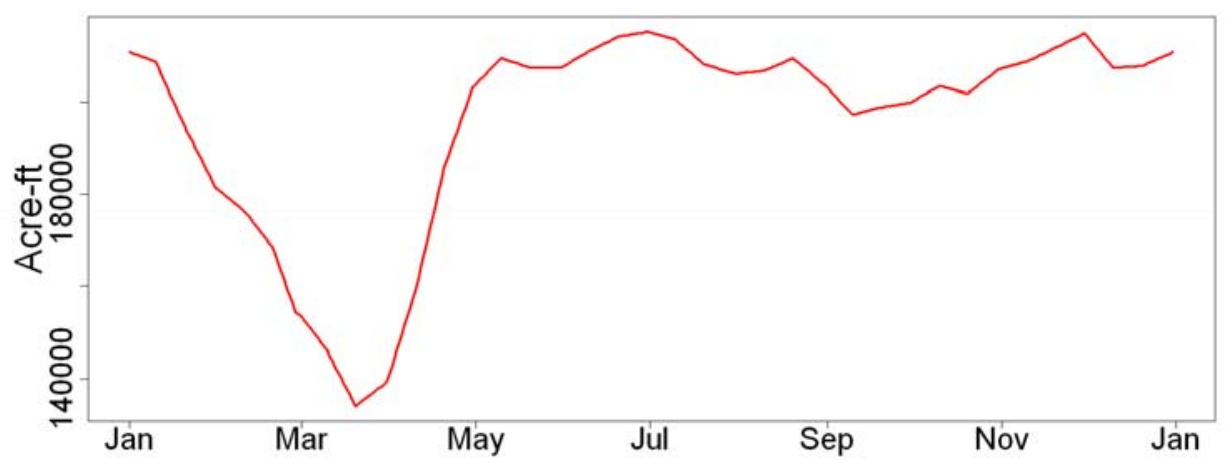

Figure 37A: Moore Target Storage 


\subsection{Comerford Reservoir}

Table 18A: Comerford Reservoir information

\begin{tabular}{|c|c|}
\hline NAT ID: & NH00165 \\
\hline FER ID: & P-2077 \\
\hline CT RIVER ID: & VT_12.13 \\
\hline Dam Type: & Concrete \\
\hline Year Built & 1930 \\
\hline Height (ft): & 170 \\
\hline Length (ft): & 2233 \\
\hline Max Storage (acre-ft): & 57700 \\
\hline Generating Capacity (MW): & 145 \\
\hline
\end{tabular}

Table 19A: Comerford Reservoir minimum releases

\begin{tabular}{|c|c|}
\hline Time of year & Flow (cfs) \\
\hline $6 / 1-9 / 30$ & 818 \\
\hline $10 / 1-3 / 31$ & 1145 \\
\hline $4 / 1-5 / 31$ & 1635 \\
\hline
\end{tabular}




\subsection{McIndoes Reservoir}

Table 20A: McIndoes Information

\begin{tabular}{|l|l|}
\hline NAT ID: & NH00166 \\
\hline FER ID: & P-2077 \\
\hline CT RIVER ID: & VT_162.02 \\
\hline Dam Type: & Concrete \\
\hline Year Built & 1931 \\
\hline Height (ft): & 25 \\
\hline Length (ft): & 730 \\
\hline Max Storage (acre-ft): & 14100 \\
\hline Generating Capacity (MW): & 10.6 \\
\hline
\end{tabular}

Table 21A: McIndoes Minimum Releases

\begin{tabular}{|l|l|}
\hline Time of year & Flow $(\mathbf{c f s})$ \\
\hline $6 / 1-9 / 30$ & 1105 or inflow \\
\hline $10 / 1-3 / 31$ & 2210 or inflow \\
\hline $4 / 1-5 / 31$ & 4420 or inflow \\
\hline
\end{tabular}

\section{Appendix B - Incorporating Time Lag in the Model}

TransCanada provided information about travel time from reservoir to reservoir. The total travel time from Second Connecticut Lake to Lake Francis is 3 hours. The travel time from Lake Francis to Moore is 44 hours. The total time from Moore to McIndoes is 1 hour. Figure 38C shows how the simulation and optimization models interpret the travel times. The first time step ends after the confluence with the Mohawk River and the second time step ends after the confluence with the Israel River. The time lag does not go into effect until the $3^{\text {rd }}$ time step in a model run. For example the flow reaching Nulhegan on day 1 is the flow leaving Mohawk on day 1 , but the flow reaching Nulhegan confluence on day 3 is the flow leaving Mohawk confluence on day 2. 


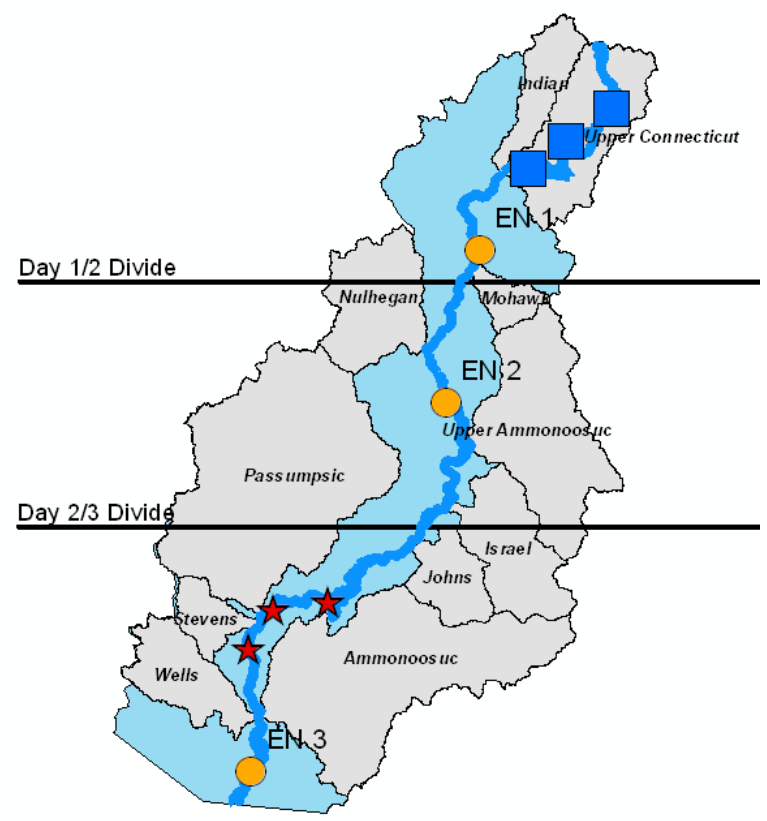

Figure 38C: The Upper Third system with the day divides.

\section{Appendix C - Optimization Model Documentation}

\subsection{Architecture of the Optimization Model}

There are four basic architectural components of the optimization model: data import/export, objective function, constraints, and targets.

\section{Data Import/Export}

The optimization models require importing and exporting data. This is accomplished by declaring all variables and the establishing links between the model and the source of the data (Microsoft Excel). Constant values such as storage capacity are incorporated into the model directly. Time varying data such as flow, target storages, or target releases are stored in an external spreadsheet and are imported into the model. The user can also specify where to export model results (back to a spreadsheet or a text file). The model exports storages, releases, and power produced for each time step.

If/then statements require binary variables in linear programming and exponentially increase the runtime of the model. To avoid these statements, much of the input data is preprocessed. An example of this would be if a dam has a minimum flow rule that requires $50 \mathrm{cfs}$ or the inflow, whichever is smaller, to be released. The input file in excel would contain the statement "if the inflow on day I is less than $50 \mathrm{cfs}$, the minimum release is the inflow, else it is $50 \mathrm{cfs}$." Then the inputted data for the optimization model only has a column of minimum releases for each day with the if/then rule already considered. 
The objective function establishes what the model will maximize or minimize. The model's current objective function includes the ability to maximize or minimize a variety of objectives, or combination of objectives. The target values include essential dam operations as well as environmental flow targets. The objective function can strive to directly hit a target, or ensure a minimum is not violated. For example, if an ecological node has a target flow of $300 \mathrm{cfs}$, the objective function will minimize the flow that is above and below that value for each time step. If the eco-node has a minimum flow of $50 \mathrm{cfs}$, the objective function will only minimize the flows below $50 \mathrm{cfs}$.

Because the numeric manner in which we represent physical features vary greatly (we might measure flows in cubic feet per second, storage in millions of gallons, power in kilowatt hours), the corresponding terms in the objective functions have to be carefully considered. Weighting and normalization are important techniques to make objective functions reflect our true priorities. Normalizing the objectives removes the distortion in values due to differing units and creates "unit-less" values.

Once the objective function has unit-less values, weighting is a way to prioritize objectives. For example if the optimization problem wants to maximize storage in Dam A and Dam B, the objective function would look like

Max $=[$ Sum of All Storages for Dam A $]+[$ Sum of All Storages for Dam B $]$

However, if the goal was to maximize storages in each, but it was much more important to maximize the storage in Dam A, the objective function would look like

Max $=100 *[$ Sum of All Storages for Dam A $]+[$ Sum of Storages of All Storages for Dam B $]$

The weighting value (100 in the example) is an arbitrary number and must be explored using a trial and error system. A value for a weighting is entered and the model is run; if the results do not achieve the desired goal without detrimentally affecting another decision variable, a different value is tested.

\section{Constraints}

Constraints restrict the range of solutions available to the optimization model. Constraints cannot be violated and if the model cannot find a solution within the constraints, the result is an infeasible model. Reservoir capacities are entered as constraints since a reservoir cannot physically contain more water than its capacity. Constraints are also used to establish continuity. For example, the releases from Third Connecticut Lake (TCL) flow into Second Connecticut Lake (SCL) so a constraint for SCL would be

Storage on Day I of SCL $=[$ Storage on Day I-1 $]+[$ Releases from TCL on Day I $]-[$ Releases from SCL on Day I]

This statement says the storage of Second Connecticut Lake on any given day is the previous 
day's storage plus the releases from Third Connecticut Lake minus that day's releases. That constraint establishes the connectivity of the two reservoirs as well as the flow/storage relationship for SCL.

\section{Targets}

Targets establish the goals of the model that the objective function will maximize or minimize; they are used for releases, storages, and ecological flows. For example, a dam release target with a minimum release of $100 \mathrm{cfs}$ would be entered into the model as

\section{[Dam Release on Day I $]-100$ cfs $=$ [Above Target $]-$ [Below Target $]$}

The model interprets this statement as [Above Target] is equal to the flow that is over the target and [Below Target] is equal to the flow that is below target. For a given day, at least one of these values will be 0 (since flow cannot be both over and under a target). If the release is 100 , both values will be 0 . In the optimization model the sum of [Above Target] and [Below Target] would be minimized, forcing the model to always try to hit the target. If the $100 \mathrm{cfs}$ in the example was a minimum release target, the objective function would only minimize [Below Target] for each day.

\subsection{Model Node Types}

There are 4 types of nodes used in the optimization model: storage facilities, hydroelectric facilties, ecological nodes, and confluences.

\subsubsection{Storage Facilities}

Storage facilities store water to be released to downstream hydroelectric facilities at opportune energy price times.

\subsubsection{Hydroelectric Dams}

There are two basic types of hydroelectric dams that are included in the optimization models: run-of-river and storage dams. Run-of-river hydroelectric dams release all inflows on a daily time step; they do not have active storage, thus do not have operating rules that need to be captured in the model. Storage hydroelectric dams have reservoirs that can store water for power generation. These dams have operating rules (minimum flows, target storages, etc.). The rules are obtained from phone calls and meeting with dam owners and operators. When dam operators have not been reached, hydropower dams are assumed to store water to its capacity, and then release the rest through the turbine.

Hydropower is calculated as

Power $=[$ specific gravity of water $] *[$ flow $] *[$ head $] *[$ efficiency $]$

Optimizing for power generation poses a problem for linear optimization, because the function is non-linear; head and flow are both decision variables that are being multiplied together. The 
current optimization models calculate power using constant head. The constant head is the average head calculated by season. Assuming a constant head makes power a linear function and allows for it to be optimized. The efficiencies for hydropower dams are modeled at 0.9 for large dams, and 0.6 for small hydroelectric stations.

Hydroelectric dams are entered into the objective function as minimizing deviations from operating rules and maximizing power generation.

\subsubsection{Ecological Nodes}

Ecological nodes are specific points of interest indicated by The Nature Conservancy. They include locations important to diadromous fish, first priority floodplains, floodplains, mussels, river herring, and tiger beetles. Place holders have been entered into the model for these nodes that have zero storage and no operating rules. Once flow regimes have been determined for each node, flow targets will be entered. If the flow target is a minimum flow, the objective function will minimize deviations below the flow. If the flow target is an exact target, the objective function will minimize deviations above and below the target.

There are also ecological reaches for diadromous fish, priority floodplains, and salmon stocking. As mentioned above, it has not yet been determined how these reaches will be handled in the optimization model.

\subsubsection{Confluences}

Confluences are nodes that join a tributary flow to the main stem of the Connecticut River. Confluences are entered into the optimization model as nodes with zero storage and no operational rules. They are just an input of flows to the main stem and away to establish connectivity of the entire system.

\subsection{User Interface}

A graphical user interface for the optimization model has been developed in Microsoft Excel. This front end software uses visual basic to link the Lingo model with the excel interface. The interface allows the user to adjust the weights on an objective function and create a trade-off curve by iteratively running the model. As a deliverable, the interface will also include options to select inflows based on different GCMs. 


\section{Appendix D - GCM Temperature and Precipitation Data}

\subsection{A2 Precipitation}
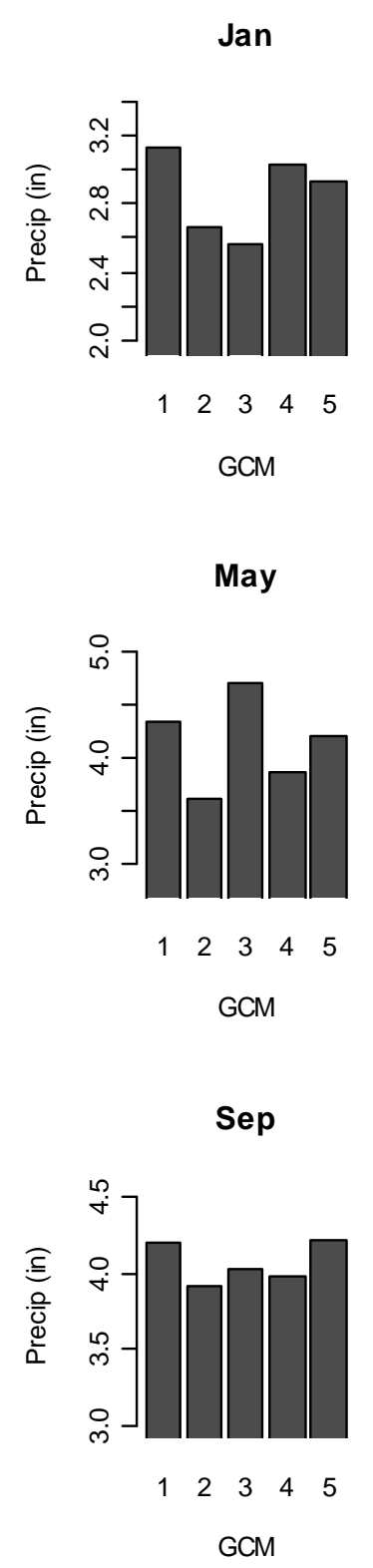

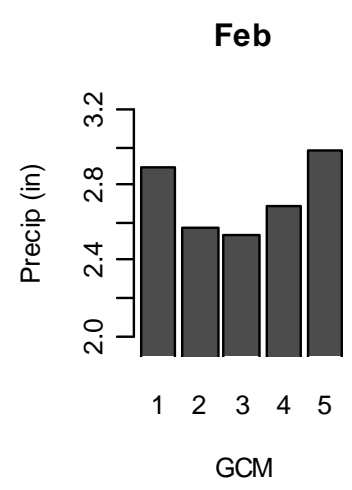

Jun

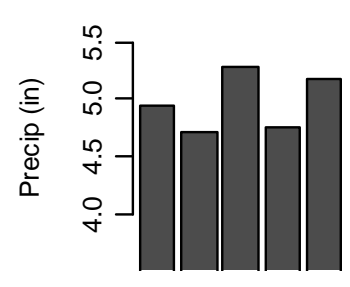

$123 \quad 3 \quad 4 \quad 5$

GCM

Oct

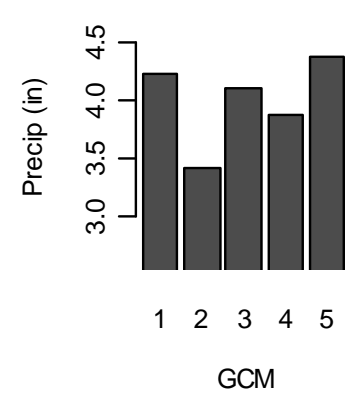

Mar

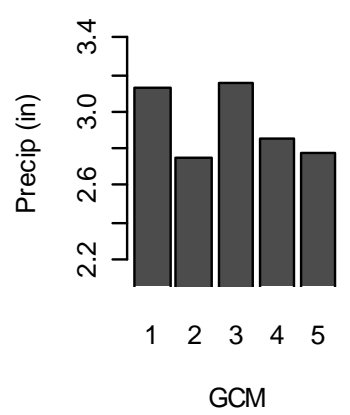

Jul

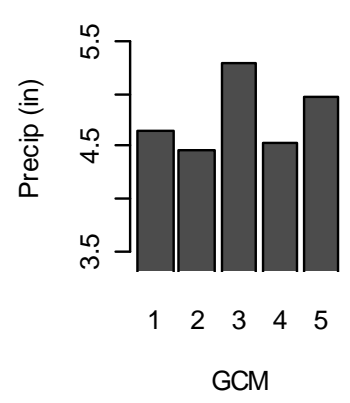

Nov

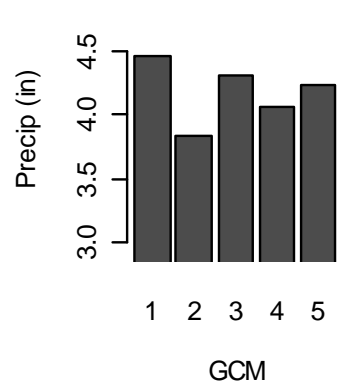

Apr

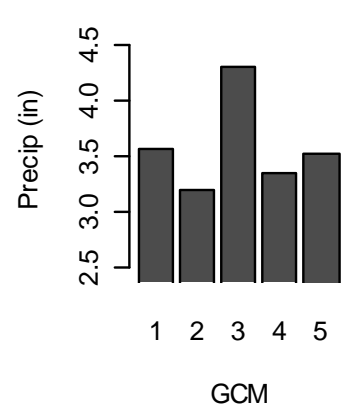

Aug

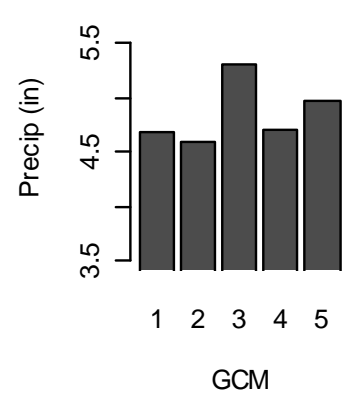

Dec

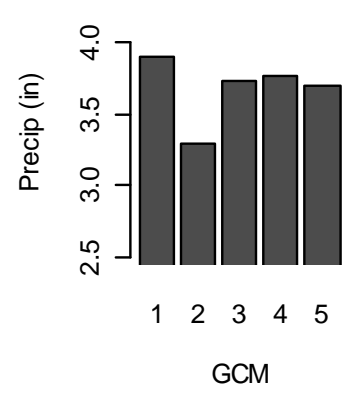

Figure 39D: Total monthly precipitation for each GCM for the time period centered around 2000 using the $\mathrm{A} 2$ emissions scenario. (1= cccma_cgcm 3, 2= ccsm3, 3= giss, 4= mri, $5=$ pcm). 


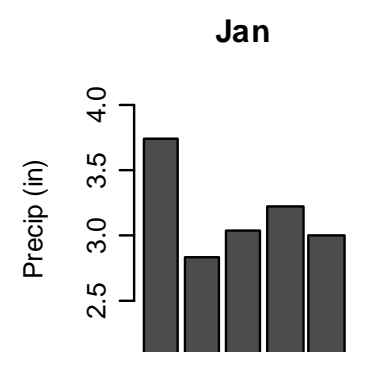

12345

GCM

May

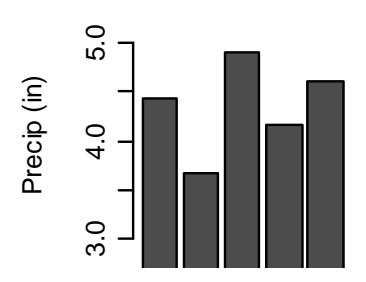

12345

GCM

Sep

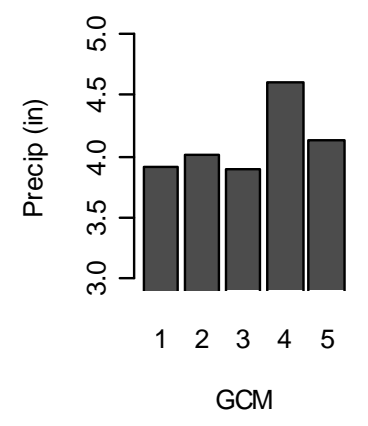

Feb

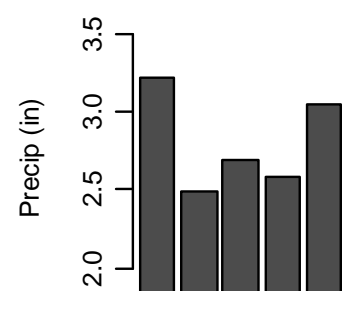

$\begin{array}{lllll}1 & 2 & 3 & 4 & 5\end{array}$

GCM

Jun

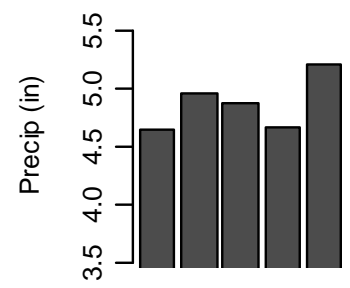

$\begin{array}{lllll}1 & 2 & 3 & 4 & 5\end{array}$

GCM

Oct

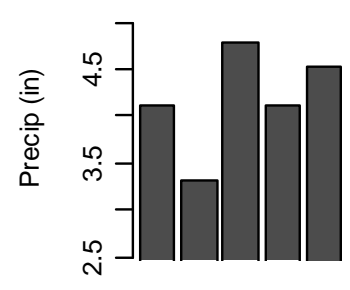

$\begin{array}{lllll}1 & 2 & 3 & 4 & 5\end{array}$

GCM

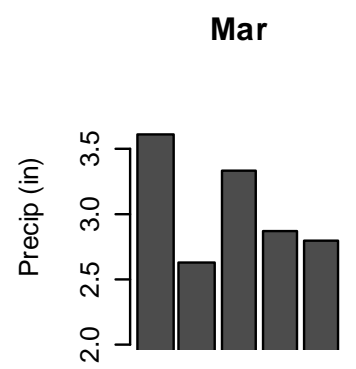

12345

GCM

Jul

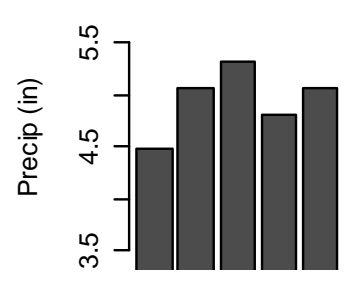

12345

GCM

Nov

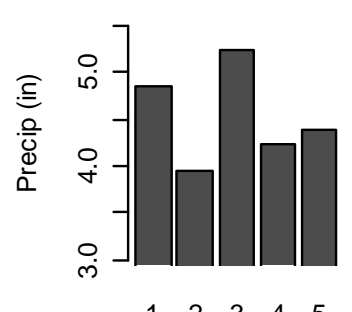

GCM

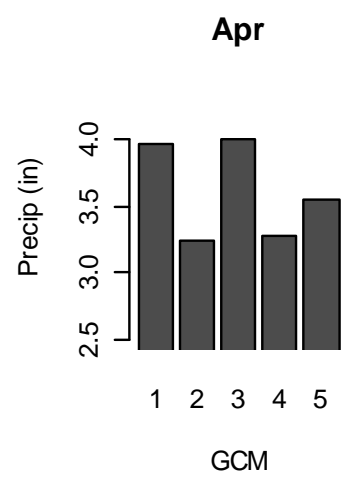

Aug

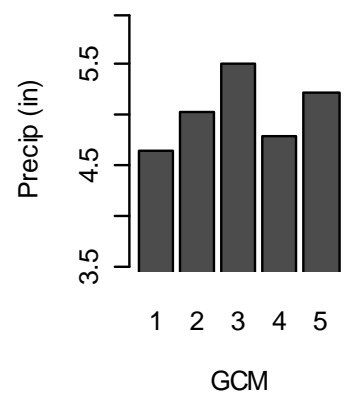

Dec

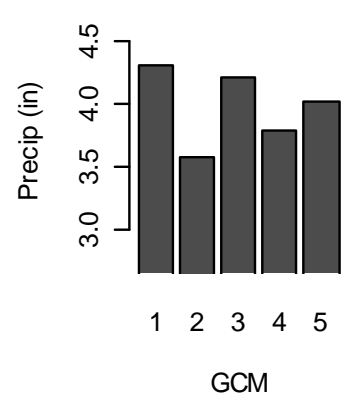

Figure 40D: Total monthly precipitation for each GCM for the time period centered around 2040 using the A2 emissions scenario. (1= cccma_cgcm3, 2= ccsm3, 3= giss, 4= mri, $5=\mathrm{pcm})$. 


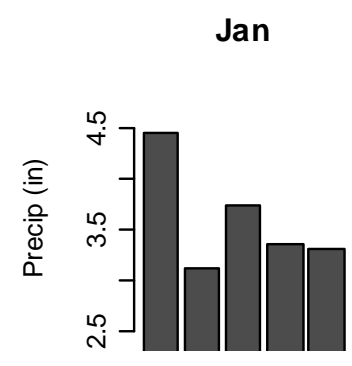

$123 \quad 3 \quad 4 \quad 5$

GCM

May

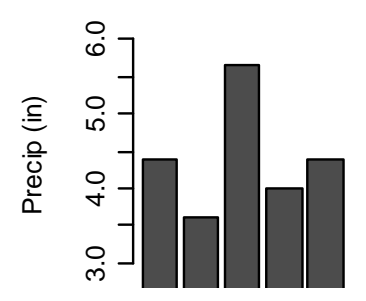

$\begin{array}{lllll}1 & 2 & 3 & 4 & 5\end{array}$

GCM

Sep

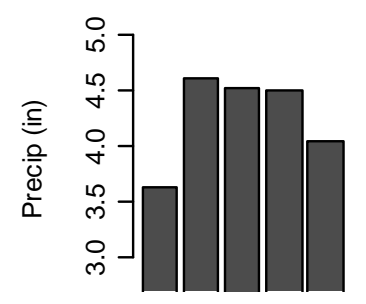

12345

GCM

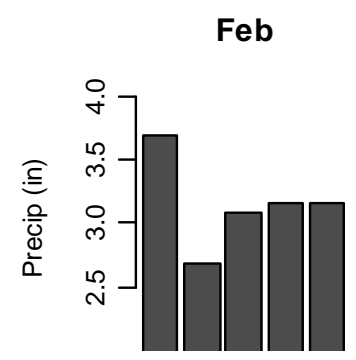

$\begin{array}{lllll}1 & 2 & 3 & 4 & 5\end{array}$

GCM

Jun

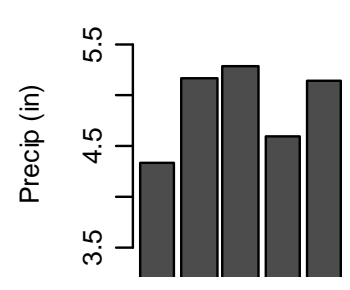

$\begin{array}{lllll}1 & 2 & 3 & 4 & 5\end{array}$

GCM

Oct

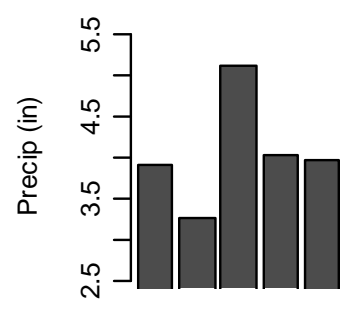

12345

GCM

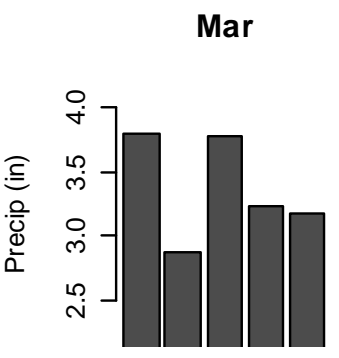

12345

GCM

Jul

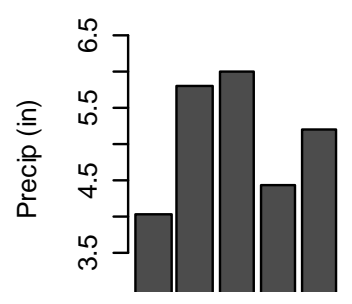

$\begin{array}{lllll}12 & 2 & 4 & 5\end{array}$

GCM

Nov

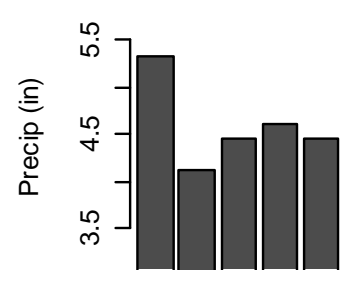

$\begin{array}{lllll}1 & 2 & 3 & 4 & 5\end{array}$

GCM
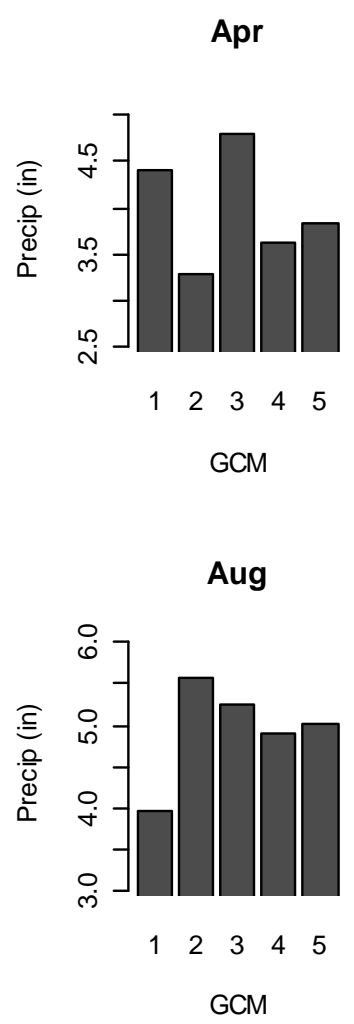

Dec

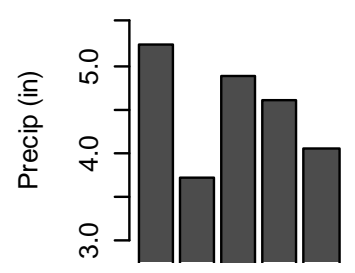

12345

GCM

Figure 41D: Total monthly precipitation for each GCM for the time period centered around 2080 using the $\mathrm{A} 2$ emissions scenario. (1= cccma_cgcm3, 2= ccsm3, 3= giss, 4= mri, $5=\mathbf{p c m})$. 


\subsection{A2 Temperature}

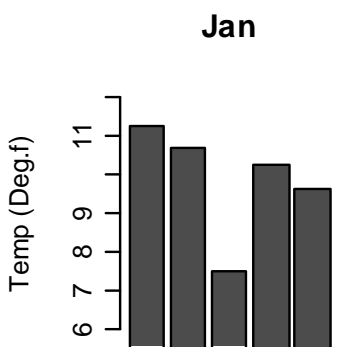

$\begin{array}{lllll}1 & 2 & 3 & 4 & 5\end{array}$

GCM

May

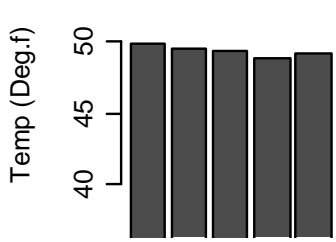

$\begin{array}{lllll}1 & 2 & 3 & 4 & 5\end{array}$

GCM

Sep

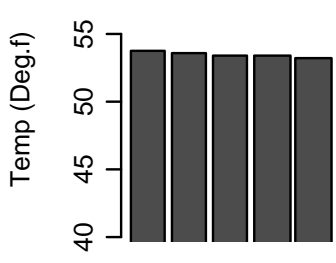

$\begin{array}{lllll}1 & 2 & 3 & 4 & 5\end{array}$

GCM
Feb

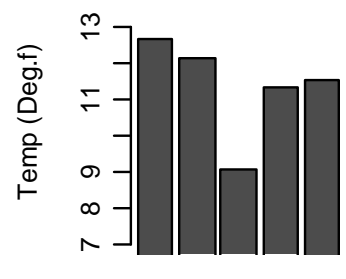

GCM

Jun

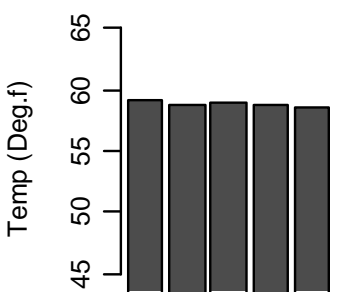

$\begin{array}{lllll}1 & 2 & 3 & 4 & 5\end{array}$

GCM

Oct

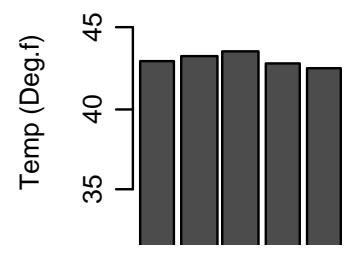

$\begin{array}{lllll}1 & 2 & 3 & 4 & 5\end{array}$

GCM

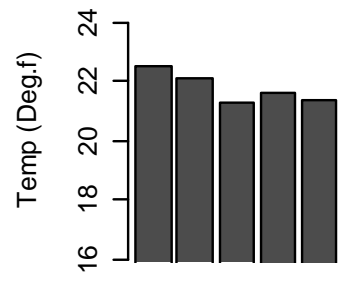

$\begin{array}{lllll}1 & 2 & 3 & 4 & 5\end{array}$

GCM

Jul

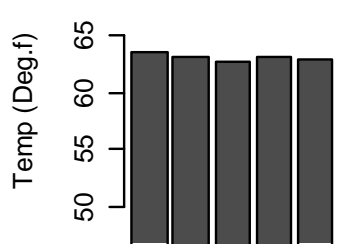

$\begin{array}{lllll}1 & 2 & 3 & 4 & 5\end{array}$

GCM

Nov

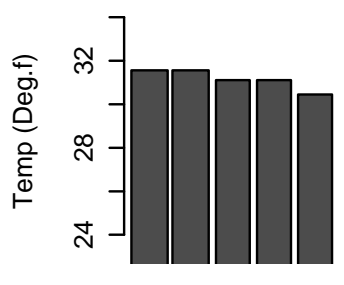

$\begin{array}{lllll}1 & 2 & 3 & 4 & 5\end{array}$

GCM
Apr

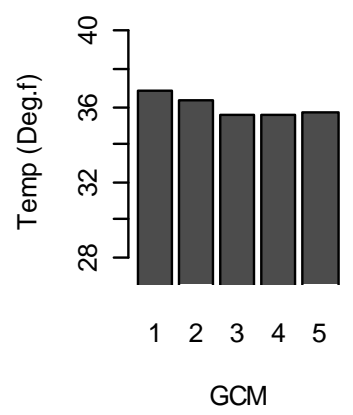

Aug

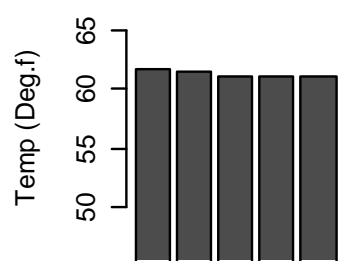

$\begin{array}{lllll}1 & 2 & 3 & 4 & 5\end{array}$

GCM

Dec

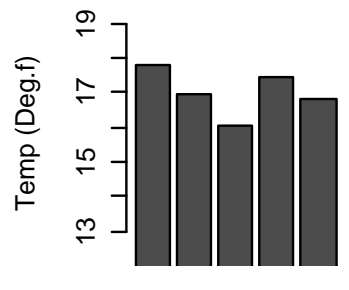

GCM

Figure 42D: Average monthly temperature for each GCM for the time period centered around 2000 using the $\mathrm{A} 2$ emissions scenario. (1= cccma_cgcm3, 2= ccsm3, 3= giss, 4= mri, $5=$ pcm). 


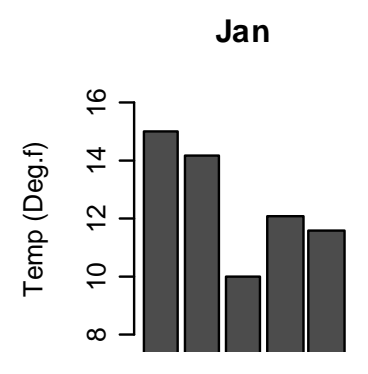

$\begin{array}{lllll}1 & 2 & 3 & 4 & 5\end{array}$

GCM

May

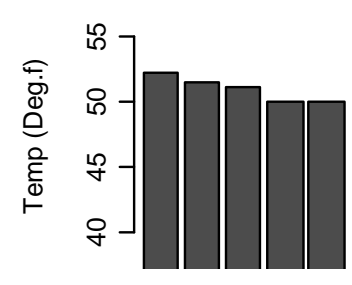

$\begin{array}{lllll}1 & 2 & 3 & 4 & 5\end{array}$

GCM

Sep

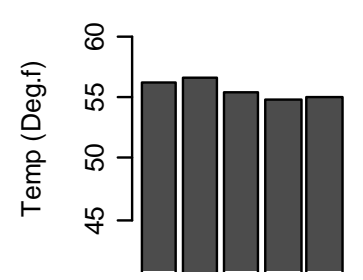

$\begin{array}{lllll}1 & 2 & 3 & 4 & 5\end{array}$

GCM

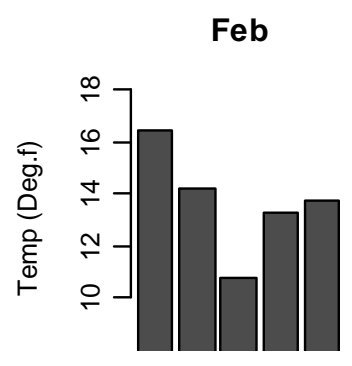

$\begin{array}{lllll}1 & 2 & 3 & 4 & 5\end{array}$

GCM

Jun

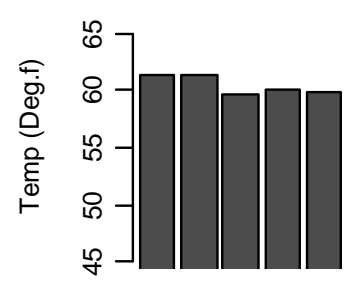

$\begin{array}{lllll}1 & 2 & 3 & 4 & 5\end{array}$

GCM

Oct

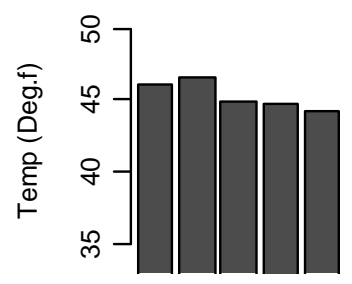

$\begin{array}{lllll}1 & 2 & 3 & 4 & 5\end{array}$

GCM

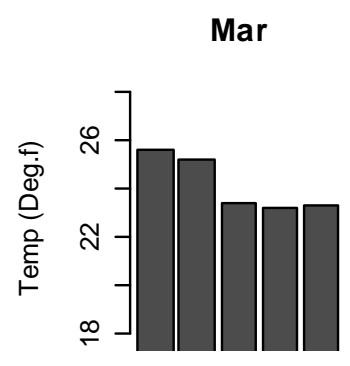

12345

GCM

Jul

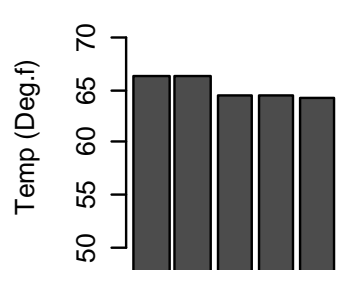

12345

GCM

Nov

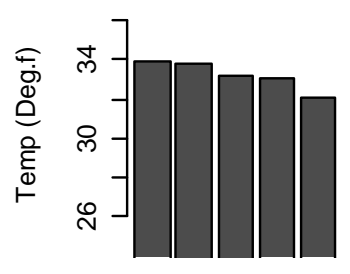

$\begin{array}{lllll}1 & 2 & 3 & 4 & 5\end{array}$

GCM
Apr

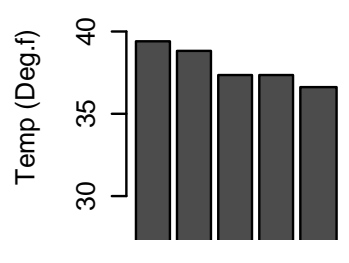

12345

GCM

Aug

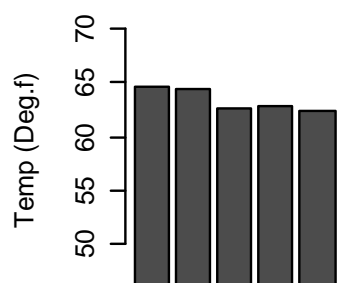

12345

GCM

Dec

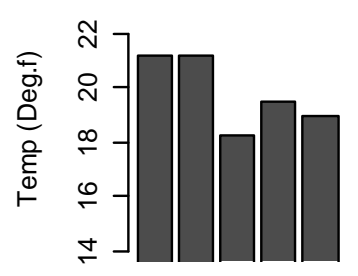

12345

GCM

Figure 43D: Average monthly temperature for each GCM for the time period centered around 2040 using the A2 emissions scenario. (1= cccma_cgcm3, 2= ccsm3, 3= giss, 4= mri, $5=\mathrm{pcm})$. 


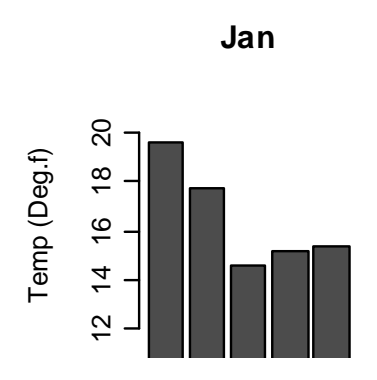

122345

GCM

May

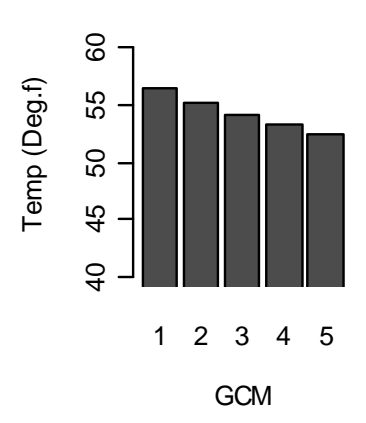

Sep

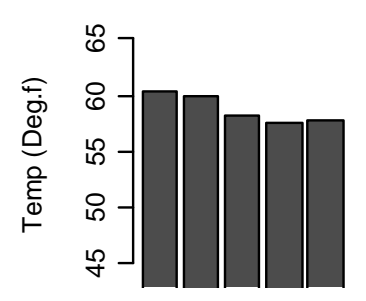

$\begin{array}{lllll}1 & 2 & 3 & 4 & 5\end{array}$

GCM

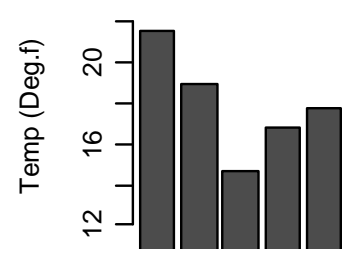

$\begin{array}{lllll}1 & 2 & 3 & 4 & 5\end{array}$

GCM

Jun

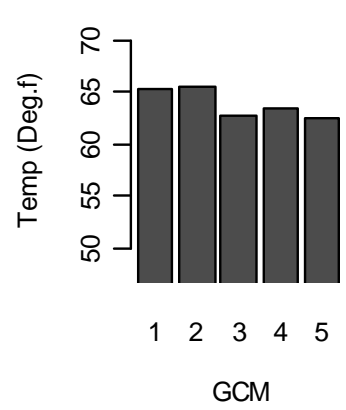

Oct

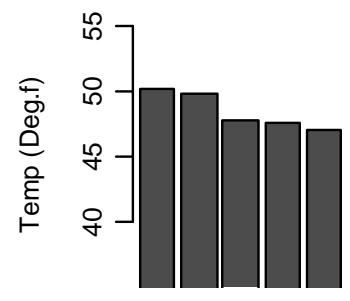

$\begin{array}{lllll}1 & 2 & 3 & 4 & 5\end{array}$

GCM

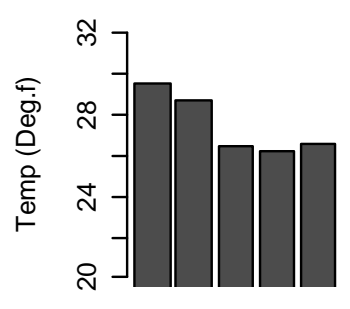

$\begin{array}{lllll}1 & 2 & 3 & 4 & 5\end{array}$

GCM

Jul

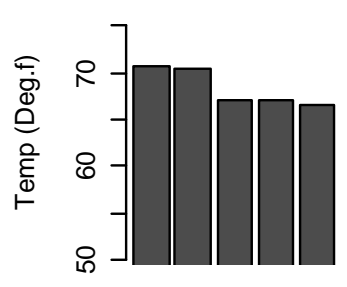

$\begin{array}{lllll}1 & 2 & 3 & 4 & 5\end{array}$

GCM

Nov

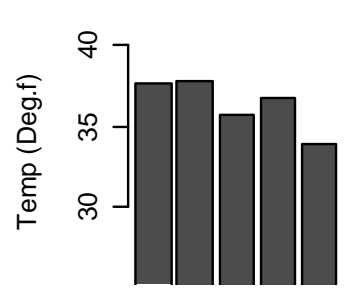

$\begin{array}{lllll}1 & 2 & 3 & 4 & 5\end{array}$

GCM

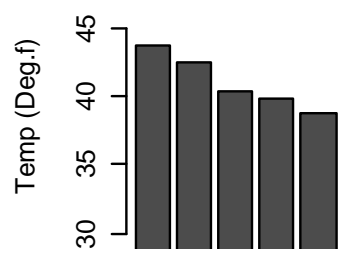

$\begin{array}{lllll}1 & 2 & 3 & 4 & 5\end{array}$

GCM

Aug

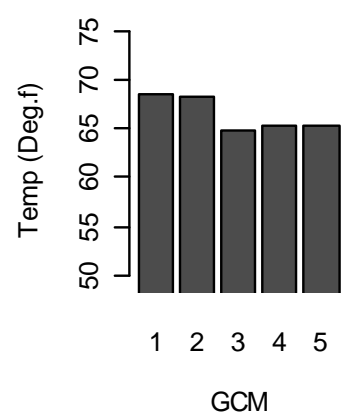

Dec

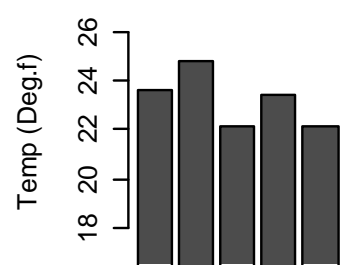

$\begin{array}{lllll}1 & 2 & 3 & 4 & 5\end{array}$

GCM

Figure 44D: Average monthly temperature for each GCM for the time period centered around 2080 using the $A 2$ emissions scenario. (1= cccma_cgcm3, 2= ccsm3, 3= giss, $4=$ mri, $5=\mathrm{pcm})$. 


\subsection{B1 Precipitation}

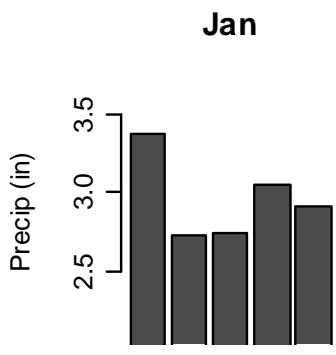

$\begin{array}{lllll}1 & 2 & 3 & 4 & 5\end{array}$

GCM

May

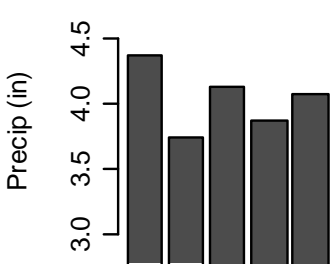

$\begin{array}{lllll}1 & 2 & 3 & 4 & 5\end{array}$

GCM

Sep

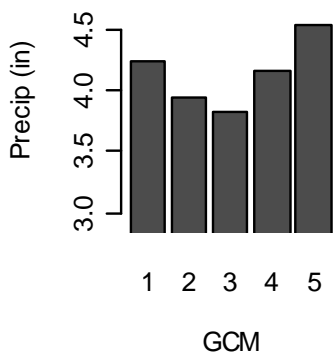

Feb

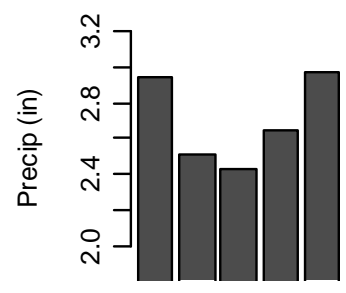

$\begin{array}{lllll}1 & 2 & 3 & 4 & 5\end{array}$

GCM

Jun

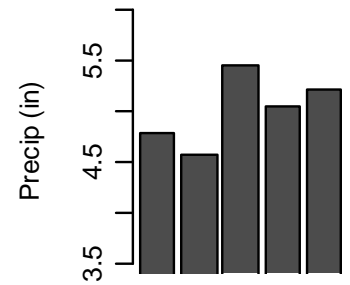

$\begin{array}{lllll}1 & 2 & 3 & 4 & 5\end{array}$

GCM

Oct

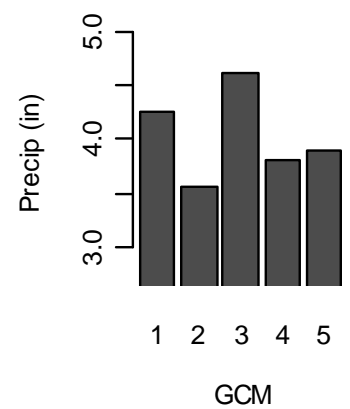

Mar

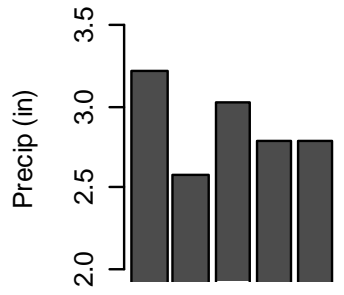

$\begin{array}{lllll}1 & 2 & 3 & 4 & 5\end{array}$

GCM

Jul

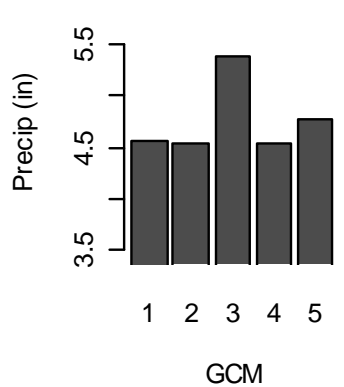

Nov

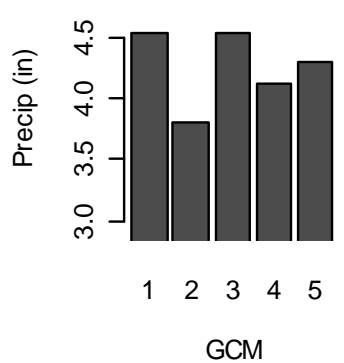

Apr

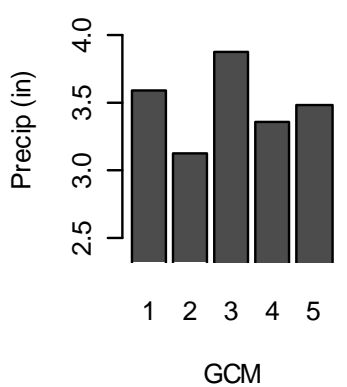

Aug

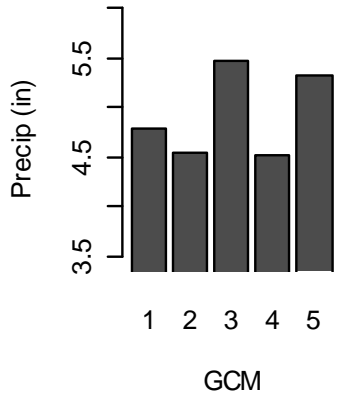

Dec

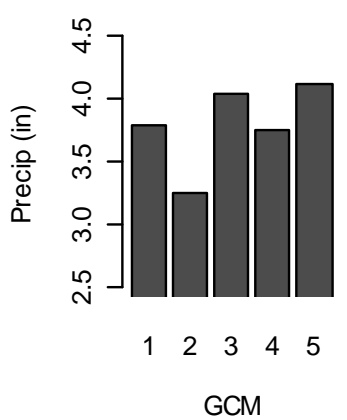

Figure 45D: Total monthly precipitation for each GCM for the time period centered around 2000 using the $B 1$ emissions scenario. $(1=$ cccma_cgcm3, $2=\operatorname{ccsm} 3,3=$ giss, $4=$ mri, $5=$ pcm). 


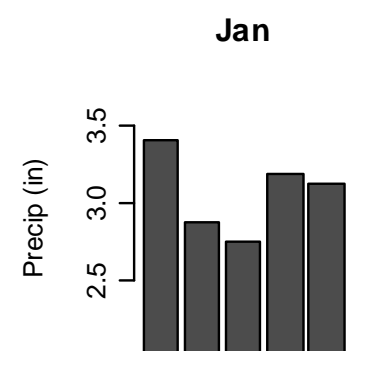

12345

GCM

May

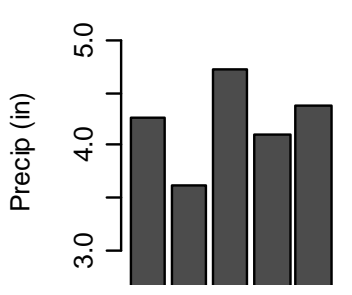

$\begin{array}{lllll}1 & 2 & 3 & 4 & 5\end{array}$

GCM

Sep

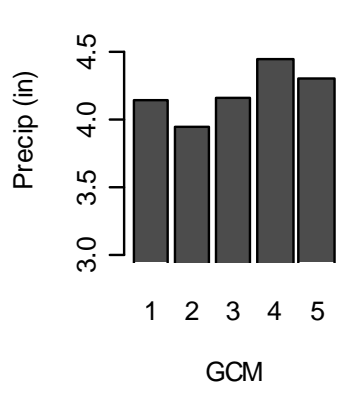

Feb

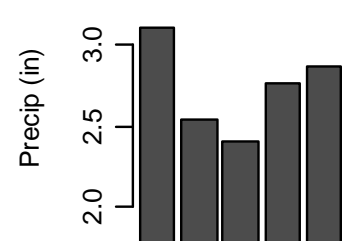

$\begin{array}{lllll}1 & 2 & 3 & 4 & 5\end{array}$

GCM

Jun

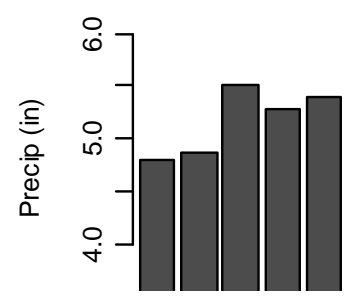

$\begin{array}{lllll}1 & 2 & 3 & 4 & 5\end{array}$

GCM

Oct

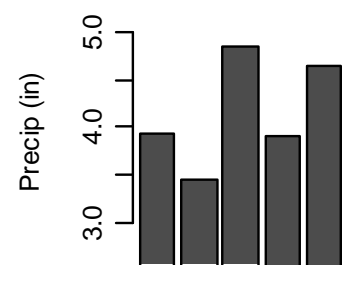

12345

GCM

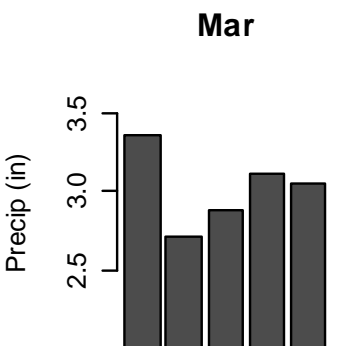

$\begin{array}{lllll}1 & 2 & 3 & 4 & 5\end{array}$

GCM

Jul

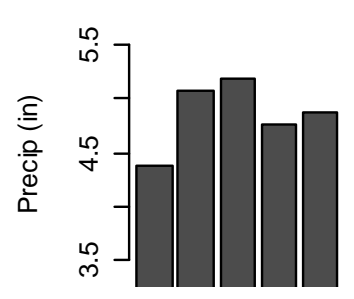

$\begin{array}{lllll}12 & 2 & 4 & 5\end{array}$

GCM

Nov

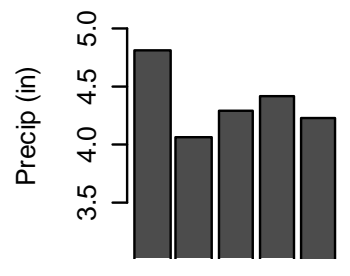

$\begin{array}{lllll}12 & 2 & 4 & 5\end{array}$

GCM

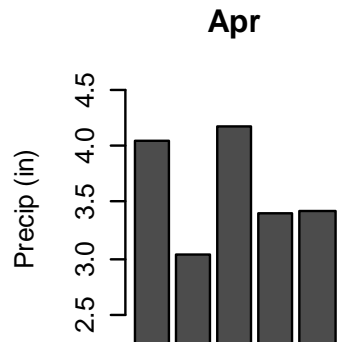

$123 \quad 3 \quad 4 \quad 5$

GCM

Aug

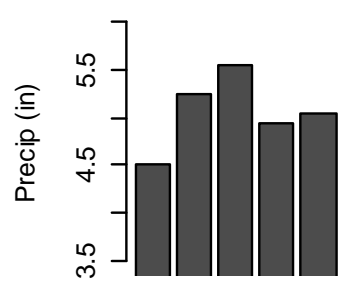

$\begin{array}{lllll}1 & 2 & 3 & 4 & 5\end{array}$

GCM

Dec

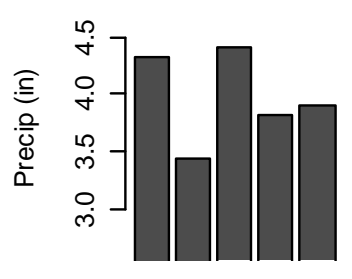

12345

GCM

Figure 46D: Total monthly precipitation for each GCM for the time period centered around 2040 using the $B 1$ emissions scenario. $(1=$ cccma_cgcm3, 2= ccsm3, 3= giss, $4=$ mri, $5=$ pcm). 


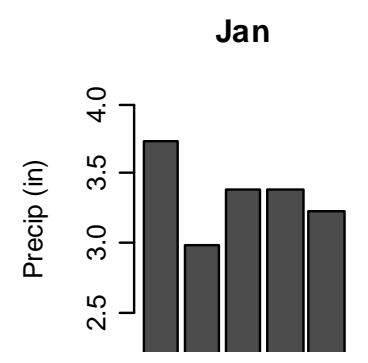

$\begin{array}{lllll}1 & 2 & 3 & 4 & 5\end{array}$

GCM

May

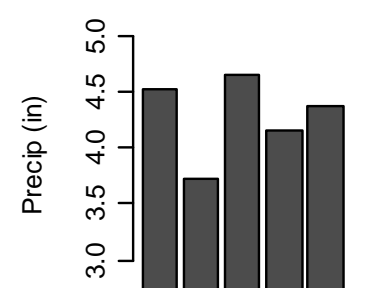

$\begin{array}{lllll}1 & 2 & 3 & 4 & 5\end{array}$

GCM

Sep

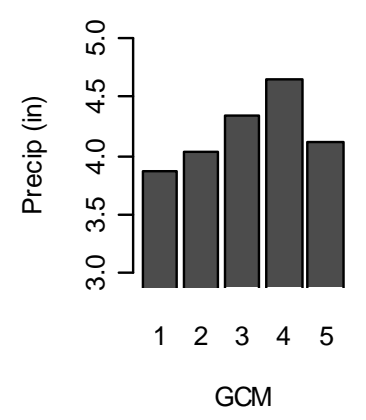

Feb

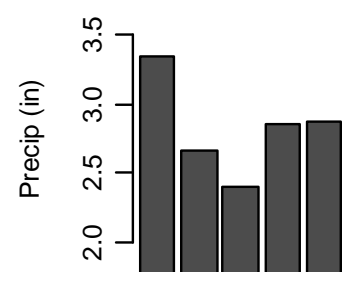

$\begin{array}{lllll}1 & 2 & 3 & 4 & 5\end{array}$

GCM

Jun

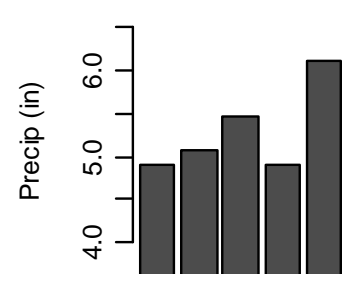

12345

GCM

Oct

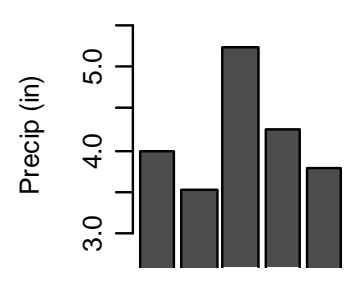

12345

GCM

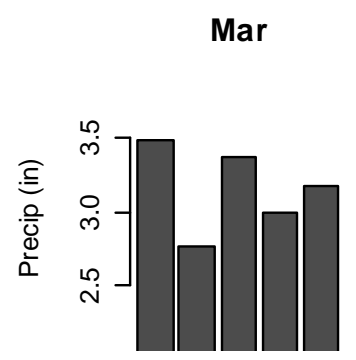

$\begin{array}{lllll}1 & 2 & 3 & 4 & 5\end{array}$

GCM

Jul

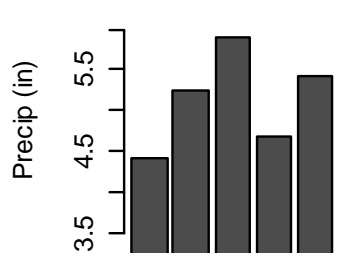

$\begin{array}{lllll}1 & 2 & 3 & 4 & 5\end{array}$

GCM

Nov

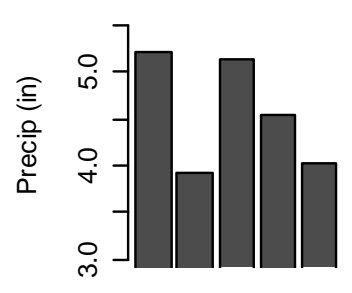

$\begin{array}{lllll}1 & 2 & 3 & 4 & 5\end{array}$

GCM

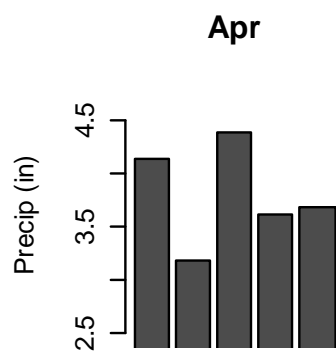

12345

GCM

Aug

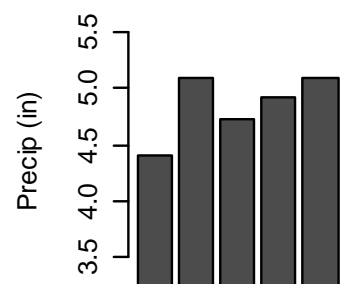

12345

GCM

Dec

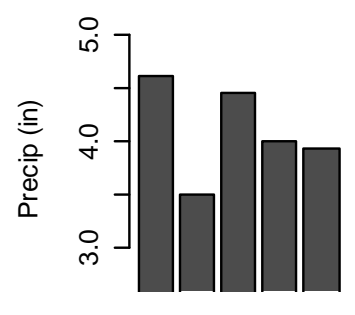

12345

GCM

Figure 47D: Total monthly precipitation for each GCM for the time period centered around 2080 using the $B 1$ emissions scenario. (1= cccma_cgcm3, 2= ccsm3, 3= giss, $4=$ mri, $5=\mathbf{p c m})$. 


\section{$12.4 \quad$ B1 Temperature}
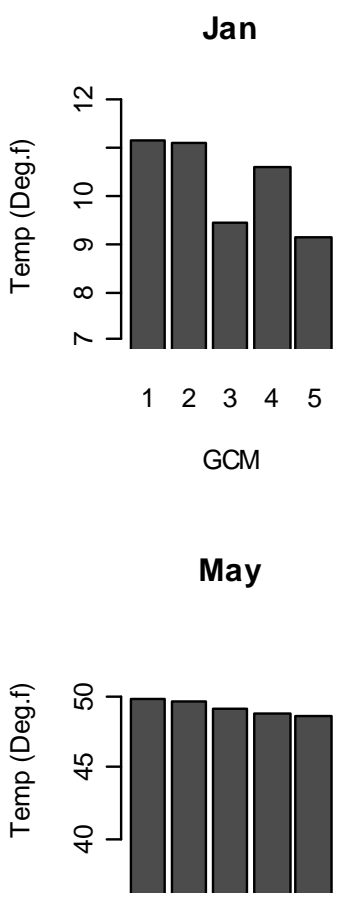

$1223 \quad 4 \quad 5$

GCM

Sep

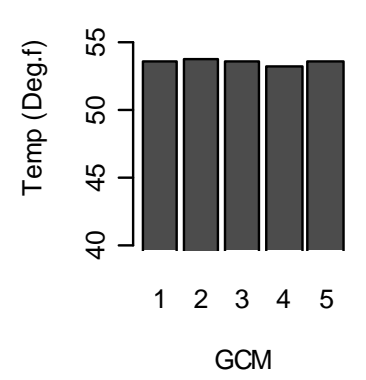

Feb

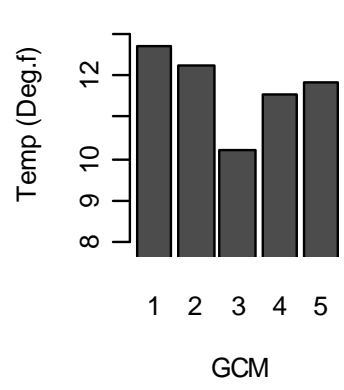

Jun

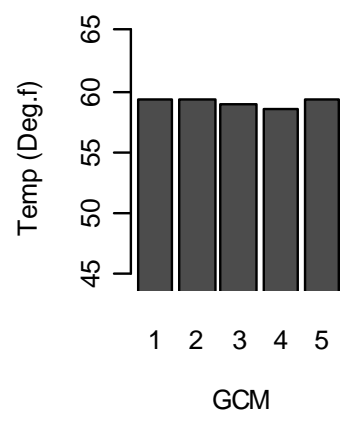

Oct

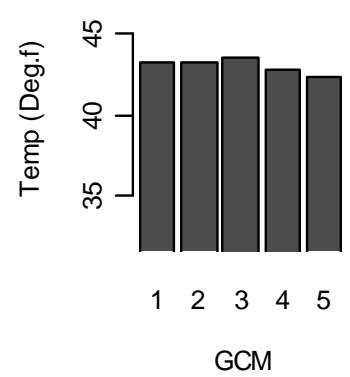

Mar

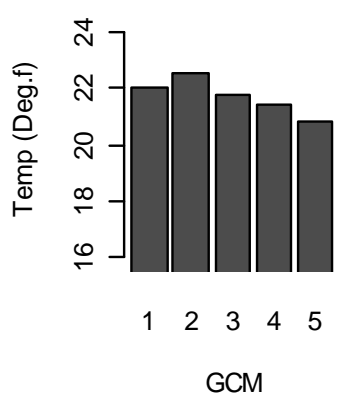

Jul

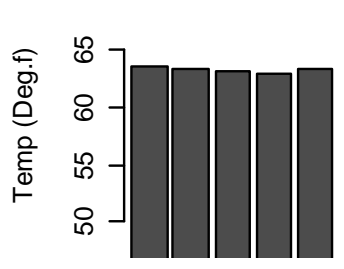

$\begin{array}{lllll}1 & 2 & 3 & 4 & 5\end{array}$

GCM

Nov

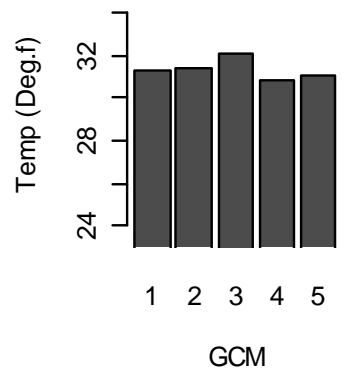

Apr

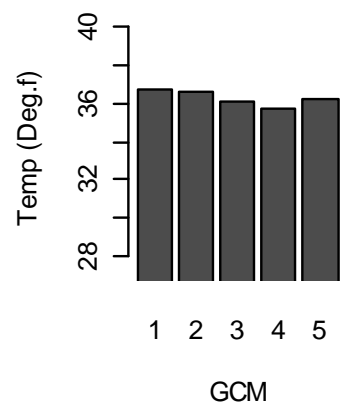

Aug

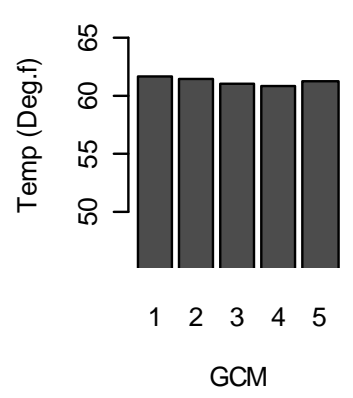

Dec

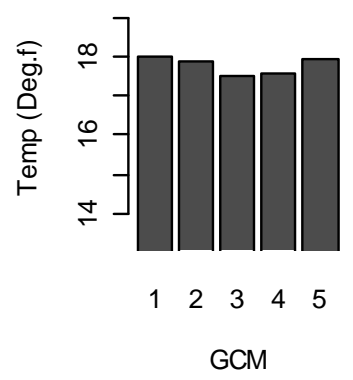

Figure 48D: Average monthly temperature for each GCM for the time period centered around 2000 using the B1 emissions scenario. $(1=\operatorname{cccma}$ cgcm3, $2=\operatorname{ccsm} 3,3=$ giss, 4= mri, $5=$ pcm). 


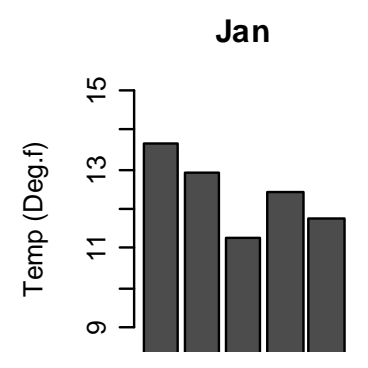

$\begin{array}{lllll}1 & 2 & 3 & 4 & 5\end{array}$

GCM

May

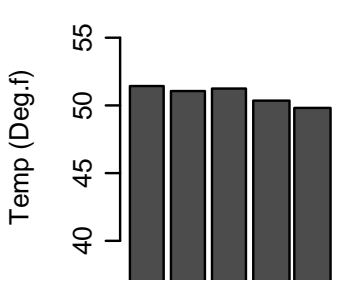

$\begin{array}{lllll}1 & 2 & 3 & 4 & 5\end{array}$

GCM

Sep

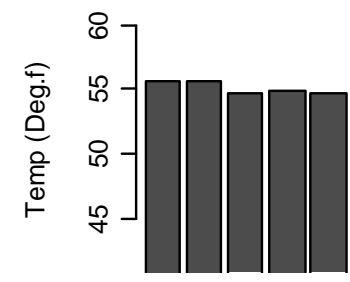

$\begin{array}{lllll}12 & 2 & 4 & 5\end{array}$

GCM
Feb

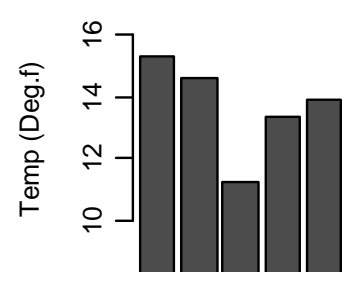

12345

GCM

Jun

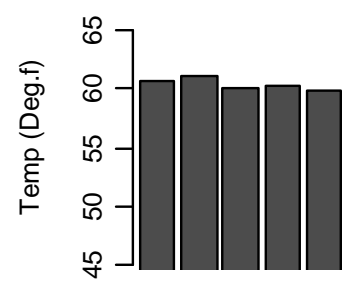

12345

GCM

Oct

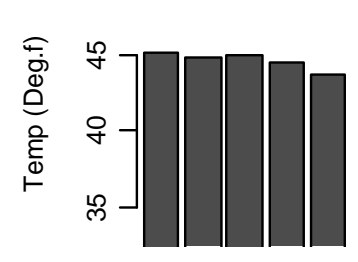

$\begin{array}{lllll}1 & 2 & 3 & 4 & 5\end{array}$

GCM

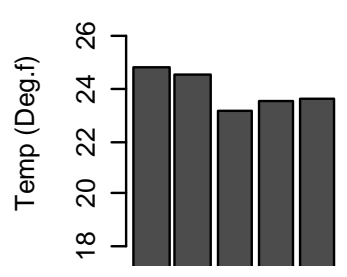

12345

GCM

Jul

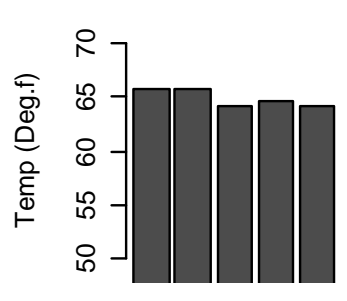

$\begin{array}{lllll}1 & 2 & 3 & 4 & 5\end{array}$

GCM

Nov

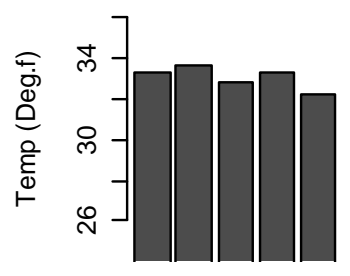

$\begin{array}{lllll}1 & 2 & 3 & 4 & 5\end{array}$

GCM
Apr

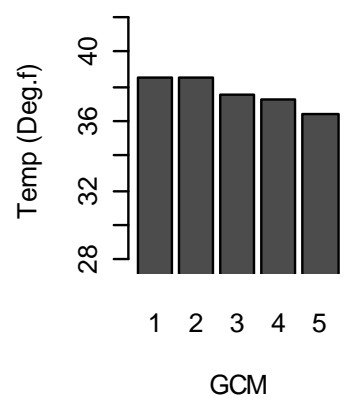

Aug

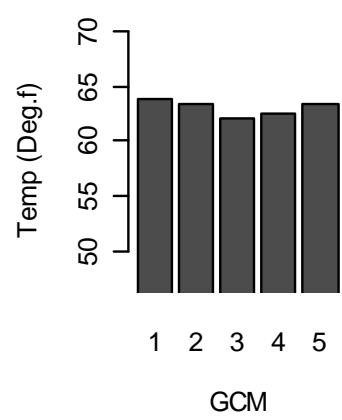

Dec

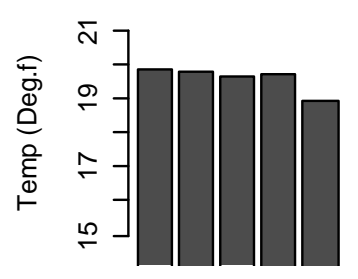

12345

GCM

Figure 49D: Average monthly temperature for each GCM for the time period centered around 2040 using the B1 emissions scenario. $(1=$ ccma_cgcm3, 2= ccsm3, $3=$ giss, $4=$ mri, $5=\mathrm{pcm})$. 


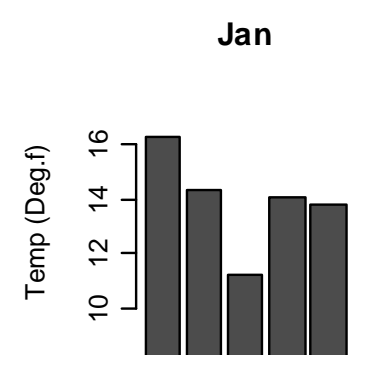

$\begin{array}{lllll}1 & 2 & 3 & 4 & 5\end{array}$

GCM

May

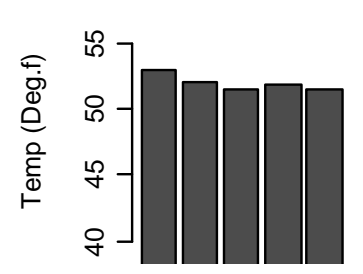

12345

GCM

Sep

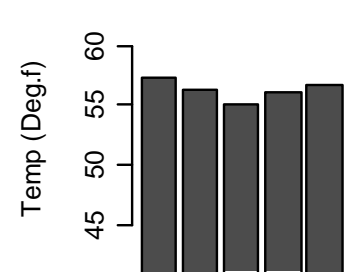

12345

GCM

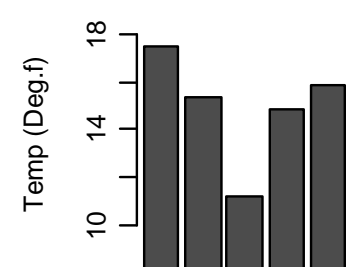

$\begin{array}{lllll}1 & 2 & 3 & 4 & 5\end{array}$

GCM

Jun

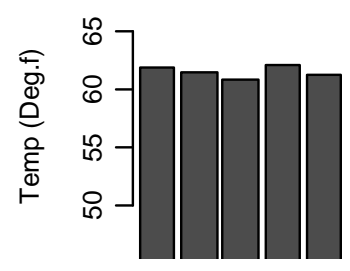

12345

GCM

Oct

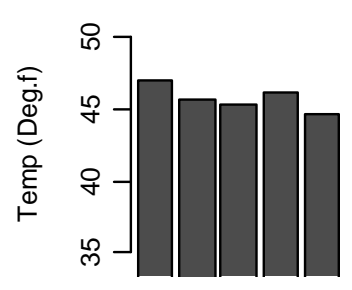

12345

GCM

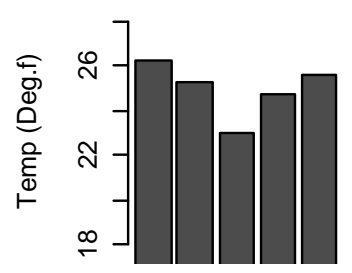

12345

GCM

Jul

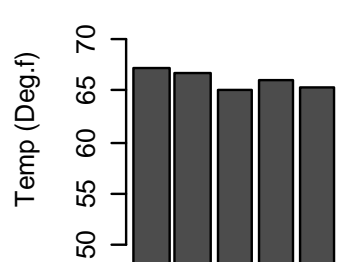

12345

GCM

Nov

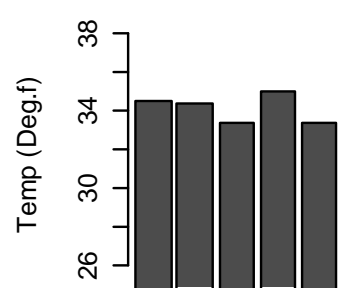

$\begin{array}{lllll}1 & 2 & 3 & 4 & 5\end{array}$

GCM

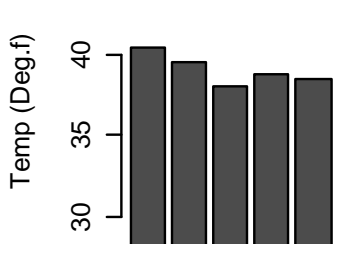

12345

GCM

Aug

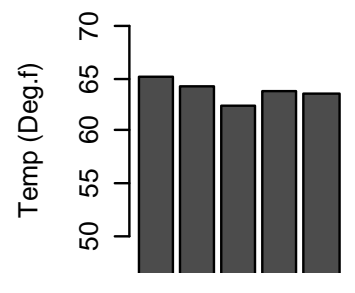

12345

GCM

Dec

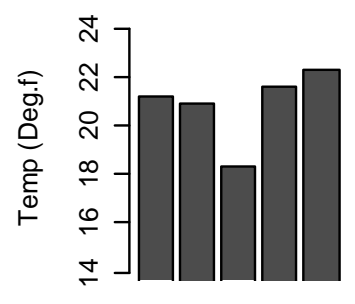

12345

GCM

Figure 50D: Average monthly temperature for each GCM for the time period centered around 2080 using the $B 1$ emissions scenario. $(1=$ ccma_cgcm3, $2=\operatorname{ccsm} 3,3=$ giss, $4=$ mri, $5=\mathrm{pcm})$. 


\section{Appendix E - Flow Duration Curves at Eco-Node 3}

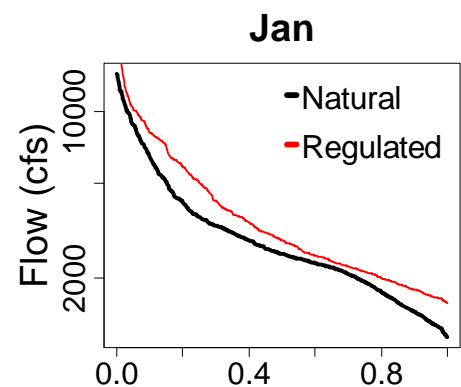

Exceedance Probability

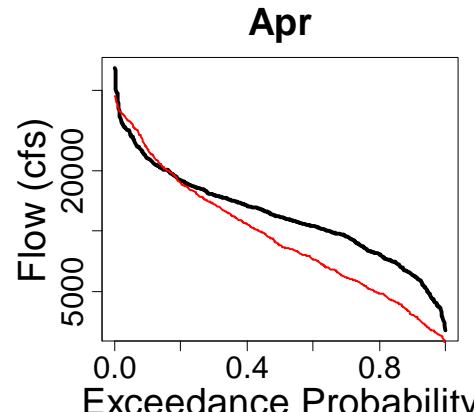

Jul

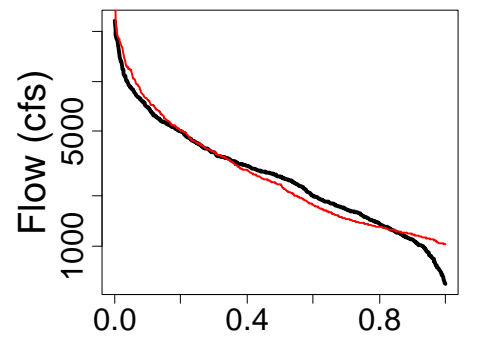

Exceedance Probability

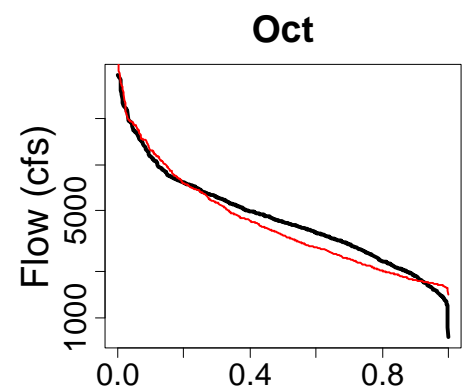

Exceedance Probability

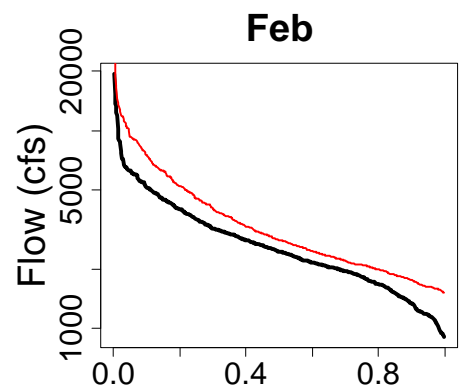

Exceedance Probability
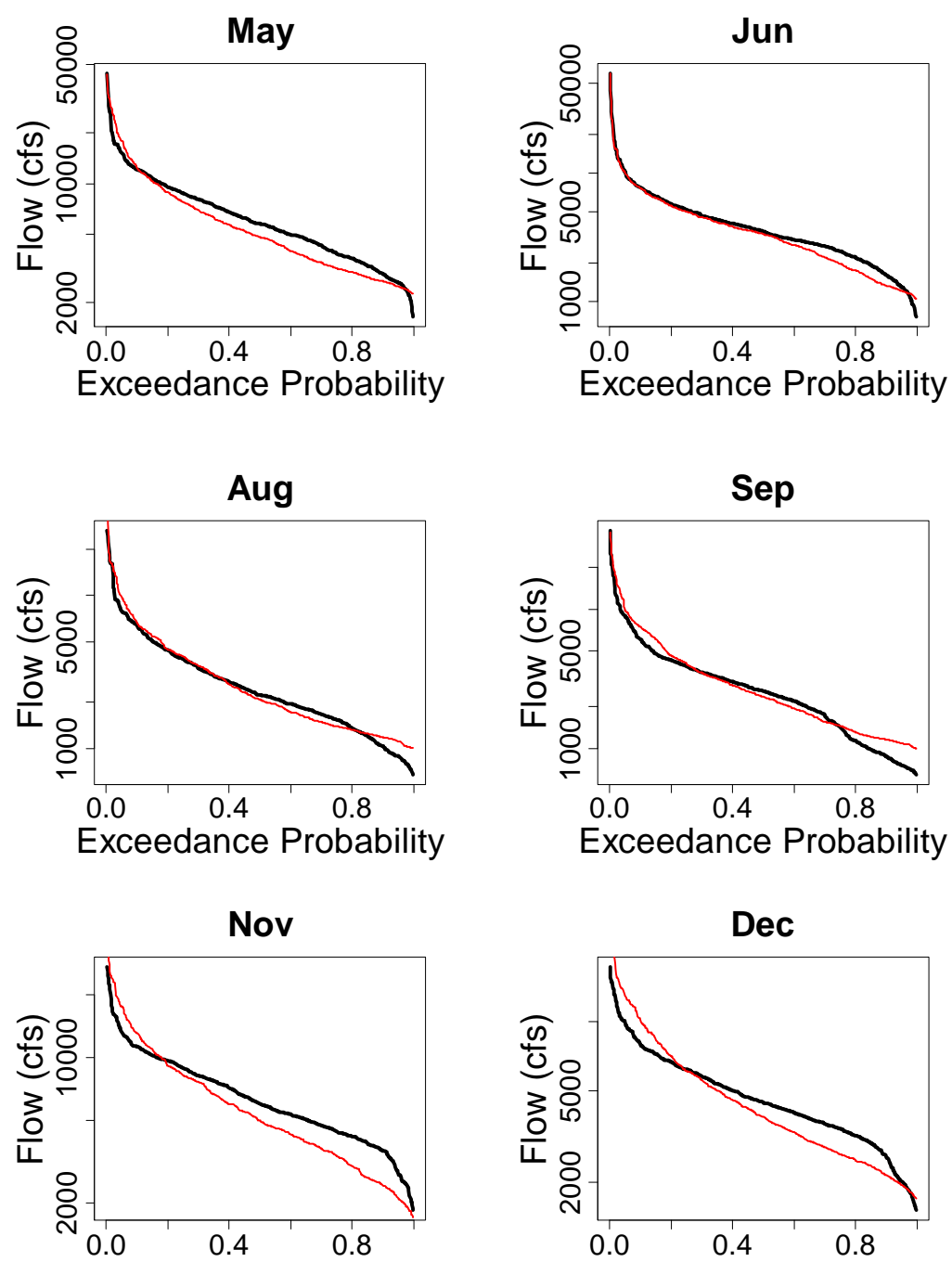

Exceedance Probability

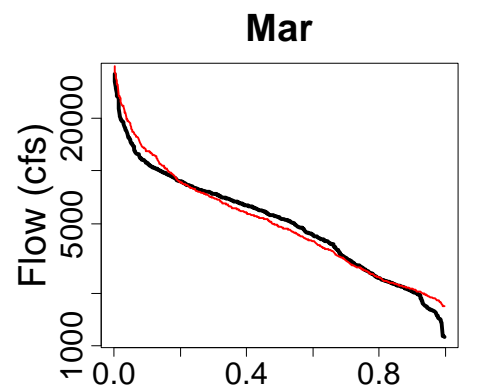

Exceedance Probability
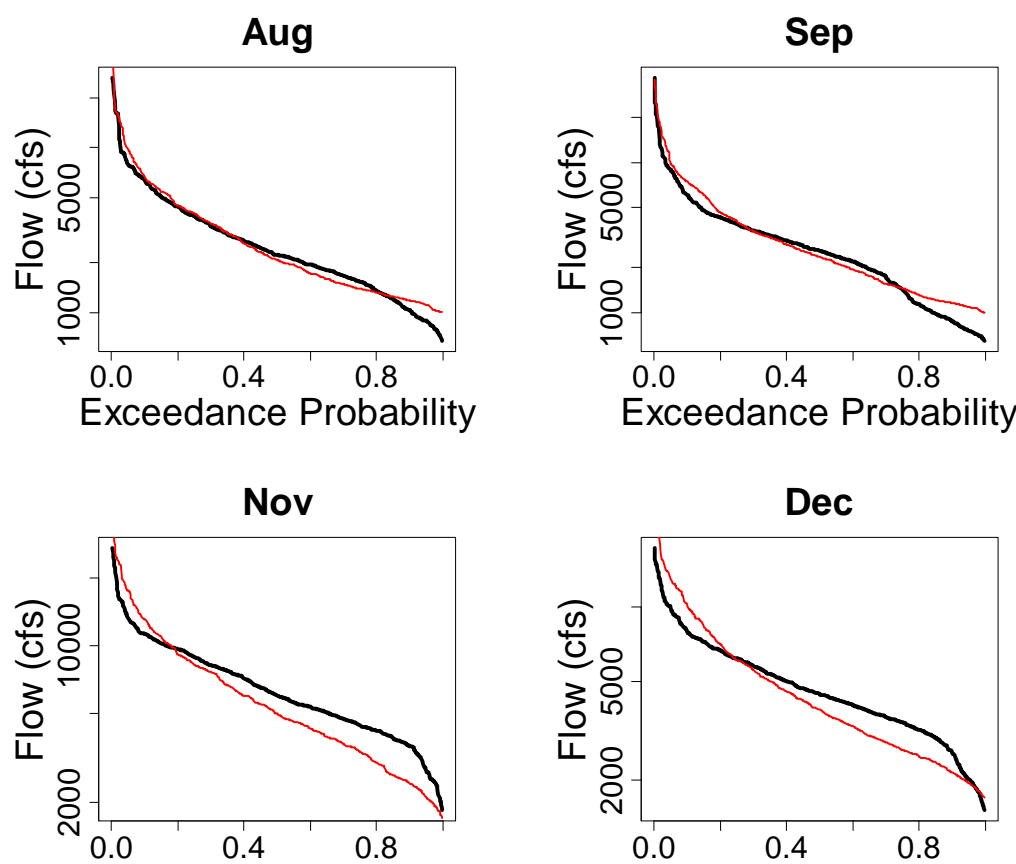

Exceedance Probability

Figure 51E: Simulation model monthly flow duration curves with current operations at Eco-Node 3 below the 3 generating facilities. The red line represents the simulation model and the black solid line is the natural flow in the river if the reservoirs passed all inflow. 


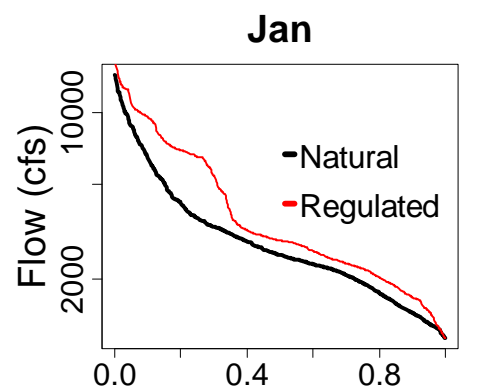

Exceedance Probability

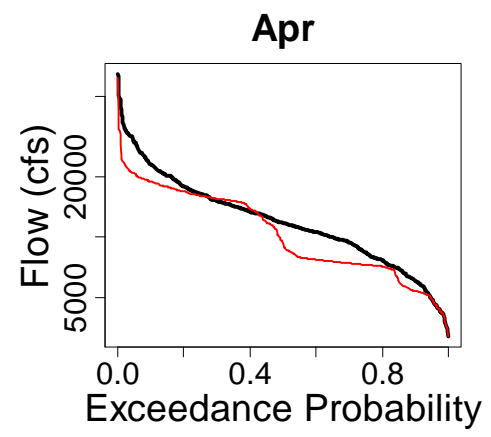

Jul

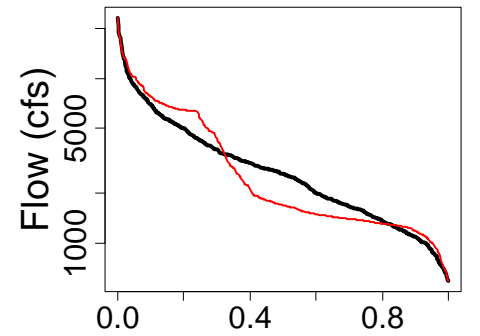

Exceedance Probability

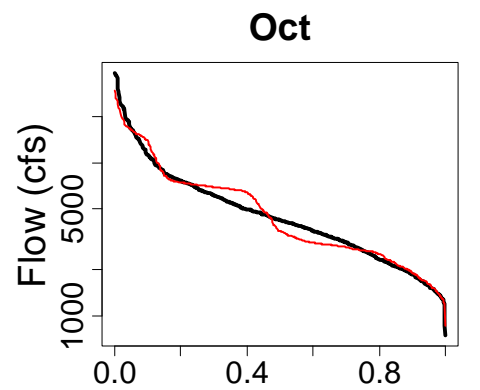

Exceedance Probability

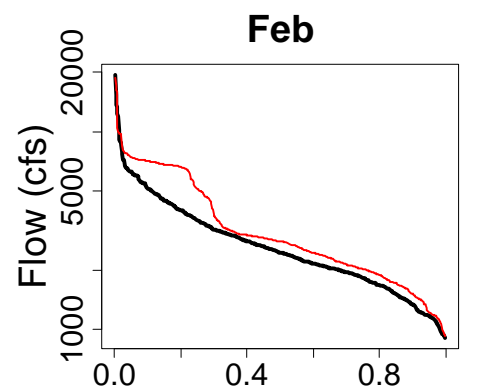

Exceedance Probability

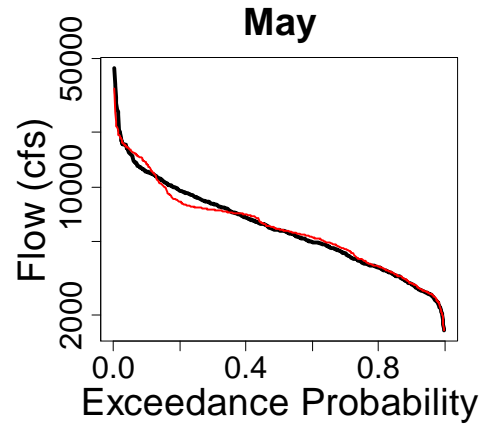

Aug

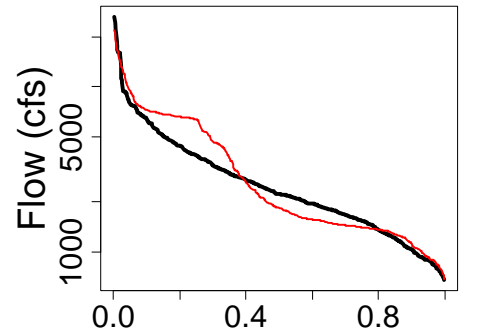

Exceedance Probability

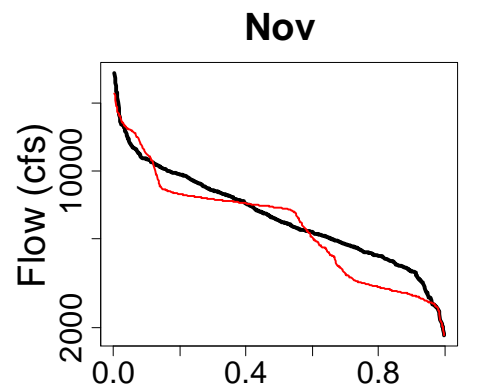

Exceedance Probability

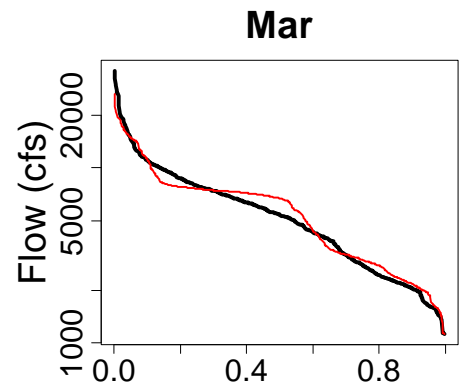

Exceedance Probability

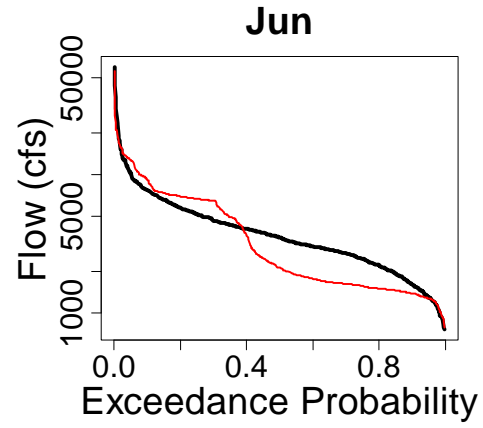

Sep

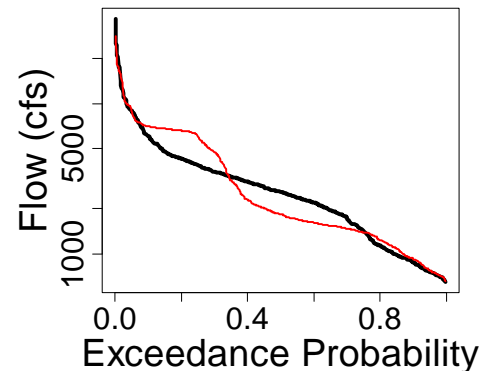

Dec

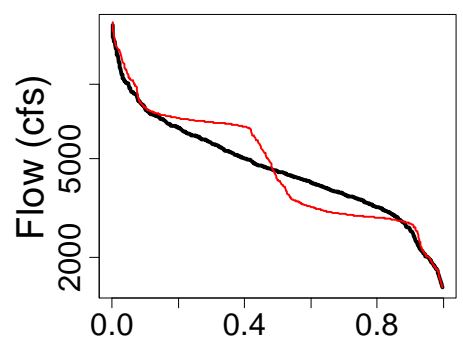

Exceedance Probability

Figure 52E: Optimization model monthly flow duration curves at Eco-Node 3 with ecological targets not considered. The objective function forces the reservoirs to follow their target storages while maximizing income. The red line represents the optimization model and the black solid line is the natural flow in the river if the reservoirs passed all inflow. 